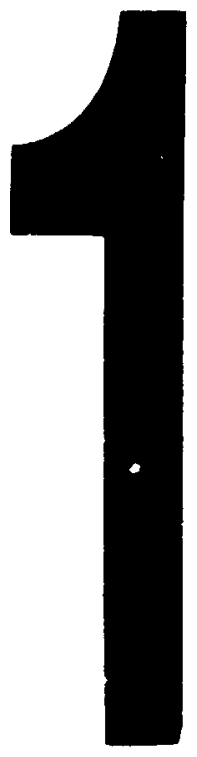

PM-1 31/2" $x 4$ " PHOTOGRAPHIC MICROCOPY TARGET NBS 1010 a ANSI/ISO \#2 EOUIVALENT

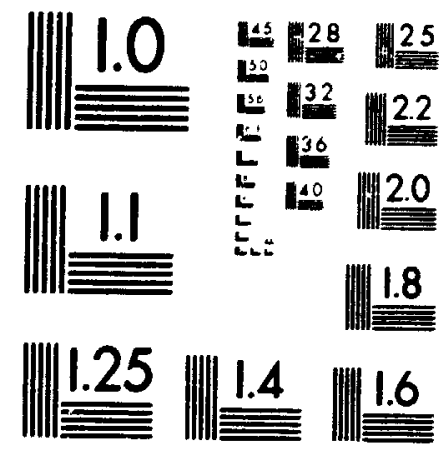

PRECISIONSM RESOLUTION TARGETS

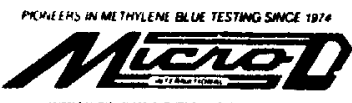

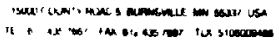


Ottawa, Canada

KIA ON4

\section{NOTICE}

The quality of this microform is heavily dependent upon the quality of the original thesis submitted for microfilming. Every effort has been made to ensure the highest quality of reproduction possible.

If pages are missing. contact the university which granted the degree.

Some pages may have indistinct print especially if the original pages were typed with a poor typewriter ribbon or if the university sent us an inferior photocopy.

Reproduction in full or in part of this microform is governed by the Canadian Copyright ACt, R.S.C. 1970, C. C-30, and subsequent amendments.

\begin{abstract}
AVIS
La qualité de cette microforme dépend yrandement de la qualité de la these soumise au microfitmage. Nous avons tout fait pour assurer une qualite supérieure de reproduc. tion.

S'il manque des pages, veuille? communiquer avec luniversité qui a conféré le grade.

La qualité d'impression de certaines pages peut laisser a désirer, surtout si les pages originales ont été dactylogra. phiées a l'aide d'un nuban usé ou si l'université nous a tan parvenir une photocopie de qualité inférieure.
\end{abstract}

La reproduction, méme partielle, de celte microforme est soumise a la Loi canadienne sur le droit dauteur. SRC 1970. c. C-30. el ses amendements subséquents 
Strands of Moonlight:

an Examination of the

Institutionalization Process

amongst Neo-Pagan witches in ottawa

by

Marc W.D. Tyrrell, B.A.

A thesis submitted to the Faculty of

Graduate studies and Research in partial fulfilment

of the requirements for the degree of

Master of Arts

in Canadian studies

Carleton University

OTTAWA, Ontario

May 13 th

1992, Marc W.D. Tyrrell 
Otlawa. Canada

The author has granted an irrevocable non. exclusive licence allowing the National Library of Canada to reproduce, loan, distribute or sell copies of his/her thesis by any means and in any form or format, making this thesis avallable to interested persons.

The author retains ownership of the copyright in his/her thesis. Neither the thesis nor substantial extracts from it may be printed or otherwise reproduced without his/her permission.
L'auteur a accordé une licence irrévocable et non exclusive permettant a la Bibliothéque nationale du Canada de reproduire, preter. distribuer ou vendre des coples de sa these de quelque manière et sous quelque forme que ce soit pour mettre des exemplaires de cette thèse à la disposition des personnes intéressées.

L'auteur conserve la propriêté du droit d'auteur qui protége sa thèse. Ni la thèse ni des extraits substantiels de celle-ci ne doivent etre imprimés ou autrement reproduits sans son autorisation. 
Tho undersigned recommend to the Faculty of Graduate Sludies and Research acceptance of the thesis "Strands of Moonlight: An Examination of the Institutionalization Process amongst

$$
\begin{aligned}
& \text { Neo-Pagan "Nitches in Ottawa" } \\
& \text { Submitted by Marc Tyrrell, }
\end{aligned}
$$

Bachelor of Arts; Sociology/Religion

in partial fulfilment of the requirements for the degree of Master of Arts

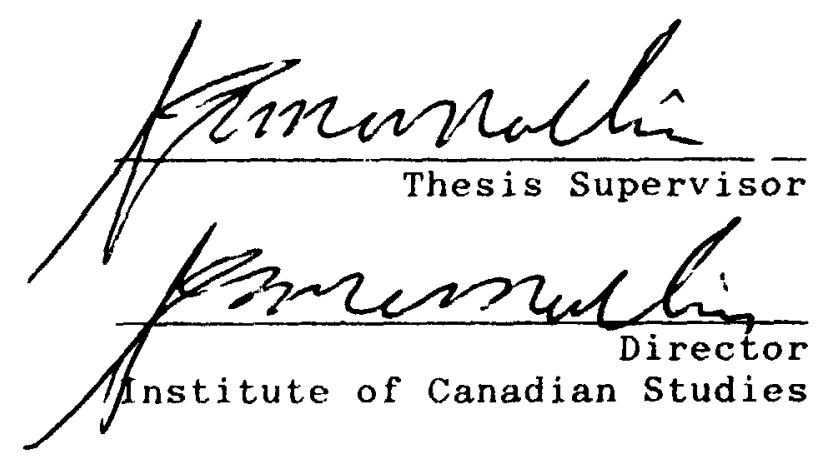

Carleton University

Ottawa, Ontario

May 13,1992 


\section{AB8TRACT}

This thesis examines the institutionalization process in a modern, Neo-Pagan wiccan community. The primary research question asked is: by what means, and through what avenues, do the ideas, practices and beliefs of individual witches come to be formalized, regularized, and institutionalized in the minds and realities of a modern Wiccan community?

The author examines one wiccan community, ottawa. Participant observation, critical exegesi: and textual analysis are used to construct an ethnography. Special attention is given to the oral nature of modern wicca, and to the formation of definitional forums within the community.

It is argued that the process of institutionalization is voluntary. Furthermore, while the processes of syncretization and institutionalization may be accelerated by available technology, there is little indication that the primacy of orality and interpersonal relations is challenged. Finally, it is argued that any examination of the process of institutionalization must examine the people in the movement. 
Table of contents

Chapter 1: Introduction . . . . . . . . . . . . 1

1.1. Towards a Working Definition of

Institutionalization . . . . . . . . . . 8

1.2. Thesis organization . . . . . . . . . . 16

1.3. Notes . . . . . . . . . . . . 18

Chapter 2: History and People . . . . . . . . . 21

2.1. Dramatis Personae . . . . . . . . . . . 22

2.1.1. The Wiccan Church of Canada
(Ottawa Member Temple) . . . . . . 23

2.1.2. Alexandriaus and other Gardnerian
Derived Wiccans .......... . . 25

2.1.3. The Web of Herodias . . . . . . . 28

2.1.4. The Merydians . . . . . . . . . 29

2.1.5. Hecate's Web ............. 30

2.1.6. The Asatru Group ............ 31

2.1.7. The Eclectics . . . . . . . . . 32

2.1.8. Discarnate Members of

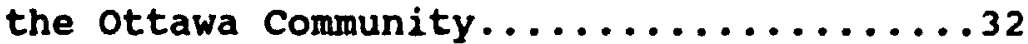

2.1.9. Conclusions . . . . . . . . . 35

2.2. Historical Developinent of

the Ottawa Wiccan Community . . . . . . . . 35

2.2.1. Pre-Communitas . . . . . . . . . 37

2.2.2. Early Communitas . . . . . . . 38

2.2.3. Witch War . . . . . . . . . . . 40

2.2.4. Middle Communitas . . . . . . . . 41

2.2.5. Late Communitas . . . . . . . . 43

2.3. Conclusions . . . . . . . . . . . . 45

Chapter 3: Communications in the Ottawa wiccan Community 46

3.1. Print and Electronic Forums . . . . . . . . 49

3.1.1. The Messenger . . . . . . . . . . . . 49

3.1.1.1. Statistical Description. . . . 51

3.1.1.2. Discussion . . . . . . . . 54

3.1.1.3. Conclusions . . . . . . . 56

3.1.2. Open Circle . . . . . . . . . . . 58

3.1.3. Pandora's Box and P.O.D.S. . . . . 60

3.1.1. Conclusions . . . . . . . . . . 64 
3.2. Oral Communications Forums . . . . . . . . 65

3.2.1. The Ottawa Pagan Council and

The Meet and Greet Society . . . . . . 65

3.2.2. The Ottawa Valley Pagan Discussion Group

(O.V.P.D.G.) . . . . . . . . . . . . . 71

3.2.3. The Occult Shop (aka the wiccan Rede) 72

3.2.3.1. Oral culture and

Conceptual Creation . . . . . 76

3.2.3.2. Oral Concepts and Community Roles 79

3.2.3.3. The "Counselling Industry" . . . . . . . . . . 81

3.2.3.4. Conclusions . . . . . . . 82

3.2.4. Conclusions . . . . . . . . . . 83

3.3. Conclusions . . . . . . . . . . . . 83

Chapter 4: Definitional Arenas . . . . . . . . . 85

4.1. From Idea to Institution . . . . . . . . . 87

4.2. The Institutional Ground of Being . . . . . . 93

4.3. Conclusions . . . . . . . . . . . . 100

Chapter 5: Ritual and Experience . . . . . . . . 102

5.1. Ritual Types . . . . . . . . . . . . 108

5.2. "Occult" Skills.. . . . . . . . . . . 113

5.3. Effects of Differential skill Development • . 117

5.4. Conclusions ................ . . 121

Chapter 6: Constructing Time . . . . . . . . . . . 124

6.1. Metaphors of Time . . . . . . . . . . 127

6.2. the Moon Cycle . . . . . . . . . . . 128

6.3. The Sabbat Cycle . . . . . . . . . . . 134

6.3.1. The Agricultural Sabbats... . . . . 135

4.3.2. The Solar Sabbat Cycj.e... . . . . 141

6.3.3. Conclusions ............. 144

6.4. Linear and Evolutionary Time . . . . . . . 146

6.5. Conclusions . . . . . . . . . . . . . 156 
Chapter 7: Mythic Structures . . . . . . . . . . 158

7.1. The Quest . . . . . . . . . . . 163

7.2. Continuance . . . . . . . . . . . 168

7.3. Empowerment . . . . . . . . . . . . 174

7.4. Conclusions . . . . . . . . . . . . 183

Chapter 8: Towards a Theory of Institutionalization - . 185

8.1. Epistemology and Truth Claims . . . . . . 186

8.2. Institutions and General society . . . . . 196

8.3. Institutions and the web
of Socio-cultural Reality . . . . . . . . . 198

8.4. Defiritional Environments . . . . . . . 205

8.5. Relational Factors in the Socio-Cultural Web 210

8.6. Conclusions . . . . . . . . . . . . . 218

Chapter 9: Conclusions . . . . . . . . . . . . 219

Bibliography . . . . . . . . . . . . . . . 229

Appendix A: A Wiccan Glossary

Appendix B: The Charge of the Goddess

Appendix c: The "old Laws"

Appendix D: Article Index from open circle 
Chapter 1:

Introduction

Perhaps there is some truth after all in the belief that witches can change their shapes. Witchcraft, as I believe, has $c$ anged its shape till it has no true shape left.... Those who seek here for a mystical profundity hidden from common men will seek in vain, and wander in the same fog hand-inhand with the eager latter-day necromancer on their left and on their right the Comparative Religionist spying out the elder gods. If they should pick up ten mocnstruck companions, let them form their cwn coven to prove their own points; it will be as traditional, as well-instructed, and as authentic as any there has been these thousand years.

Rose, $1989: 230$

with these well chosen words, Elliot Rose ends his 1962 analysis of Witchcraft, A Razor for a Goat. Rose's conclusions are, to a large degree, valid. There is little doubt anymore that modern witchcraft is a "created" religion. There is also little doubt that the modern witch does indeed walk "hand-inhand with the eager later-day necromancer on their left and on their right the Comparative Religionist". Furthermore, Rose's comments about people forming their own covens are equally true.'

And yet, the modern witchcraft movement grows both in size and sophistication. Current estimates place the size of the movement at 100,000 people in the United states and 1989.

1 Adler, 1986; Kelly, 1991; Luhrman, 1989; Valiente, 
England (roughly 50,000 each), 10,000 in Canada, 1,000-2,000 in Australia and New Zealand, and another 10,000-20,000 ir. continental Europe. ${ }^{2}$

The people who are attracted to modern witchcraft are not the social misfits and escapists that one might expect from Rose's comments. Modern Witches are computer programmers, students, doctors, housewives, market analysts, and social workers. We also know that people join modern witchcraft for such reasons as feminism, interests in related subjects, or a feeling of kinship. ${ }^{3}$

Furthermore, it is readily apparent to anyone who spends any time examining wiccan publications (both print and electronic) that the movement is becoming quite theologically sophisticated." However, the wiccan movement is not organizationally, thealogically, or cosmologically unified.

2 These US and UK estimates are from movement internal sources. The Canadian estimates are from Shelly Rabinovitch (personal communication).

3 "Related subjects" include magic, mythology, ecology, anthropology, etc. For more, see Adler, 1986; Farrar and Farrar, 1987a; Luhrman, 1989.

4 For an examination of the role of electronic media in the wiccan movement, see chapter 3. The word "thealogy" was coined by carol Christ to refer to knowledge about, and discussion of, the Goddess. This is the most readily observable form of theology in modern Wicca. A second term "polytheology" has been coined by Isaac Bonewitz to describe knowledge about and discussion of the Gods. 
Major differences are apparent between different : raditions.' In addition to differences between "Traditions", there are numerous "solitaires" or solo practitioners, ad hoc groups, small multi-traditional networks, and public "churches", all of whom are creating their own understandings of witchcraft. The interesting question is not "Why do people join these groups?" or "What do these groups believe and practice?". Rather, what is interesting is how modern witches come to create their communities. While "Why?" and "What?" are the most frequently researched questions, the "How?" is, to my mind, to more important and interesting.

The first question ("Why?") has already been answered (Adler, 1986; Farrai and Farrar, 1987a; Luhrman, 1989). And, while an exacting analysis of reasons for joining, and the mechanisms of entering into the movement would be interesting, it is beyond the scope of this paper. 6

The second question (What?") is both culturo-centric and impossible co answer. First, any attempt to present wiccan beliefs at the movement level will, inevitably be in the form

5 A "Tradition" might be referred to as a "sect" or component of the general Wiccan movement. However, this usage would inply a degree of standardization inside the individual Tradition that is not apparent. A better term would be "School", after Kunn's (1970) usage of the term.

- A partial analysis of reasons for joining is currently being conducted by Shelly Rabinovitch, Department of Religion, carleton university, Ottawa. 
of voyeuristic ethnography: the "strange people and strange beliefs" format of the 19th century. Second, giver the lack of agreement between wiccan groups, any attempt to extrapolate for the entire movement will fail due to the diversity of groups and individuals.?

I am interested in the creation, communication and adoption of ideas and practices. The "How" of religious community formation. More specifically, I am interested in how these ideas and practices become part of the natural attitude of Wiccans. Thus my research question may be stated as follows: By what means, and through what avenues, do the ideas, practices and beliefs of individual Witches come to be formalized, reqularized, and institutionalized in the minds and realities of a modern Wiccan community?

Hodern witches are not uniform in beliefs and practices. Any attempt to examine the process of the institutionalization of modern Witchcraft must, of necessity, be limited. My original intention had been to examine the main Canadian centers of the wiccan movement. This exceeded the

7 For an example of an attempt which failed, see Lloyd, 1978. The few successful studies of modern witchcraft have succeeded by either limiting their focus to a single community (e.g. Luhrman, 1989), or by not attempting to extrapolate movement wide beliefs (e.g. Adler, 1986).

- My use of the term "natural attitude" derives from the usage of Alfred Schutz (Schutz, 1967; Schutz and Luckmann, 1973,1989 ). 
limits of both time and monetary resources. ${ }^{\circ}$ with these limits in mind, I decided to examine one wiccan community in ottawa. ${ }^{10}$

Tils choice brought a number of advantages. First, the members of the Ottawa Wiccan community were, on the whole, highly supportive of my research. They were, and still are, as interested in my research as I am. This study would have been impossible without their encouragement and support.

But the decision to study the ottawa community also brought with it certain problems in ethics, methodology, and of a personal nature. All of these problems hinged around one key fact: my own participation in the construction $c$ ? the Ottawa wiccan community.

Was it possible for me to divorce myself sufficiently from my own actions so that I could objectively examine the process of institutionalization in the ottawa commurity? This question was answered for me, inaivertently, by Lawrence

9 The major centers of Canadian witchcraft are Vancouver/ Victoria, Calgary, Winnipeg, Hamilton, Toronto, and ottawa. Smaller communities exist in almost every other canadian city. Any cross-Canada eramination of the process of communal institutionalization would require years of study.

10 Furthermore, I decided that it would be impossible to present an adequate analysis of the Dianic (Femirist) component of the ottawa community. This decision centered on two reasons. First, the Dianic component is, for all intents and purposes, a separate community, thus if I studied them, I would be researching two communities. Second, as a male, I would not be able to gain access to many of the events and this would seriously hamper any investigation. 
Hennigh (1981). In his discussion on performing fieldwork in one's own culture, Hennigh (1981:132) argues that

... a field worker in his or her own culture has at least one research opportunity not available to marginal natives [traditional informants] in an alien culture: The [sic] fieldworker may become his or her own key informant by becoming a significant member of the community under study.

Becoming one's own "key informant" should, according to Hennigh (1981:132), bring with it certain research advantages. First, one "...comprehends the entire system and is therefore able to place component parts into their proper perspective." Second, it should be possible to quickly reduce the number of hypotheses that might be generated. Finally,

The objectivity of a key informant is the testing of reality by responding significantly to strong social stimuli. It is the resulting sense of significance that allows the key informant to test hypotheses and to provide perspectives for the anthropologist as stranger.

The ethical questions involved in researching one's own culture are different from those of working in another culture. First, it is unlikely that one will misrepresent the group with which one is involved since that wousd in turn reflect back on the researcher. ${ }^{11}$ second, it is unlikely that

11 It is possible, however, to misrepresent through an overly optimistic bias of one's own group. In order to ccunter this, I have relied on a number of non-wiccan advisors who have acted as "reality checks" on my interpretations. In order to counter possible perceptual biases based on my own place in 
I would reveal any "secrets" that the members of the group would wish to maintain hidden. ${ }^{12}$ Finally, any presentation biases that were in my work would reflect, at least in part, Wiccan attitudes. ${ }^{13}$

The next question was how to study the ottawa Wiccan community. The traditional use of participant observation as applied to foreign cultures had to be extended. My initial proposal was to conduct a series of interviews and supplement these with specific observations. However, it became painfully obvious to me during the interview process that most of my informants were saying what they assumed I wanted to hear. ${ }^{14}$ As a result of this, I terminated the interview process in favour of using specific key informants, informal interviews,

11 (...continued)

the ottawa community, I have relied $0: 2$ a number of wiccans. Both groups have not hesitated to question my perceptions, and I believe that their aid has been invaluable.

12 Before my Initiation, I had spent hours with my Initiator going over my oath of secrecy. In short, if it is already published, or if it can be logically extrapolated from published sources, "common sense", and/or readily observable actions then it is not "under oath". Any information which I have received "under oath" has remained secret.

13 See Messerschmidt (1981a, 1981b) for a discussion of the debate within anthropology over field work within one's own culture.

14 of the ten interviews conducted, only one proved to be of any use (Magnus, 1992). 
and increased observation. ${ }^{15}$

1.1. Towards a Working Definition of Institutionalization

The sciences that would interpret and explain human action and thought must begin with a description of the foundational structures of what is prescientific, the reality which seems self-evident to men remaining within the natural attitude. This reality is the everyday life-world. It is the province of reality in which man continuously participates in ways which are at once inevitable and patterned."

Schutz and Luckmann, 1973:3

All too often, the academic study of institutions has focused on their organizational aspects and neglected the "taken-for-grantedness" that allows these organizations to exist. ${ }^{16}$ And, when the process of institutionalization is considered, it is frequently assumed to be synonymous with that of institutional organization. ${ }^{17}$ only rarely is the process whereby a new "reality" becomes self-evident considered. ${ }^{18}$ This process must, to my mind, be the basis for

15 My key informants were Khaled, Adrienne, Merydydd, Anahita-Gula, and myself.

16 For example, see stark and Bainbridge, 1985; dechant, 1991 ; Demerath and Hammond, 1969; Johnson, 1984; Spiro, 1932; Ellwood, 1973.

17 e.g. Stark and Bainbridge, 1985.

18 This process was considered by Max Weber (1947:363-373) when he dealt with the routinization of charisma. It has also been considered by a number of social constructionists (e.g. Best, 1989; Spector and Kitsuse, 1987; Gusfield, 1981), Bainbridge (1991), and to some degree, by Eyerman and Jamison 
any examislation of institutionalization.

This bias is also apparent when one considers the sociological literature on the "occult" and new religions. Religious movements such as the Church of All Worlds are considered as being the same as UFo "cults", and practitioners of astrology. New religious movements are frequently represented using terminology designed to provoke a negative response from the reader. For example, Ben-Yehuda (19:25:95) states

There are groups that demand a total change in life style, communal life, various restrictions of food, sex, and entertainment. They require that members disconnect themselves from their families, friends, original community reference groups and nationalities. One relinquishes control over one's private life in return for a career and an alternative vision.

Hicks (1989:2), describing one "cult", Tnevnoc, describes

it in the following manner:

Cuit members must abandon their former lives, even surrendering their outside friendships and personal possessions. Cult members' activities, then, involve the cult exclusively. Members must arise at 4:30 in the morning, wear prayer beads attached to their wrists, engage in long, monotonous chants and prayers, and in one of the most bizarre activities, members consumed food they were told represented the dead cult founder's body.

Hicks' description uses the "jargon of police cult seminars"

${ }^{18}$ (... continued)

(1991). Other considerations of the topic are by (Ginzburg, 1985, 1991; Hobshawm, 1983; Niccoli, 1990). 
to describe "the socialization of young women into christian convents." In his article, Hicks wished to illustrate how the use of certain terms conditions our response to the group described. And it is many of these terms, the "jargon of police cult seminars", that we find in sociological investigations of both new religions and the "occult movement" (e.g. Ben-Yehuda, 1985; Ejerfeldt, 1974 ; Greely, 1969 ; Jorgenson and Jorgenson, 1982; Melton, 1986). ${ }^{19}$

Even the works that manage to present a fairly accurate picture of modern witchcraft (e.g. Kelly, 1982, 1991; Luhrman, 1985, 1986, 1989; Melton, 1983, 1986) are not without problems. For exampie, Melton's (1983) article on witchcraft concludes with advice to Christian ministers on the best way to convert Wiccans. ${ }^{20}$ Aidan Kelly, a protege of Melton's, has aroused much ire (and laughter) in the general wiccan commun-

19 For an overview of the development of the concept of "cults", together with a critique of its use, see Campbell, 1972. This use of prescriptive, negative terminology is not new. Ginzburg (1991) has shown how the same accusations were levelled at various "heretical" groups by the Catholic church. In fact, the "atrocity tale" is a standard rhetorical device designed to prejudice an audience against a specific group (Best, 1987; Bromley, 1991; J.M. Jonson, 1989). The specific accusations do not appear to have changed much in the past 2000 years. See Luck (1985:163-225) for examples from classical Greek and Roman literature.

20 Melton is currently in a suspect position as far as many American Wiccans are concerned for his actions stemming from the Larry Lea Crusade, and his possibie involvement with Eric Pryor (see Green Egg, 24(92), Ostarra, 1991, 8-9. 
ity over his recent (1991) "analysis" of Gerald Gardner's Book of Shadows. 21 Despite these problems, the works of Melton, Kelly, and Luhrman give essential insight into the formation and maintenance of wiccan communities. ${ }^{22}$

When we turn to other academic literature on witchcraft, the situation is even worse. Anthropology has traditionally defined witchcraft using the European early modern model (e.g. Parrinder, 1958). The use of the term "Witch" has been restricted to the practice of "evil" magic in a given society. The classic anthropological texts on witchcraft have assumed a) that "magic" is superstition which is a form of "false consciousness", and b) that "witchcraft" is a form of scapegoating mechanism in general society (e.g. Evans-Pritchard, 1976; Malinowski, 1954).23

Furthermore, most anthropological work on witchcraft has taken place in non-Western societies, while witchcraft in Western societies has been left in the hands of folklorists (e.g. Randolph, 1947), sociologists (e.g. Ben-Yehuda, 1981,

21 Luhrman's field work in the British occult culture during 1983-1985 has apparently caused a number of covens to mark the Books of Shadows with notices saying "Not For Academic Research or other Misuse!" (personal communication from Adrienne)

22 As do certain others, e.g. Adler, 1986; Marron, 1989; Neitz, 1990; Starhawk, 19?9, 1982, 1987.

23 For an examination of the various anthropological formulations of the relationship between magic, science and religion, see Tambiah, 1990. 
1985) and historians. ${ }^{24}$ Few anthropologists have ventured into the field of modern witchcraft.

But it is to these few, most notably Jeanne Favret-Saada (1980, 1989) and Tanya Luhrman (1985, 1986, 1989), that this work owes a great debt. Luhrman's ethnographic work in the London (England) occult milieu provided both a framework for field methodology, and several useful categorizations. ${ }^{25}$ Favret-Saada's (1980) work in the Bocage emphasized the essentially oral and psychological nature of peasant witchcraft. This led me to examine the use of orality, and psychological techniques of "unbewitching" in the ottawa community (see chapter 3 ).

Since I had been involved in the ottawa community from its beginning, I was well aware that it had not developed in a linear fashion. Various community members have struggled to bring factions together, while others have gone off to pursue their own beliefs. Basic definitıons (e.g. Priest/ess, Witch, ard Initiate) have changed radically since 1985 when the community was "founded".

Tris required that my initial theoretical position be

26 For an extensive examination of the later (post 1971) historical literature on Witchcraft, see Gijswijt-Hofstra, 1990.

25 Most notably, her four part categorization of witchcraft, Western Hysteries, ad hoc ritual magic, and noninitiate paganism. (Luhrman, 1989:32-38). 
able to accept "chaotic" fluctuations. 26 In addition, it became necessary for me to consider how what Berger (1980) has termed the "Heretical Imperative" operates in the ottawa community. I also had to consider exactly what "institutionalization" means, both in the context of this study and in the larger context of new religious movements. Were religious movements categorically similar to social movements? Was the distinction between "religious" and "social" merely a culturally based, categorical fiction derived from the legal separation of Church and state?27

All these considerations led me to realize that no single analytic paradigm could adequately "explain" the development of the ottawa wiccan community. It would be necessary to follow a multi-paradigmatic, "eclectic", approach in my analysis.28 The first requirement was a tentative working definition of institutionalization. This definition must allow for institutionalization to occur outside of a bureaucratic

26 See Young (1991) for more on the correlation and convergence between chaos theory and certain types of social theory.

27 This question is extremely important in studying any religious movement in Canada. While there may be a de jure separation of church and state in Canada, the history of Canadian social movements is centered around religious groups and motivations (for example, see crysdale and Wheatcroft, 1976; Smillie, 1991).

28 For one example of a multi-paradigmatic approach in anthropology, see Bennett and Kohl, 1981. 
structure. Any definition that relied on structure alone could not account for the past and present forms of the ottawa community. Nor could it account for the conscious creation of institutions in the community.

It has often been argued that institutions exercise a certain amount of power in the social world, and many people have spent a considerable amount of time describing and modelling this social power of institutions (e.g. Douglas, 1986; Galbraith, 1983; Habermas, 1984, 1987). However, what of the reverse?

Several theoreticians, working primarily from a phenomenological perspective, have attempted to formulate models of individual-social interaction. ${ }^{29}$ others, working on the question of the development of social problems, have developed several models that include randomness and orality (e.g. Best, 1987, 1989; Hilgartner and Bosk, 1988; Lippert, 1990; Richardson, Best and Bromley, 1991; Spector and Kitsuse, 1987). In addition, the literature on social movements provides some useful analytical tools. ${ }^{30}$

29 For example, Schutz, 1967; Schutz and Luckmann, 1973, 1989; Berger, 1980. The development of ethnomethodology by Garfinkle and cicourel has also provided valuable insight into this area (see Heritage, 1984; Leiter, 1980). The Symbolic Interactionist school, derived from G.H. Mead, has also provided some insight.

30 Eyerman and Jamison (1991) have refined the concept of "movement intellectual" which is especially useful. Others include Hsia (1988) and Smillie (1991). 
This process, whereby the social individual affects the social institution, has also been examined in other academic disciplines. One of the most comprehensive examinations has been made by the microhistorical school in Italy, which has attempted to combine anthropological techniques with historiography to great success.31 A second comprehensive examination has been conducted by Melucci (1989), who stresses the importance both of a multilevel approach, and of "submerged networks". 32 other related examinations have been conducted in the fields of comparative religion ${ }^{33}$, linguistics ${ }^{34}$, political economy ${ }^{35}$, biology ${ }^{36}$, psychology ${ }^{37}$ and analysis of technological effects ${ }^{38}$.

31 For the seminal agenda of Italian Microhistory, see Ginzburg and Poni, 1991. For other works of this school in English, see Ginzburg, 1980, 1985, 1991; Levi, 1988; Muir and Ruggiero, 1991, Niccoli, 1990.

32 An "submerged network" is a network or series of interpersonal interactions that is not readily identifiable as an organizational forum.

$$
\begin{aligned}
& 33 \text { e.g. Albanese, 1990; Chidester, 1987; Eliade, } 1976 . \\
& 34 \text { e.g. Ong, 1982; Sapir, 1961. }
\end{aligned}
$$

35 Harold Innis (1951, 1956, 1972) has been one of the foremost pioneers in combining political economy, social interaction, and the effects of communications technology.

$$
\begin{aligned}
& 36 \text { e.g. Margulis, } 1987 \text {. } \\
& 37 \text { e.g. Bateson, 1991; Jung, 1976; Wilber, 1977, } 1984 \text {. } \\
& 36 \text { e.g. Innis, 1951, 1956, 1972; McLuhan, 1964; Pacey, }
\end{aligned}
$$
1983, 1990. The effects of technology on community an belief (continued...) 
My examination of the ottaws Wiccan community will be multi-disciplinary. It will be based primarily within anthropology, however it will also draw on concepts and models developed in a broad range of disciplines. I believe, along with Bennett and Kohl (1981), that the "willingness to be eclectic and to learn" is the "most anthropological aspect of all".

With this eclecticism in mind, I propose the following tentative definition:

Institutionalization is 1) the process whereby a consciously created thought pattern, 2) together with its concomitant action/response sequences and 3) categorization schemata, 4) comes to be a part of the natural attitude of an individual such that 5) it acts to control the actions of that individual. 39

1.2. Thesis organization

38 (... continued)

formation should not be overemphasized. While there is little doubt that technological change effects the religious beliefs of individuals, this appears to take place over a fairly long time; decades or even centuries.

39 This definition is based to a large degree on Geertz's (1973:90) definition of religion. This definition might also serve as a model for "quiet" conversion, the process whereby a religious reality comes to slowly appear to be "true". However, it does not serve as a full definition of "conversion" since it cannot account for a "Damascus Road" style of conversion. Furthermore, while a belief system may become "institutionalized" within an individual, this does not necessarily imply that it will become "truth" for that individual. Thus, "institutionalization" is the process whereby social rules are created, modified and accepted rather than the "truths" which these rules claim to represent. 
developed in a broad range of disciplines. I believe, along with Bennett and Kohl (1981), that the "willingness to be eclectic and to learn" is the "most anthropological aspect of all".

With this eclecticism in mind I propose the following tentative definition:

Institutionalization is 1) the process whereby a consciously created thought pattern, 2) together with its concomitant action/response sequences and 3) categorization schemata, 4) comes to be a part of the natural attitude of an individual such that $5)$ it acts to control the actions of that individual. ${ }^{39}$

\subsection{Thesis Organization}

The thesis is divided into nine chapters. Each chapter is thematically organized. For the most part, I have attempted to introduce theoretical arguments and models only where they are necessary in order to comprehend the data presented. The main exception to this general rule, is in chapter 8 .

The first half of chapter 2 concentrates on introducing

39 This definition is based to a large degree on Geertz's (1973:90) definition of religion. This definition might also serve as a model for "quiet" conversion, the process whereby a religious reality comes to slowly appear to be "true". However, it does not serve as a full definition of "conversion" since it cannot account for a "Damascus Road" style of conversion. Furthermore, while a belief system may become "institutionalized" within an individual, this does not necessarily imply that it will become "truth" for that individual. Thus, "institutionalization" is the process whereby social rules are created, modifier and accepted rather than the "truths" which these rules clain to represent. 
ottawa community. Second, the various skills involved with the production and maintenance of "ritual skills" are examined. Finally, the various groups in the community are analyzed using praxitic categorization.

In chapters 6 and 7, my analysis shifts from the ottawa community to the wider Wiccan and Neo-pagan movements. Chapter 6 examines the construction of time, and hence space and event, in modern wicca. Chapter 7 examines the general Western religio-cultural background in which modern witchcraft is embedded. While specific examples are drawn from the ottawa community, much of the analysis in these two chapters is applicable (as much as anything is) to the general movement.

In chapter 8, I bring together the various theoretical strands that have been woven in the previous chapters. The purpose is not to create a full fledged theory of institutionalization but rather to present a model based on the data presented and to reformulate my initial working definition. Finally, in chapter 9 I examine this new model and definition and consider what still needs to be done.

\subsection{Notes}

While I have attempted to define wiccan terms in the text, this has not always been possible. Thus, I have also included a glossary originally written by Derwyd McTara and 
Rowan Starseeker and expanded by myself (Appendix A). 40 I have also included certain texts that are quoted from in the main body of this work, namely The Charge of the Goddess (Appendix B), and the Gardnerian de=ived Laws or the craft (Appendix C). 49 Appendix D contains an index of articles from open circle (see section 3.1.2.).

Nomenclature is problematic in modern witchcraft. I have used the term "Gardnerian derived" to refer to the constellation of traditions which draw their inspiration from Gerald Gardner. Traditions included within this general term would include Gardnerians, Alexandrian, Georgian, Algard and several others. Rabinovitch (1991) and Sandilands (1988) use the term "traditional". However, I find that this $i=$ not adequate since there are several groups that would count as "traditional" which clearly are not Gardnerian derived (e.g. Hecate's Web).

other nomenclature problems appear with the names of the Sabbats. Unless otherwise specified, I have used my own personal preferences. I use the terms "Wicca(n)" and "Craft" synonymously to refer to the broader wiccan movement. "Neo-

40 Both the inclusion and the expansion are by permission of the authors. Permission has been granted by them to distribute this glossary so long as the copyright notice remains in place.

4 Both of these texts were downloaded from Pandora's Box and are in a publicly available Book of shadows compiled from printed sources by sekhet-Sophia. 
pagan" is used to describe the general reconstructionist movement in which modern wicca is embedded. 
Chapter 2:

yistory and People

All the world's a stage, and all the men and women merely players; they have their exits and entrances, and one man in his time plays many parts

Shakespeare ${ }^{42}$

The ottawa wiccan community is composed of individuals; "players" on the communal "stage". And, as with all plays, there are two main components: the players and the script. Unlike stage productions, the events in the ottawa wiccan community cannot be characterized as comedies, tragedies or farces, they are simply life. The "script" is unknown at the start: it is created by the improvisations of the players. ${ }^{43}$

The purpose of this chapter is twofold. First, to introduce the reader to the dramatis personae of the Ottawa wiccan community (section 2.1). Second, to sketch out the historical development (the "script") of the community from late 1985 to the end of 1991 (section 2.2). This sketch in

42 As you Like It, II, vii, 139-142.

43 The use of dramaturgical terminology in this chapter derives from two main sources. First, many members of the ottawa wiccan community use dramaturgical terminology to describe certain of their "performances" (e.g. rituals, "public" social interactions, etc.). There is an awareness in the community of the performative aspect of communal formation. The second source comes from the literature of performance anthropology, primarily from the work of victor Turner $(1974,1982,1986)$. 
this chapter is, of necessity, limited, a brevis rather than a full script. And, while certain parts of the script are developed in greater detail elsewhere in this work, many are left undeveloped due to constraints of time and space.

\section{1. pramatis Personae}

The people and groups discussed in this work are not fictitious. And, in most instances, neither are their names. There is a general convention in wiccan circles that people are referred to by pseudonyms called "Craft names", or "Witch names". This is done in part to protect the identities of the people involved. 44

I have followed this convention, with several exceptions. First, well known, public Wiccan figures are referred to by the names under which they are best known. Second, in a limited number of cases, I have changed names to protect the identities of the individuals.

This work is concerned with the public and semi-private Wiccan community in ottawa, and with those groups who influence it. I have not included the Dianic groups and individuals since in most cases they have little contact with

44 Frequently, wiccans (and other magical practitioners) will have numerous pseudonyms. Two names are protected: the "real" or "mundane" name, and the "true" name. For more on this, see Farrar and Farrar, 1984:24. 
"mainstream" craft. ${ }^{65}$ Neither have I included the strictly secret groups. ${ }^{46}$

This section will consider seven major groups in the Ottawa community: the Wiccan Church of Canada (Ottawa Member Temple); the Alexandrian and Gardnerian derived groups and individuals; the Web of Herodias; The Merydian Tradition; Hecate's Web; the local Asatru group; and local eclectic groups and individuals. each sub-section contains demographic information on the group. Finally, I will examine the role of "discarnate" actors in the ottawa community. 47

\subsubsection{The Wiccan Church of Canada (Ottawa Member Temple)}

The wiccan Church of Canada (WCC) was founded by Richard and Tamarra James in Toronto in 1979. It is a hierarchical, temple centered, public wiccan tradition. The ottawa Temple of

45 Also, as a male, I would not be able to participate in many of their activities. The "script" of Dianic craft in ottawa will have to await a female researcher.

46 I know of the existence of one "secret" group (Gardnerian derived), and have found traces of others. However, they have no interaction with the general community, and their desire for secrecy must be respected.

47 "Discarnate" members of the ottawa community include both "supernatural" beings (e.g. elementals, Gods and Goddesses, fairies, etc.) and beings who are not physically present (e.g. absent coven members, "ancestors", the "dead", etc.) 
the WCC was founded by Jennifer Holding in early $1986 .{ }^{48}$ According to Richard James (1987:17-18), the WCC recognizes six degrees, namely: "pagan"; Dedicant; Neophyte, 1st degree; 2nd degree; and 3 rd degree.

"Pagan" and Dedicant are "degrees" that may be undertaken at the will of the individual. The sole difference is that there is a ritual for dedication, while there is none for a "pagan". Neophytes are "...commited ... to studying to become a priest(ess)..." (R.James, 1987:17). The bestowing of Neophyte "degrees" is at the discretion of any Initiate (1st, 2nd or 3rd degrees). First, 2 nd and 3 rd degrees are equated with the academic degrees of B.A., M.A. and PhD.

The Ottawa Member Temple holds open circles (rituals) every Sunday evening, and public classes every Monday. Attendance at Sunday circles has varied over the years between 10 and 60 . As of the last quarter of 1992, attendance was in the 30-40 range. However, there is a fairly high turnover rate averaging about every three months. Somewhere around 10\% will stay with the Temple longer.

If we include all attendees and private groups centering around the wCC temple, I would estimate that there are between

48 originally, the Temple was a member coven of the wCC. However, this distinction has had little bearing on the events in the ottawa community. For more on the role played by Ms. Holding in the development of the ottawa Wiccan community, see sections 2.2 .2 . and 2.2 .3 . 
40 and 60 people involved as of December, 1991. WCC attendees are generally $(65 q+)$ in the 16 to 25 age range. There is a slight predominance of males in attendance (approximately 528 to 55\%). The average income is around $\$ 10,000$, with the top incomes in the $\$ 30,000$ to $\$ 40,000$ range.

The current Priesthood of the Temple, Mara and Corliss, are the second pair. The first Temple Priestess, Jennifer Holding, returned to Toronto in 1988. The next set of Temple Priesthood, Chandra and spider, left for personal reasons (see $2.2 .5)$

The wCC is one of three Canadian wiccan organizations that are a) public, and b) multi-city. The others are the Covenant of Gaia in Alberta, and the congregationalist Witchcraft Association in British Columbia. The wcC currently has three fully functional Temples (Toronto, ottawa, and Hamilton) and a new one starting north of Toronto. As one researcher has noted (Rabinovitch, 1991:24)

For good or for ill, the Wiccan Church of Canada has had a profound effect on the tone and timbre of public and semi-private wicca in ontario.

\subsubsection{Alexandrians and other Gardnerian Derived Wiccans}

The Alexandrian tradition derives from the groups founded in the 1960's by Alex Sanders. Sanders became famous in England during the 1960's as the "King of the witches" (Johns, 
1969; Sanders, 1976; Valiente, 1989:163-177). His tradition was based on the earlier work of Gerald Gardner and Doreen Valiente.

The Alexandrian tradition appeared in Toronto in the late $1960^{\prime} \mathrm{s}$, and spread from there to Halifax. ${ }^{49}$ The spread of the Alexandrian tradition has been augmented by the wide spread circulation of the writings of Janet and stewart Farrar. Preliminary data from the first Canada wide study of Wicca shows that the Farrars' writings have been seminal in many Canadian groups. 50 The Alexandrian tradition appeared in Ottawa in 1985, when three members of Quicksilver coven of Hal ifax moved here. 51

Alexandrians are hierarchical and recognize three

49 The Alexandrian tradition may also have spread from Toronto to Montreal. Most Alexandrian activity in ontario stems from the Toronto base, and Alexandrian groups may be found throughout the country.

50 This study was conducted by Shelly Rabinovicch of the department of Religion, Carleton University, dhring the summer of 1991. She has been kind enough to show me some of her preliminary results. Two other "Canada-wide" examinations were made prior to Ms. Rabinovitch's. Catriona Sandilands (1988) of York University administered a questionnaire in Toronto, ottawa, and British Columbia. However, she missed large numbers of Wiccan groups due to difficulties in communicating with them. Kevin Marron, a journalist, wrote a popular book on witchcraft in Canada (Marron, 1989). His work suffers from many of the same communications limitations as does Ms. Sandilands.

51 Several Alexandrians were already in Ottawa. However, none of them were Initiates. 
degrees: 1st, 2nd, and 3rd.52 Unlike the wCC, Alexandrians are not a public tradition. They are organized into covens and study groups ranging from 3 to 13 members. Covens are led by a High Priestess aided by a High Priest.

The main local coven is called "Quicksilver". The founding (and current) High Priest and Priestess are Khaled and Adrienne. Quicksilver coven currently has "more than six and less than twelve" members. 53 In addition to the main coven, Quicksilver oversees two study groups. These are run by members of Quicksilver, and are between 3 and 10 members each. Quicksilver ran its first study group, Merrigold, in 1989.54

The main age group in Quicksilver and its training covens is 30 to 40 . Average income is between $\$ 20,000$ and $\$ 30,000$ per year. Unlike the wCC, Quicksilver tends to retain its people for long periods of time, and the average member of the coven has been involved in Wicca for 4 to 7 years. Khaled has been involved for 20 years.

There are also several Gardnerian derived individuals and ad hoc grcups in the ottawa community. Many currently nonGardnerian derived Wiccans have received training and/or

52 There is also an honourary title of "Witch Queen" or Tradition Elder that is given to a High Priestess (HPS) who "hives off" two covens. This is more a title of respect than a degree.

53 Personal communication, Adrienne.

54 open Circle, \#6, January, 1989. 
Initiation from Quicksilver. For more on the Gardnerian derived traditions, see Adler (1986), Crowley (1989), Farrar and Farrar (1981, 1984), and Valiente (1989)

\subsubsection{The Web of Herodias}

The Web of Herodias is a network of individual wiccans. It was founded in ottawa in 1989 by Marios and Sekhet-Sophia. currently it contains between 5 and 15 members in ottawa and New Jersey. Members of the Web of Herodias tend to fall into the 25 to 35 age range. Annual income varies from around $\$ 10,000$ per annum to $\$ 70,000$ per annum. Members of the Web have been involved in Wicca for an average of 4 to 6 years, however due to the eclectic interests of the membership, many have been involved in "spirituality" or "mystical paths" for much longer (10 to 15 years).

The Web of Herodias was founded with several purposes in mind. First, there was a desire to create a synthesis between the folklore of Herodias (aka Aradia, Abundia, Holde, Dame Hel, etc.), the Western Mystery Tradition, and Gardnerian derived wicca. Second, it was felt that the wcc public priesthood and the Alexandrian coven models of Wicca did not allow for sufficient individuality of "paths".

Herodians tend towards a functional hierarchy. They recognize three degrees: 1st, 2nd, and 3rd. However the meanings of these degrees are radically different from both 
the WCC and the Alexandrians. This difference stems from the adoption of the radical Protestant position of the "priesthood of all believers".

A lst degree is someone who, in the opinion of a 2 nd or 3 degree is a) capable of acting as their own priest, b) has met their own, subjective criteria for initiation, and c) "feels" like an Initiate. A 2nd degree is someone who, in the opinion of a 2 nd or 3rd degree, "acts" and "feels" like a 2 nd. Finally, a 3rd degree is someone who is recognized by all Initiates of the Web of Herodias as a $3 \mathrm{rd}$, and who accepts this degree. There are currently no 3rd degrees.

\subsubsection{The Merydians}

The Merydian tradition grew out of the study groups and covens run by Merydydd, a local Elder (see 2.2.1. to 2.2.4.). There are currently two Initiates, and between 10 and 25 nonInitiates in the tradition. The age range of the members is between 20 and 30 . Income varies considerably between $\$ 10,000$ and $\$ 50,000$. The length of involvement in wicca averages between 3 and 6 years.

Merydians tend to be the least political group in the Ottawa community. Merydians recognize three degrees. At 1st, an individual should be competent to run a group. At 2 nd, the individual should be a community Elder. Third degree is "honourable retirement" from active participation in the 
community. There are currently no $3 r d$ degrees in the Tradition, and only one 2nd degree.

2.1.5. Hecate's Web

Hecate's Web was founded in December of 1990. It currently has 5 members. This group centers around the production of Sabbat mystery plays. Attendance at their rituals is by invitation, and numbers run between 20 and 70 . The actual membership of Hecate's Web ranges from 34 to 60 , while the average age of attendees at their rituals is in the 35 to 45 range. Income levels vary highly, but centre around the $\$ 35,000$ to $\$ 45,000$ range. Length of involvement in wicca ranges from 2 years to 15 years, with the average around 5 years.

Members of Hecate's Web tend to have little direct contact with the rest of the ottawa community. Attendees at their rituals frequently have no other contact with the rest of the community. They also tend to be older than most members of the ottawa community, averaging in their 30's and 40's as opposed to the 20 's of the wCC. Current standards for initiation (1st degree) and elevation (2nd and 3rd degrees) are under negotiation by the group. No elevations have taken place, and only one initiation. 
2.1.6. The Asatru Group

Asatru is a Norse reconstructionist tradition, with members throughout North America and Europe. 55 They are not neo-Nazi nor wiccan. The local Asatru group was founded in March of 1991 by Magnus. It currently contains 10 members, most of whom were originally with the wCC. The age range is from 20 to 30 . Income varies considerably, but averages around $\$ 20,000$. The length of time involved in wicca (and/or Asatru) varies between 1 year and 15 years, with an average of 3 to 4 . While Asatru is not a wiccan tradition, many of the local members are or were wiccans and retain close ties with the rest of the community.

This group is based on a strong "familial" principle. Members of the group are "family". It is also much better organized than any wiccan tradition in the ottawa community both financially and socially. The group has its own bank account into which members pay monthly "dues". They also brew their own beer, wine, and mead, and produce all of their own ritual tools.

While they are not tachnically hierarchical, a functional hierarchy exists based on knowledge. Knowledge, in any form, is highly prized, as are numerous skills. Initiates of this

55 Norse reconstructionist traditions are attempts to recreate Norse paganism. Earlier attempts include the Nazi movement to paganism. 
group are generally accepted as wiccan Initiates. Magnus is generally considered to be an Elder of the ottawa community.

\subsubsection{The Eclectics}

In addition to the above groups and traditions, there are numerous solitary practitioners and ad hoc groups (between 75 and 200 people), with varying degrees of contact into the ottawa community. Ritual style, beliefs and practice vary enormously, but tend to derive from either published sources (e.g. Alexandrian [and other Gardnerian derived], Dianic, Erisian, $\left.{ }^{56}\right)$, from WCC open classes and rituals, and training with any of the above mentioned groups. No comprehensive survey is possible due to constant changes and shifts in membership, practice and belief.

\subsubsection{Discarnate Members of the Ottawa Community}

The final set of members of the ottawa community are the "discarnate" (literally "out of the body") members. These beings fall into three dist nct categories. First, there are currently "incarnate" (living) individuals who are not currently present "in the flesh" at an event. In certain cases (mainly sabbats), these individuals are considered to be

56 Based on Eris (Erys), the Greek Goddess of chaos and discord. The primary printed source for Erysians is the Principia Discordia. Erysians are also referred to as "Discordians". 
present, and are interacted with, by those members of the group who are physically present. The absent individual is considered to have "projected" (i.e. astral projection) into the circle, so that they could attend. ${ }^{57}$

A second category of discarnate beings are humans who are currently non-incarnate. There are three main forms of these beings. First, there are those who have evolved beyond the necessity to incarnate and now act as "guides".58 second, there are the "souls" (viewed as incarnation personas or masks) of the dead. ${ }^{59}$ These beings may be either generic ("the Ancestors", "the Dead", "the souls of Witches past", etc.), or they may be specific (discarnate members of a tradition, individual people, etc.). Finally, there are the "souls" of the discarnate which have remained operating in the material world (e.g. Ghosts, Vampires, Revenants, etc.) .60

57 This belief is directly related to early modern beliefs in attendance at certain specific rituals "out of the flesh". For more on this belief, and on its historic links with Witchcraft, see Ginzburg (1991).

58 The formulation is closer to the theosophical formulation of the "Ascended Masters" than to the Spiritualist formulation of Spirit Guides.

59 In this view, the "soul" is a mask worn by an eternal spirit so that that spirit may interact with others in the material world.

60 These beings may either be the "soul masks" (see footnote 59) or the soul and spirit of an individual who refuses to withdraw from action in the material world, or one who is compelled to act in the material world. For an example (continued...) 
The final category of discarnate beings considered to be members of the ottawa community are non-human beings. These fall into two main subcategories. First, there are other "races" that are considered to be evolving along different "paths". This category would include elementals, beings of an essential element (e.g. Fire - Salamanders, Earth - Gnomes, etc.), and the "fairy folk" (e.g. Elves, Manitous, etc.). Second, there are beings who are considered to be "Gods" and "Goddesses" who are seen both as individual beings and as essential forces (Starhawk, 1979).

While inclusion of supposedly "fantastic" beings amongst the membership of a community may appear irrelevant, I would argue that it is not. First, the incarnate members of the ottawa wiccan community accept the existence of these discarnate beings. Second, the incarnate members of the ottawa community engage in intersubjective social interaction with the discarnate members of the community. This social interaction ranges from forr $\lrcorner$ lized rituals to informal "chat" sessions (during meditation and/or day dreaming). For ottawa witches, as for many other religious people, discarnate beings are an important and integral part or their religious community.

\footnotetext{
${ }^{60}(\ldots$ continued $)$

of the former, see Fortune (1976) for the latter, see 1 Sam 28 -- Saul and the witch of Endor.
} 


\subsubsection{Conclusions}

In total, excluding Dianic and gender-specific, femaleonly groups, I estimate the size of the ottawa community at between 179 and 420 members. If we were to add in the Dianic and female-only groups, there would probably be an additional 40 to 400 people. 61

In general, there is no single characteristic religious or philosophical upbringing for members of the ottawa community. Nor does there appear to be much correlation between early religious upbringing and current group membership. For example, it is possible to find people raised originally as Anglicans and Salvation Army members. This lack of correlation may well stem from the low numbers of people involved in the community.

Additional information on the groups examined in this section is contained primarily in section 5.2 .

2.2. Historical Development of the Ottawa Wiccan Community

The development of the ottawa wiccan community breaks down into five main periods (see Figure 2.1). As can be seen,

61 There are immense difficulties in estimating the size of the local Dianic and all female group population. The minimum of 40 was arrived at from personal observation. The maximum of 400 is based on extrapolation, guesswork, and rumour. I would not be surprised to find that there were twice as many as my estimated "maximum". However, with a very few exceptions, they have little or no contact with the general community. 
there are temporal overlaps between periods. These overlaps are used to show periods of "turbulence" arising from the actions of certain "chaotic attractors". 62

Figure 5.2: Developmental Periods in The ottawa Community

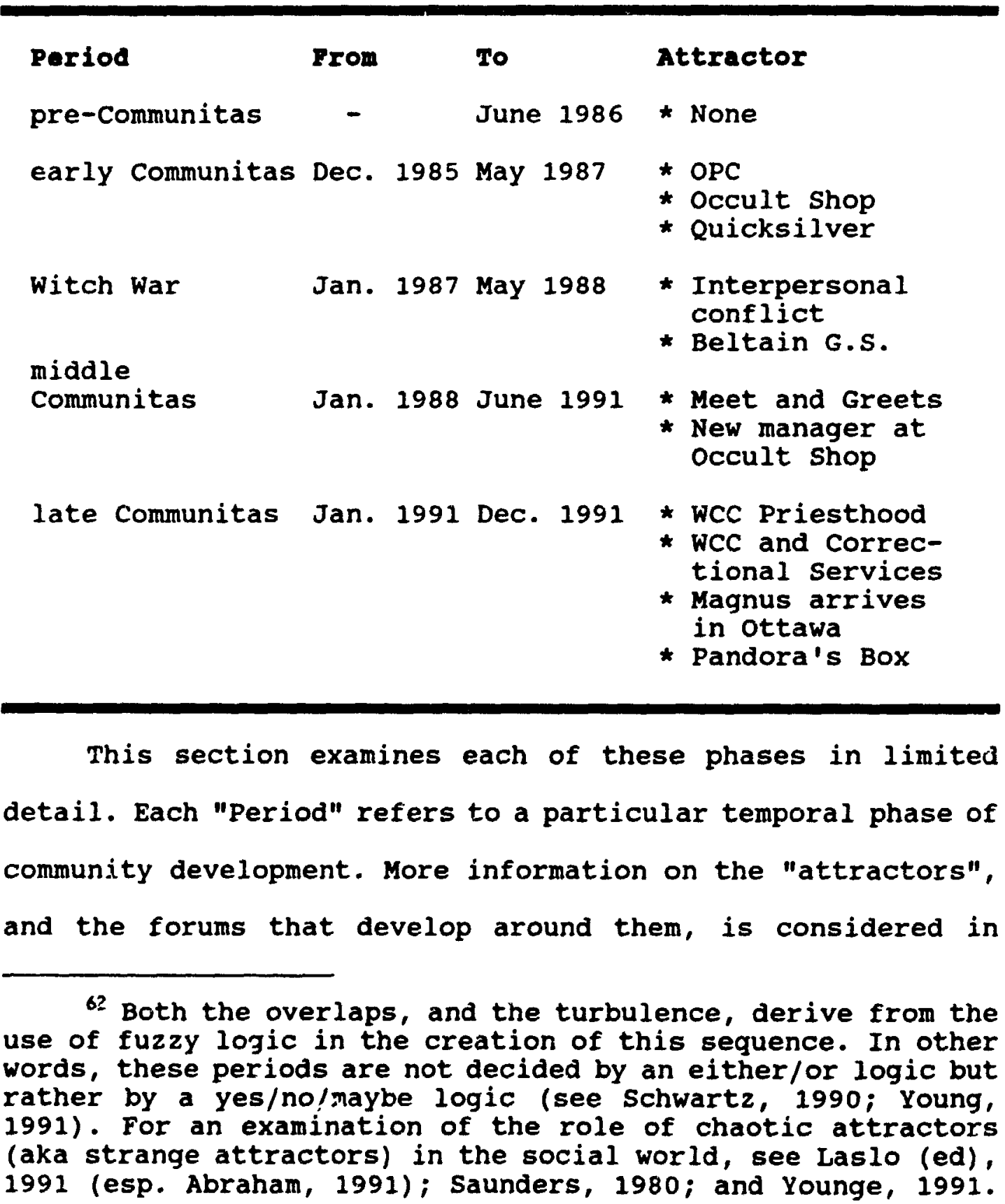


chapter 3 .

\subsubsection{Pre-Communitas}

Unlike many other craft communities, there is a definite starting point for the ottawa community: December, 1985. This is not to say that there were no neo-pagan witches in ottawa before this time, there were. ${ }^{63}$ However, there was no sense, or discussion, of an "Ottawa community". Contact between craft practitioners was, with the exception of a few contributors to the Messenger (e.g. Marios, Amethyst), sporadis. Covens operatin .1 the Ottawa area were closed. 64

j) early 1985, there were signs of the development of an indigenous ottawa community (e.g. Seafire coven, founded in September 1985). Contact networks were being established through science Fiction conventions (e.g. Maplecon). These nascent networks were quite fragile and soon overshadowed, although they continued to develop on the fringes of the Ottawa community (see section 3.2.2.)

63 For example, Marios (1972), Anahita-Gula (1976), Pashta Marymoon (1979), Merydydd (1984). Bracketed dates are the year of arrival in ottawa.

64 At least two, and possibly three, covens operated in the ottawa area before 1985. However, none of these covens communicated with the solitaires or other groups in the area. A "closed" coven is one in which membership is by invitation only. "closed covens" tend to be highly secretive. NB: these comments do not apply to two to three Dianic groups operating in the Ottawa area. 


\subsubsection{Early Communitas}

Two major events led to the creation of the ottawa "community". First, on December 14th, 1985, Richard and Tamarra James opened the Wiccan Rede on Rideau Street. While this opening provoked protest from local christian fundamentalists, it also served to provide a focal point for Witches in the Ottawa area. ${ }^{65}$ The Wiccan Rede served a dual purpose. First, it served as a supply house for local Witches. ${ }^{6}$ Second, it served as a store front for the wiccan Church of Canada. ${ }^{67}$ The second major event was the movement of three members of Quicksilver from Halifax to Ottawa. ${ }^{68}$

Both the WCC and Quicksilver had local contacts, and both set out to "create" an ottawa community. ${ }^{69}$ Both groups were also initially unaware of the presence of the other, and this

65 On local fundamentalist reaction, see couple protests occult shop opening, ottawa Citizen, Monday, december 16, $1985, \mathrm{C2}$. For a more indepth examination of the role of the Wiccan Rede (later "The Occult Shop"), see section 3.2.3.

66 See Janet McFarland (1987). Before the opening of the Wiccan Rede, the primary source of books wa:s sunyside Books (113 Murray street, ottawa), and the primary source for incense and certain other ritual supplies was Desmarais and Robitaille, Ltd (333 Dalhousie street), a local church supply house.

67 See, McFarland (1987).

One in September, 1985. The High Priest and High Priestess moved to Ottawa in late October, 1985.

69 Quicksilver wished to network, whereas the wcc wished to recruit. Either action would serve to start a community. 
in turn led to a certain amount of intergroup friction and competition. The initial attempts to resolve these differences were the ottawa Pagan Council (OPC; see section 3.2.1) and the Grand Sabbat of Beltaine, 1987.

The Beltaine Grand Sabbat of 1987 marks a watershed in the role of the OPC. Initially, it was conceived as an attempt to unite the various groups and individuals in a single ritual, hence the term "Grand sabbat". Writing and producing the ritual, was to be jointly conducted by the wCC and a member of Quicksilver.

The Grand Sabbat took place at Vincent Massey Park. There were many practical problems: the site needed extensive cleaning; the participants had not memorized their parts, and made frequent reference to their scripts; differences in ritual presentation style created some awkwardness amongst the various participants. However, all of these difficulties were surmountable, and the ritual proceeded to its conclusion.

In general wiccan culture, Sabbats include feasts which give the participants an opportunity to discuss the ritual as well as engage in general social interaction. In this case the feast was interrupied by members of a local rugioy team intent on using the ritual site for a "beer bash". Conflict soon broke out between the more inebriated members of the rugby team and several Grand Sabbat attendees. This led to the withdrawal of Grand sabbat attendees from the site (not to 
mention the spoilage of several gallons of rabbit stew). The feast was shifted to the wiccan Rede, but half of the participants went elsewhere.

without the full attendance of participants at the relocated feast, social interaction was limited. Problems with the ritual were discussed without resolution, and variant interpretations of events appeared. Within the space of weeks, the Beltaine Grand Sabbat came to symbolize the fracturing of the ottawa community.

\subsubsection{Witch War}

The events following the Beltaine Grand Sabbat shattered the initial optimism about an ottawa "community". Interpersonal conflicts, as well as intergroup conflicts, flared into what later became know as the "Witch War". Quicksilver's first two initiates in the ottawa area (Marios and Merydydd) withdrew from contact with them and proceeded to develop their own traditions. ${ }^{70}$

This fracturing set the conditions for the expansion of craft ideas. The witch war forced many of the people involved to reexamine and expand their concepts of Craft. Contacts with the early, science Fiction based, networks were reestablished

70 Merydydd forms Serendipity in December, 1987. Marios, after working solitaire for a year, and with several ad hoc ritual groups, co-founds (with sekhet-sophia) the web of Herodias in 1989. See sections 2.1.3-4. 
and new groups were founded.

\subsubsection{Middle Communitas}

In May of 1988, the wiccan Rede moved to its current address on Bank Street $(5931 / 2)$, and changed its name to "The Occult Shop". This change in location also included a change in store managers. Jennifer Holding, the original manager and local WCC Priestess, was replaced by the current manager, Dobhran. ${ }^{71}$ This change involved a shift not only in management policy, but also in attitude towards the concept of community.

In August of 1988, the Meet and Greets (see section 3.2.1.) were established by Khaled and Dobhran. The initial venue was at the occult shop, however this changed to the Glebe Community Centre (September to May) and Vincent Massey Park (June to August) in 1989.

Between May, 1988, and April, 1989, the wCC Temple was without a local priestess. During this time year, numerous local, non-wCC Initiates performed public rituals and taught classes at the Occult Shop. In addition, wCC Priesthood would sporadically appear from Toronto. This situation led to three main results.

7 Ms. Holding was initially from Toronto and wished to return there. She does, however, still keep some contact with the ottawa community. Dobhran, the current manager, was not at the time connected with either the wCC or Quicksilver. 
First, there was a growing dialogue between tha non-wCC members of the community and the members of the wCC. Second, the Toronto WCC Priesthood became viewed by many as imperialistic, uncaring, and insensitive to local issues. 72 This view resulted in a fairly widespread distrust of the wCC Home Temple. Finally, the growing dialogue, and the constant presence of representatives from many different traditions, led to an increase in intertraditional cross-training. In April, 1989, Chandra was initiated and became the local wCC Priestess. She continued, and strengthened, the intertraditional dialogue started by Dobrhan and Khaled.

At Samhain, 1989, a second Grand Sabbat was staged by Marios with representatives of every group in the ottawa community. Approximately 60 people attended, with a ritual "cast" of 20. Unlike the Beltaine Grand Sabbat of 1987, the Samhain Grand Sabbat was not presented as a zommunity sponsored ritual: it was sponsored by a single person. Other differences included the invitation of non-wiccans and the employment of a professional, non-craft, director (Brian Graham). Finally, the Grand Sabbat was followed by a feast at the site and by a "cast" party at Marios' home.

The period from the samhain Grand Sabbat until early 1991

7 There were certain notable exceptions, e.g. Tamarra James. This perception of imperialism sprang primarily from the actions of certain newly Initiated first degrees. 
was marked by a growing interaction between the various groups and individuals in the community. Numerous non-wCC initiates performed public rituals and gave open classes at the occult shop. Cross-training between various teachers became the nurm for students, and numerous teachers evolved specialties (see chapter 5).

\subsubsection{Late Communitas}

The dynamic in the community changed radically between February and June, 1991. In February, Chandra's husband Spider was refused Initiation by the wCC Council in Torontc. This sparked protests from many people in the ottawa community. At least two local offers of Initiation were proffered to him (Marios and Anahita-Gula: see Rabinovitch, 1991:13-14). A second council meeting offered him his Initiation, which was accepted. However, Chandra and Spider subsequently chose to leave the wCC in May.

Their departure, and the rapid Initiation of the current Priesthood (Corliss and Mara) marked a radical change in the local wCC attitude to other traditions. Under its current Priesthood, the wcc has effectively withdrawn from most intertraditional communication, and is now fairly isolated from the rest of the community.

This isolationist tendency has also been heightened by other factors. First, the appearance of Magnus in ottawa (Dec, 
1990) led to the emergence of the local Asatru group, and the defection of a number of WCC members to it (see section 2.1.6.). Second, the Initiation of several wCC members by nonWCC Elders. ${ }^{3}$ Third, interpersonal conflicts between Corliss and a number of ottawa Elders. ${ }^{74}$ Finally, a noted perception by a number of WCC attendees, that sunday open Circles are "cotton candy" that have little to do with "spirituality" or "Wicca". 75

This active "isolationist" tendency is limited to the wCC component of the community. Nor, according to Mara, is it by design. ${ }^{76}$ While general intergroup communications and contact is lower than in 1989-90, this situation seems to have arisen more from a lack of time than from any particular political

73 Notably Hawk (Samhain, 1991) by Marios and Merydyd, and Mabd, by Andy B. Both Hawk and Mabd were wCC Neophytes who had become involved in personal conflicts with the local WCC Priest.

${ }^{76}$ Personal communications from Merydydd, Marios, AnahitaGula, Magnus, and Adrienne.

T) Field notes (July, 1991). This perception was also noted more recently (Feb, 1992) at a post-ritual discussion. This perception is, to some degree, fostered both by non-WCC groups and by the wCC hierarchy. Members of the non-wcc groups will usually describe Sunday circles as "pagan, not wiccan". The wCc hierarchy takes a position that witches are priesthood only, thus the "true" Wiccan rituals are only for priesthood.

76 Personal communication, January 10th, 1992. However, observation tends to indicate that while Mara is interested in intertraditional communication, Corliss is vehemently opposed to it. 
"fights". And, whereas the wCC once provided a "gateway" for these groups to the non-craft world, this function is now disappearing as groups and individuals "go public".

\subsection{Conclusions}

The purpose of this chapter was to give the reader background information on the "players" and the "script" of the ottawa wiccan community. In chapter 3 , this examination continues with an analysis of the various communications forums active in the community. 
Chapter 3:

Communications in the Ottawa Wiccan Community

In its pure form charismatic authority has a character specifically foreign to everyday routine structures. The social relationships directly involved are strictly personal, based on the validity and practice of charismatic personal qualities. If this is not to remain a purely transitory phenomenon, but to take on the character of a permanent relationship forming a stable community... it is necessary for the character of charismatic authority to become radically changed.

Weber, $1947: 363-364$

In his analysis of the routinization of charisma, Max Weber (1947:358-373) argued that ideal charismatic authority comes from "originating", rather than "continuing". In order for a stable community to be formed, the source of authority must be changed from the "miraculous" to the "everyday". The path towards the "sacred" gate, opened by charismatic leaders to "prove" their validity and their authority, must be explored, mapped, described, and regularized. These actions serve to move the path from the "sacred" to the "profane": from the "miraculous" to the "everyday".

When a community begins to "explore" a pathway (or set of paths), they may use any number of specific techniques. Some of these techniques will be taken from previous explorations of similar paths. $n$ others will be developed through trial

7 For example, the techniques of "pathworking", ecstacy, mediation, "mystery plays", etc. See, Kelly (1991) for an (continued...) 
and error, necessity, or questioning what is presented. ${ }^{78}$ Still others will be inherent in the formulation of the paths being explored. 79

The act of "mapping" a pathway involves the symbolization of that pathway. ${ }^{80}$ This symbolization may be visual, linguistic, poetic, musical, tactile, olfactory, etc. ${ }^{81}$ Regardless of the sensory form of symbolization, technical vocabularies will be modified and/or developed to "describe" the symbolization ("map") and the path ("territory").82

$\pi$ (....continued)

examination of the sources of the techniques in Gardner's Book of Shadows.

78 Kuhn (1970:90) notes that most new developments stem from people who are either young, or new to the field. In short, they do not realize that they cannot do $x$, so they go ahead and do it.

79 Kuhn's (1970) "normal science". An example of this in the Ottawa Wiccan community would be the "given" of the Sabbat cycle (see 6.3.).

80 This symbolization process is what Holy and stuchlik (1980) refer to as the creation of "folk models". The process of symbolization "translates" the experience of the sacred into symbols that allow for a non-experiential communication of the experience.

${ }^{81}$ For example, many Indo-Aryan cultures developed poetic representations of paths: the Mahabharata, the Illiad and the odyssey, the Eddas, the Poems of Taliesin or Cretien de Trois.

${ }^{82}$ Clifford Geertz (1973:90), has defined a religion as:

a system of symbols which acts to establish powerful, pervasive, and longlasting moods and motivations in men by formulating conceptions of a general order of existence and clothing these (continued...) 
Confusion is an inevitable consequence of this process since there cannot be "perfect" understanding between individuals, and differences will exist in the "decoding" of the symbols by different individuals. ${ }^{83}$

The act of description may lead to the process of "regularization", or "institutionalization". But description only leads to institutionalization if the language of description becomes part of a communal stock of linguistic knowledge (Schutz and Luckmann, 1973:99-331). It is with the act of interpersonal communication that linguistic concepts and their communicative forums become institutions. The routinization of the presentation (description) of paths arises from these forums. And from this routinization stems the emergence of "gatekeeping" positions which control access

82 (... continued)

conceptions with such an aura of factuality that

the moods and motivations seem uniquely realistic.

Geertz is discussing religion in the sense of "to bind back", a religion of faith (or the faith component in a religion). Such a definition is useful in examining the social expression of an institutionalized religion. It is, however, useless for examining a religion which is still in the process of regularizing its "system of symbols".

83 See Nattiez (1990) for an analysis of the difficulties in communication through music. I find Nattiez's analysis of more use than a structuralist approach (e.g. Hawkes, 1977), since Nattiez also considers the effects of the trans-semiotic nature of music: the evocation of emotions. It is this transsemiotic component that, to my mind, renders most structuralist analyses of religious experience (and hence symbolization) inadequate. They can, at best, analyze the presentation of "faith", but not "gnosis" (see 8.1.). 
to these paths.

This chapter examines the type and development of communications forums in the ottawa wiccan Community. Section 3.1. concentrates on print and electronic media, while section 3.2. examines the development of oral forums.

3.1. Print and Electronic Forums

The ottawa community has made use of a number of communicative media. By far the most important is gossip, and the "kaffe klaich". Attempts have been made, however, to use print and electronic communication. This section considers the three attempts to institutionalize non-verbal communication: The Messenger, Open Circle, and Pandora's Box.

\subsubsection{The Messenger}

The Messenger is a Wiccan A.P.A. ${ }^{84}$ which consists of thirteen rembers. It is published eight times a year at the Sabbats. ${ }^{85}$ In the first issue (Michaelmas, 1984) it contained the following statement of purpose:

84 (A) mateur (P) ress (A)ssociation. These APA's derive primarily from the science Fiction community. They are organized into a general membership and a collator. Each member must provide a minimum contribution which is sent to the collator in a given time period. The collator then collates all the issues and mails them out to the general membership.

85 The Erighid, 1992 Issue is number 60 . 
The Messenger is an offshoot of a conversation between two pagans trapped together on a long drive. What we have in mind is to set up an APA to serve as a forum for a free exchange of ideas among Pagans of as many different regions and Traditions as we can reach.

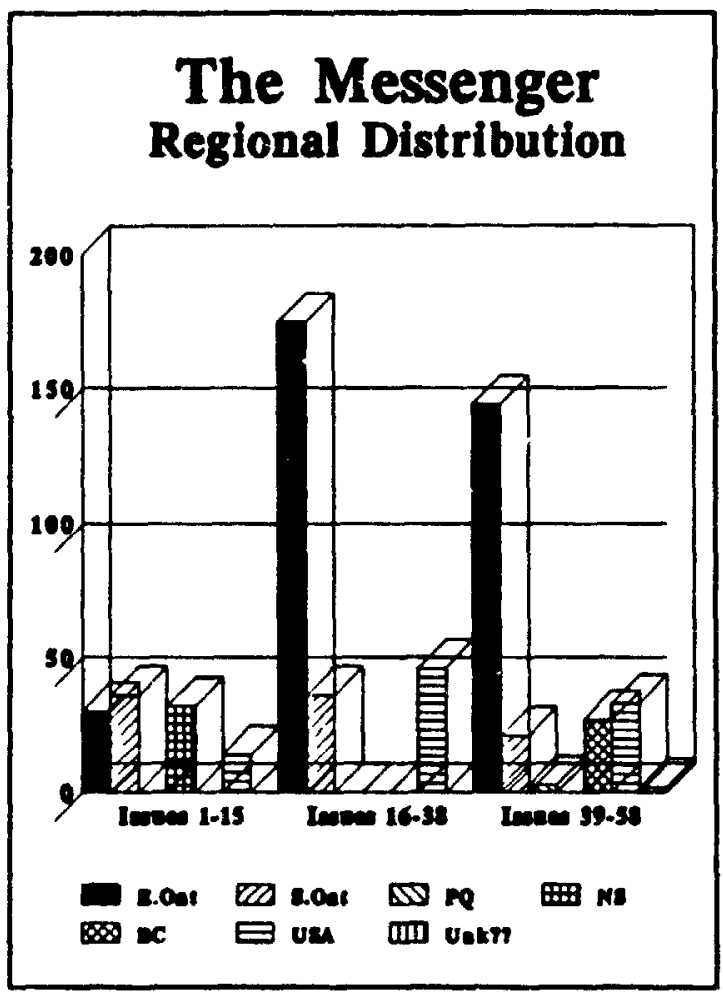

Figure 3.1
The collator was, and still is, Khaled. The earliest contacts with wiccans in ottawa were through Amethyst (Issue 1) and Marios (Issue 3).

The distribution of The Messenger breaks down into three main periods: Mabon 1984 to Midsummer 1986 (\$115): Lammas 1986 to Beltaine $1989(* 16-38) ;$ and Midsummer 1989 to the present (\#3958). .86 Figure 3.1 shows the relative regional distribution of the Messenger during these three periods.

The numbers shown (the $Y$ axis) is the sum of memberships within the given period from a given, regional area ( $N=599)$. Eastern Ontario includes both Ottawa $(\mathrm{N}=335)$ and Perth $(\mathrm{N}=12)$.

\$6 The "present" is, for data purposes, Samhain, 1991 (Issue $\$ 58$ ). 
Southern ontario includes Toronto $(N=79)$, Hamilton $(N=9)$, and Guelph $(\mathrm{N}=4)$. All memberships from Quebec are from Montreal $(N=3)$. All memberships from Nova scotia are from the Halifax/Dartmouth metropolitan area $(\mathrm{N}=32)$. British Columbia includes memberships from Kispoix $(N=7)$ and Vancouver $(N=20)$.

\subsubsection{Statistical Description}

The first period (Issues 1-15: $N=112$ ) shows a fair balance between ottawa, Toronto and Halifax $(26.8 \%[N=30]$, $32.18[\mathrm{~N}=36]$ and $28.6 \%[\mathrm{~N}=32]$ respectively). American involvement is limited to $12.5 \% \quad[N=14] .87$ The average membership per issue is 8.6, with a high of 13 ( $\# 15$, Midsummer, 1986), and a low of 4 ( $\$ 1$, Michaelmas, 1984). Of the total memberships, 43.78 [N=49] were "null" memberships (i.e. the member did not submit anything). This gives the period a participation factor of

\section{Figure 3.2: Issues 1-15}

\section{Region Null Full PF}

$\begin{array}{lrrr}\text { E. Ontario } & 9 & 21 & 0.429 \\ \text { S. Ontario } & 22 & 14 & 1.571 \\ \text { Nova Scotia } & 11 & 21 & 0.524 \\ \text { USA } & 7 & 7 & 1.000 \\ \text { All } & 49 & 63 & 0.786\end{array}$

87 NB: Issues $\$ 2$ and 7 were unavailable for examination and hence are excluded from this data set. According to Khaled, they are "similar" to the other issues of the period. 
.786 .88

As Figure 3.2 clearly shows, there are major differences in the participation rates of the various regions. This arose partly because of Khaled's and Adrienne's move to Ottawa.

The second period (Issues $16-38: \mathrm{N}=257$ ) shows a radical shift from the first period. Ottawa is clearly the dominant region (68.18 [N=175]) followed by the USA $(17.98[N=46])$ and lastly by southern ontario $(148[N=36])$. The average membership per issue is

11.2, with a high of 14

\section{Figure 3.3: Issues 16-38}

(\$24, Lammas, 1987), and

Region

E. Ontario

S. Ontario USA

A11
NuIl Full PF

$\begin{array}{rrr}71 & 104 & 0.683 \\ 18 & 18 & 1.000 \\ 23 & 23 & 1.000 \\ 112 & 145 & 0.772\end{array}$

1989]). of the rotal 43.68

memberships,

[N=112] were "null" memberships. This gives the period a participation factor of .772

While there is little difference between the overall PF's of periods one and two, there are decided differences in their composition. In period one, Eastern ontario had a PF of .429. However, in period two this shifts to a PF of .683. Changes in participation are also noted for Southern Ontario

28 The participation factor (PF) is defined as the ratio of "null" memberships compared with members who submitted material. 
(PF 1.571 to 1.000), while the PF for the American contributions remain constant at 1.000 .

The primary difference between the two periods, however, is the complete disappearance of Halifax contributions from the Messenger. The vast majority of actual contributions (71.7\%) come from the ottawa community. As far as content is concerned, each issue of the Messenger in this period contained an average of 4.5 pages of material from Ottawa, 1 page from American sources, and .78 pages from Southern Ontario.

The third period (Issues 39-58: $\mathrm{N}=230$ ) marks a spreading out of the Messenger. While Eastern Ontario (primarily Ottawa) is still the dominant region $(62.6 \% \quad[\mathrm{~N}=144])$ followed by the USA (14.38 $[\mathrm{N}=33])$, the Messenger expands to include members in British columbia (11.7\% $[\mathrm{N}=27])$ and Quebec (1.3\% Figure 3.4: Isgues 39-58 Region Null Full PF

$\begin{array}{lrrr}\text { E. Ontario } & 77 & 67 & 1.149 \\ \text { S. Ontario } & 12 & 9 & 1.333 \\ \text { Quebec } & 2 & 1 & 2.000 \\ \text { BC } & 12 & 15 & .800 \\ \text { USA } & 20 & 13 & 1.538 \\ \text { Unknown } & 0 & 2 & 0.000 \\ \text { All } & 123 & 107 & 1.149\end{array}$
$[N=3])$. Southern ontario is still represented, although it is now the fourth largest region (9.18 [N=21]). The average membership per issue is 11.5, with highs of 14 (\#50 [Samhain, 1990] and $\# 52$ [Brighid [1991]), and lows of 8 
(*44 [Brighid, 1990] and $\# 45$ [Ostarra, 1990]). Of the total memberships, $53.48 \quad[\mathrm{~N}=123]$ were "null" memberships. This gives the period a participation factor of 1.149 .

This period is marked both by a spread in the geographical membership base, and by a decline in the overall participation $(0.772$ to 1.149$)$. In part, this marks the increasing networking activities of the collator (e.g. the memberships from British Columbia and Montreal). The general decline in participation also marks a shift in the importance of the Messenger in the ottawa community (PF 0.683 to 1.149).

\subsubsection{Discussion}

The Messenger tends to reflect the interests and actions of the Alexandrian part of the ottawa community. The audience is either Alexandrian or Gardnerian derived. Before the creation of the Ottawa community (Issue 1-12), the Messenger served primarily as a networking medium between parts of the Ottawa, Toronto and Halifax communities. The move of the collator to ottawa, coupled with the growing ottawa community, shifted the focus from intercommunity to intracommunity contact.

As early as issue 23 (Midsummer, 1987), the Messenger was used by certain of its members as a forum to discuss what "happened" at the Beltaine Grand Sabbat (i.e. to write or 
rewrite "history").89 The tensions in the ottawa community spill over into the Messenger in articles, comments, and fiction. These accusatory comments finally culminated in Meryddyd's contribution in the Yule Issue (\$27) which had a white flag of surrender for the cover signalling her withdrawal from the general community and from the debate.

This half year period (\$23-27) marks a watershed of conflict in the Messenger. From this point on, contributions are more on technical, rather than interpersonal, subjects. This shift in emphasis contributes to the shift in regional contributions apparent in the third phase, as does the move of Jennifer Holding to Toronto (Issue \$30).90

The period betifen Issue 23 and Issue 27 also marks a shift in the Messtriger:s functional purpose. While the Messenutit originally served as a forum for interpersonal networking, this had shifted by Issue 16 to include a component of status recngnition within the ottawa community. The conflict diring these four issies served to change the form of status recognition $f-2 m$ one based on conflict (Win/Lose) to status based on technical contribution (win/win). The

89 It should also be noted that all of the main participants in the Beltaine Grand Sabbat were members of the Messenger at this time. See section 2.2. for details on the Beltaine Grand Sabbat.

90 Ms. Holding's move to Toronto served to distribute the Messenger in the Toronto WCC community. 
Messenger's audience is now viewed as technical, rather than community.

\subsubsection{Conclusions}

When we examine the Messenger as a definitional arena, we can see four main points. First, the Messenger has functioned as a networking and contact point between communities. Second, it was an early arena for establishing status within the ottawa community. Third, it served as an arena in which conflicts were aired, and to rewrite the "history" of the ottawa community. Fourth, because of internal changes brought about from Issues 23-27, the Messenger has partially returned to its original networking role, with a modified method of gaining and consolidating status.

The Messenger played a crucial part in the ottawa community's first 2 years. First, by serving as a networking forum, it encouraged individuals to write down their ideas on craft. 91 second, as an arena where status could be gained, the Messenger served to shape the community's natural attitude of who had or did not have status. 92

91 This is in opposition to the more normal practice of verbal discussion. The act of writing forced members to clarify their thoughts and present them in a logical manner. follows:

92 the 13 members in Issue 23 can be classified as

* 6 are currently operating as Elders in the ottawa (continued...) 
Finally, due to the events discussed in Issues 23-27, the natural attitude of the community regarding conflict resolution changed. Interpersonal and intergroup conflicts were to be resolved through one of two methods: privately, in the case of individuals; or withdrawal from the arena in the case of groups. Open conflict in a public forum became unacceptable action within the community.

The Messenger now serves the ottawa community as a forum for a) networking, b) technical information exchange, and c) establishing local status due to technical merit. It has also served to produce a community action norm that may be stated as "It's unacceptable to wash our dirty linen in public".

Finally, it is highly unlikely that the Messenger will survive beyond the interests of its current collator (Khaled). If he were to stop collation, the Messenger would probably fold. Consequently it should: be considered as protoinstitutional, rather than as an institution.

92 ( . . . continued)

community;

* 3 hold Elders positions in ottawa, but are not currently involved in the community;

* 2 live in the United States (both are Elders in their own traditions);

* 1 is an Elder in Toronto; and

* 1 is a highly respected, non-Elder in ottawa.

of the 16 currently operating Elders in the ottawa community, 10 have been contributors to the Messenger. It is also interesting to note that only 9 of the roughly 27 currently operating non-Elder Initiates have been contributors. 


\subsubsection{Open Circle}

open circle was an $81 / 2 "$ by $11 "$, double sided, single sheet news flyer produced by khaled. There were 22 issues between May, 1988 and July, 1990.93 Open Circle was

Published irregularly on behalf of the ottawa Pagan Council for free distribution to interested persons in the National Capital region. open circle is not an official publication of the OPC.

During its two year existence, open circle served as a bulletin sheet for general public information. The primary topic concerned groups in the ottawa community, mainly which ones were accepting students. Twelve issues (issues $\neq 7-10,13$, 15-20,22) also contained short articles on community building, leadership, and other general craft subjects.

Despite its 22 issues, Open circle was generally perceived as Khaled's production rather than as a community magazine. It served a limited role as a definitional arena, by publishing the names of groups available to students. In general, Khaled's articles on community building and leadership appear to have generated more hostility than interest amongst community members.

In his introduction to the october 1989 article (issue 13), Khaled remarks

93 For a full listing of issues and articles, see Appendix D. Khaled recently informed me that he is considering starting publication of open circle again. 


\section{Moa Culpa}

It has come to my attention that I wove distressed a few people with my recent articles on leadership and community building. As it happans, human beings aren't perfect and the sort of issues I was addressing won't go away just because you'd rather ignore them. However, open circle is here to serve the community at large, not just my ego, so I've moved the least savory of the remaining topics to a more appropriate forum. How appropriate that the next in the series is...

\section{YA CAY'T PLENBE EVERYBODY}

Many of these articles appear to have created an impression throughout the Ottawa community that Khaled was "empire building". This supposition is encouraged by a comment in issue 20 regarding the OPC where Khaled states

Contrary to what you may have heard, Quicksilver controls neither the OPC nor the Meet Greet. Other groups and individuals do, indeed, both regularly attend and financially support OPC activity.

Khaled's final article, "STUCK IN CHARGE?" (issue 22), appears to have been the final straw for many people. open circle folded with little fanfare because, according to Khaled, people refused him any more information. 94

open circle failed both as a community definitional arena

9h This supports my own observation that khaled was partly ostracized by the community. The perception of "empire building", together with a general distrust of Quicksilver's motives, appears to have been the reason for the downfall of open circle. Another major reason was Khaled's refusal to attend wCC circles. This necessitated his reliance on secondary sources for community information. 
and as a communications forum, because of the community's perception of it as an extension of Khaled himself. A political and/or status oriented organ unacceptable to nonQuicksilver supporters. 95

3.1.3. Pandora's Box and P.O.D.S.

"Pandora's Box" is a local ottawa electronic Bulletin Board System (BBS). Pandora went into operation on October 1st, 1990 and "crashed" December 7th, 1991.96 It is the ottawa distribution point for the Pagan/Occult Distribution System (P.O.D.S.; aka Podnet), and Magicnet. As of May 1st, 1991, there were 196+ BBS's tied together across the United States, Canada, Australia, and England accessible through various echoes.

In order to study the effects of Pandora's Box, I monitored five of the more important echoes:

* ONT_PAGAN, a regional echo for ontario;

* METAPHYSICAL, a magic/Craft articles only echo;

* WICCA, an international "chat" echo;

* PR_STUDIES, a Craft/Academic echo; and

Is Adrienne, while resigned to such charges directed towards Quicksilver and haled, vehemently denies such motives (personal communication).

96 The system operator (Sysop) is still trying to recoup all of the losses. Pandora went back "up" on Feb. 12th, 1992, without most of its echo feeds. 
* AMTHEO, an amateur theology echo.

Members of the Ottawa community were active in all areas, except for METAPHYSICAL. The highest activity was noted in PR_STUDIES, followed closely by ONT_PAGAN.

As of November, 1991, five Ottawa Elders were making extensive use of Pandora.97 Three main uses are apparent. First, the LOCAL area provides a private E-mail service. Second, regional and international networking areas (WICCA, and ONT_PAGAN) provide an opportunity for members of the Ottawa community to "meet" and "talk" with people in different communities without paying for long distance telephone calls. Finally, several "technical" areas (WICCA, PR_STUDIES, METAPHYSICAL, and AMTHEO! allow members of the ottawa community to engage in definitional debates around the continent. ${ }^{88}$ There is no doubt that Podnet is an institution. Local nodes can and do drop out, but the net continues. Pandora's Box should be seen as a proto-institution which represents numerous other proto-institutions (echoes) and several institutions (nets). However, Pandora's Box is highly susceptible to damage and service interruptions. This

97 Khaled, Adrienne, Marios, Meredydd, and Anahita-Gula. At least 15 other people in the ottawa community were also using Pandora.

98 While there are echo nodes in Australia, and some contact with England and Germany, most nodes are in North America. Contact is, with one Australian exception, sporadic and limited. 
susceptibility was shown when the system was "crashed" from outside by the assistant sysop.

Pandora's Box (and the nets in general) is also susceptible to infiltration. According to several sources, one MAGICNET node in Texas was infiltrated by several students at oral Roberts University. They identified a number of users and publicized their names. Subsequently many of these "outed" pagans lost their jobs, and several involved in legal actions found their cases had been prejudiced because of disclosure of their religious beliefs. 9

This susceptibility has led to a certain amount of reserve shown to newcomers in various echoes. While christians and Satanists are accepted on the boards, they are also "vetted". 100 The presence of Christians on a BBS has meant that certain areas, most notably AMTHEO, have engaged in ecumenical conversations and, in some cases, ecumenical action. ${ }^{101}$

99 Personal communications from Farrell McGovern (Ottawa) and Granny Spider (Texas). The court cases involved were child custody suits. The term "outing" derives from the Gay subculture and means public disclosure of others private affiliations or practices in such a manner as to cause the individuals "outed" maximum harm.

100 For example, the AMTHEO echo contains one exPentecostal (now Greek orthodox) priest, and an avowed Satanist (Luciferian). Attempts at conversion are met by isolation or the removal of access privileges.

101 In particular, the candlestick Park crusade of televangelist Larry Lea provoked a strong negative response from many members. Most of the Greek Orthodox members of (continued...) 
Pandora's Box has had a major impact on the ottawa community. First, unlike most international BBS's, it has no user fees. This has encouraged a large number of people to use it. Second, before Pandora's Box, people who wished to become movement "operators" (see chapter 4) either had to travel to numerous festivals, publish a book, or engage in frequent verbal and/or written communications with other wiccans. Once it was "up", it provided a fast, efficient and inexpensive method of gaining status as an "operator". International recognition could be gained in months as opposed to years. ${ }^{102}$ Finally, Pandora's Box has served to provide a forum in which solitaires can interact with other people and groups without the pressure of physical meetings. Intracommunity communications, via the LOCAL and ONT_PAGAN echoes, is encouraged without the necessity of developing interpersonal skills. Also, members of the techno-pagan sub-culture are coming into more frequent contact with the other parts of the

${ }^{109}$ (. . . continued)

AMTHEO organized prayer sessions opposing Lea's "Crusade". One member went so far as to contact numerous acquaintances in Kentucky. This incident also caused much discussion in the WICCA echo, centering on the ethics of using magic to stop Larry Lea's "Prayer Warriors". While opinions ranged from "let karma handle it" to "Blast them where they pray", the general feeling was that Candlestick Park should be "shielded" to contain Lea's "negative energies". These "energies" would then turn back or Lea and his cohorts: instant karma.

102 This includes the opportunity to publish articles, since many neo-Pagan journals regularly advertise both for subscriptions and articles in various echoes. 
community.

These effects notwithstanding, I believe the homogenizing results of access to Pandora's Box will be minimal in the ottawa community. This belief is based on three observations. First, large numbers of people in the ottawa community are unlikely to acquire access to a computer with modem. Second, wicca derives much of its subjective reality from practice (see chapter 5-8) and this is not available on the nets. Finally, there is little indication that the theory discussed in the various echoes will be translated into local practice. In conclusion, Pandora's Box serves a number of functions in the ottawa community. It is a networking tool at the local, regional, national and international levels. It also serves as an inexpensive and reasonably accessible method for gaining status outside the local community. Finally, while there is little indication of an homogenizing effect, access to outside "experts" will tend to introduce new ideas to the ottawa community.

\subsubsection{Conclusions}

This section set out to examine the use of print and electronic media in the ottawa community: the Messenger, open Circle, and Pandora's Box and the electronic nets. This examination has concentrated on each medium's role as definitional arena within the ottawa community. Khaled has been the 
driving force behind two of these three (The messenger and open (ircle), and has been instrumental in maintaining Pandora's Box. His role cannot be minimized in any examination of the development of internal communications in the ottawa community.

\subsection{Oral Communications Forums}

The primary mode of community and group formation in human societies is verbal discourse. "We talk, therefore we are." Group and community differentiation appears through the development of group specific technical vocabularies, and shared experiences. The ottawa wiccan community is no different. Despite the introduction and use of chirographic, typographic and electronic technologies, the primary modes of communication in the ottawa community are oral and performative. ${ }^{103}$ This section will examine the various oral "arenas of discourse" that have affected the ottawa community.

3.2.1. The Ottawa Pagan Council and The Meet and Greet Society The Ottawa Pagan Council (OPC) was, in the words of Khaled, a

(very) loose association of neo-Pagans living and

103 For a discussion of the various types of communicative technologies and their cultural effects, see Ong, 1982. For an examination of the nature of performative communications, see V. Turner, 1974, 1982, 1986. 
working in the Regional municipality of OttawaCarleton. Membership is open to anyone who wishes to participate. ${ }^{104}$

The OPC "grew into" existence in 1986 from a series of informal discussions between neo-Pagans in the ottawa region. It was originally modelled on the Red Cord councils of Halifax and Toronto. ${ }^{105}$ The OPC officially dissolved itself at a general meeting on May 18th, 1990. 106

The Ottawa Pagan Council of icially sponsored two events. The first was the Beltaine Grand Sabbat of 1987 (see section 2.2.). The second was the Meet and Greets. The OPC was invoked as a source of legitimacy by khaled in the first issue of open circle. ${ }^{107}$ The initial venue for OPC meetings was the New Star restaurant on Rideau street, close to the Wiccan Rede. ${ }^{108}$

104 Publishers statement in open circle (all issues).

105 The term "Red Cord" refers to the colour of the cingulum (belt) worn by ist degree initiates in most Gardnerian derived traditions. Although the Halifax and Toronto Red Cord Councils include initiates only, this was not practical in ottawa because of the small number of initiates, and the differences in training standards between traditions.

106 OPC DISSOLVES, open Circle, 21 (June), 1990.

107 "Published irregularly on behalf of the ottawa Pagan Council...", open circle, Publishers statement, \#1 (May), 1988. This was followed in later issues with the statement that "Open Circle [sic] is not an official publication of the OPC."

108 Later venues included the Glebe cafe $(840$ Bank street), the Glebe Community Centre, and Vincent Massey Park. 
While the OPC was based on the Toronto and Halifax Red Cord Councils, at no time did it establish a community wide set of initiation standards. ${ }^{109}$ There was some discussion in 1986 and early 1987, but no minimal agreement could be reached due to differences in the various traditions represented (Odyssean, Alexandrian, Erysian/techno-pagan, and various eclectic solitaires).

The failure of the Beltaine Grand Sabbat irrevocably altered general perceptions of the OPC. The restructuring of the community that followed this failure reinforced a generalized distrust of any central body. Concerns about group (and solitaire) sovereignty, coupled with increasing eclectic tendencies of the WCC and several solitaires (e.g. Marios and Meredydd), blockec all attempts at a central, "legislative" body. ${ }^{110}$

In place of any recognized body, a series of shifting interpersonal alliances defined the norms of the community. These alliances set the standards of operation for many newcomers to the ottawa community. The OPC, when it

109 For a discussion of the Toronto Red Cord Council, see Sealgaire's contributions in the Messenger 1 (Mabon, 1984; summarized in footnote 100). A sheet entitled "Halifax Council standards" was provided to me by khaled in 1986. Similar standards lists have also been produced by Wicca communitas (Charles Arnold), and the WCC.

110 I define "legislative" as the perceived authority to make declarative statements about the craft in the ottawa community. 
irregularly held meetings, became a forum for airing ideas and gaining project $\cdots$ - Ented allies, as well as recruiting members to a given group.

The development of the Meet and Greets shifted the locale of all of these activities, thereby reducing the role of the OPC even further. 111 The Meet and Greets, founded by Khaled and Dobhran, were to be a monthly "social" yathering where members of the community could get to know each other. The necessity for some such forum had been argued by Adrienne as a result of the failure of the Beltain Grand Sabbat. 112

The first Meet and Greet took place on August 20th, 1988, at the occult shop. According to an article in open circle (3),

the bulk of the attendees were solitaries, primarily novices, soine seaking training, some a like minded circle to join, still others simply looking to see what craft and crafters are like.

The Meet and Greets continued at the occult Shop until mid1989. On July 15th 1989, an emergency meeting of the OPC took place at the Glebe Cafe, and the site of the Meet and Greets was moved to the steiner roon at the Glebe community centre.

111 By the time of its dissolution in May of 1990, the OPC was effectively synonymous with attendance at the Meet and Greets.

112 Adrienne, Random Wanderings, in The Messenger, 24 (Lammas), 1987. 
This move was necessitated by increasing tensions between Meet and Greet attendees and occult shop staff. The Meet and Greets remain there to this day. ${ }^{113}$

Attendance at OPC functions, both meetings and Meet and Greets, grew steadily from circa 10 in late 1926 to between 30 and 40 in 1988. After the move of the Meet and Greets to the Glebe community Centre, attendance tended to fluctuate with highs of 20-30 in October and November, and lows of 5-8 during the rest of the year.

Between mid-1988 and mid-1989, the perception that Quicksilver was controlling the Meet and Greets (and the OPC) grew steadily. This came about partly due to the shift in locale, and partly due to perceptions of Khaled stemming from open Circle (see section 3.1.2.). The dissolution of the OPC, and the creation of the Meet and Greet Society (M.A.G.S.), was an attempt to change these perceptions. However, after an initial success, the perception resurfaced and has intensified, leading to a drop in general attendance.

At present the Meet and Greets attract between 5 and 10 people every month. Current plans include the adoption of a workshop format, complete with presentations and discussion, and reconstituting M.A.G.S. as a presentation of the England-

113 With the exception of Meet and Greets during June, Juiy and August which take place in Vincent Massey Park. 
based Pagan Federation. 114

If we were to assume that a definitional arena can only be analyzed by its proscriptions, we would be mistaken. The function of definitional arenas is to serve as forums to transfer ideas into the communal natural attitude (see Chapters 4 and 9). This transference may take place in either a proscriptive, or a reactive format. The influence of the OPC is reactive.

By its existence, and through its failure to act as a central proscriptive body, the OPC served to inculcate an attitude of distrust for central bodies in the community. The "failure" of the OPC served to reinforce several tendencies. First, the already anarchical tendencies in the wiccan movement as a whole were reinforced (see Farrar and Farrar, 1987a:179). Second, the hierarchical and centralist tendencies of the wcc were, in part, countered. ${ }^{115}$ Finally, when coupled with the rapid numerical expansion of the community, the various functional elders were drawn closer together. ${ }^{116}$

116 The Pagan Federation (PF) is a European (primarily English) organization. Quicksilver is the only member of PF in the ottawa community. This represents the first formal ties between Ottawa and English Craft communities.

115 For an examination of the centralizing tendencies of the WCC on Witchcraft in Ontario, see Marron (1989:75-90) and Rabinovitch (1991).

116 In his essay entitled "The Web of Group Affiliations", George simmel $(1955: 161-2)$ remarks that (continued...) 
3.2.2. The Ottawa Valley Pagan Discussion Group (O.V.P.D.G.)

The Ottawa Valley Pagan Discussion Group was fourided in 1985 and is currently in its third incarnation. Its primary audience is techno-pagan, Erysian/Discordian, and Merydian. Membership and attendance varies between 5 and 20 at any given meeting.

Unlike the OPC and the Meet and Greets, O.V.P.D.G. has made little attempt to contact other craft groups in the Ottawa area. Members of the O.V.P.D.G. tend towards an eclectic, non-Gardnerian derived form of craft practice. There is also a marked "distaste" expressed by many O.V.P.D.G. members for the Gardnerian derived groups and solitaires, as well as the WCC, in the rest of the ottawa community.

${ }^{116}($. . . continued)

The relationship between believers and priests involves representation and leadership, control and cooperation, veneration and the provision of material sustenance. To be sure, the sociological form of this relationship varies in some respects with each reigion. But the relations between believers and priests have so much in common that one can, with reservations, speak of a formally similar position of the priest within groups, however much these differ in all other respects. Out of this there arises above all a solidarity of interests, a mutual understanding, a cohesiveness among the priests, which under certain conditions can even drown out the substantive antagonism between Evangelical Ministers and Catholic priests.

or, in the ottawa community, between Odyssean Priests, Alexandrian Initiates, and solitaire Mystics and Magicians. This "solidarity of interests" has been encouraged by the failure of the OPC. 
This general distaste runs both ways. ${ }^{117}$ Many Gardnerian derived Wiccans in ottawa view the O.V.P.D.G. as "pagan fen". 118 In turn, many members of the O.V.P.D.G. consider the Gardnerian derived Wiccans as "stuffed shirts". What contact exists is at a personal and social level, rather than at a formal level.

The O.V.P.D.G. is a definitional arena whose legitimacy is not recognized by the majority of the ottawa community. It is, however, a haven for many people who are sick of incessant political fighting in the rest of the community.

\subsubsection{The Occult Shop (aka the wiccan Rede)}

The Occult shop is the focus of oral definitions in the ottawa community. From its opening on December 16th, 1985 until the present, the occult shop has served a number of functions: drop-in centre, gossip centre, information exchange, supply house, ritual space, and recruitment centre.

The Occult shop is owned by Richard and Tamarra James, the High Priest and Priestess of the wCC. In her analysis of

117 This distaste was heightened when the moderator of the O.V.P.D.G. "crashed" Pandora's Box in December, 1991.

118 "Fen" is a term that derives from science Fiction fandom and refers to groupies who are "into" something because it is fashionable. "Pagan fen" is a fairly movement general term for people who claim to be craft, wnrk and train outside Gardnerian derived traditions, are not Dianic, and are generally involved in science Fiction fandom. The term is not compl imentary. 
the effects of the WCC on wicca in Ontario, Shelly Rabinovitch (1991:16) notes that

...two of their [WCC] Member-Temples are situated within the same buildings as the very lucrative occult Shops owned by the Jameses. Consequently, anyone interested in wicca who queries the storekeepers about the availability of covens in their area are [sic] immediately informed about the public rituals and classes (all free except for voluntary donations) held at the self-same location!

This was certainly the situation in ottawa during the tenure of Jennifer Holding as manager of the Occult Shop (December, 1985 to May, 1988). Holding, originally from Toronto, also served the WCC as its local Priestess in ottawa. In an article appearing in the ottawa citizen (July 11th, 1987), Janet McFarland (1987) described the role of the store.

The store also doubles as a gathering place for Ottawa's small community of witches. Upstairs is a small room, painted jet black, where witches hold their weekly "circles" or ser vices.

The change in verue and management (May 1980), also produced a marked change in the role of the occult snop. The new manager, Dobhran, was not an Odyssean and had no official connection with the wcC. She was also intensely interested in bringing the various factions in the community together. This interest was shown, in part, through her support for the Meet and Greets (see section 3.2.1.). Her desire for a united community is also shown through her arrangement of interviews 
with non-WCC people. For example, in an article by Charles Lewis (August $3 \mathrm{ru}, 1988$ ) appearing in the ottawa Citizen, ho find the first interview with a non-WCC person since the Occult shop opened in 1985.119

In a similar manner, when Kevin Marron was re.earching his book on witchcraft in Canada (Marron, 1989), Dokhran arranged for him to meet with a number of non-WCC witches in the community. Marron (1989:107) notes the effects of the new management in his discussion of conflict among witches: ${ }^{120}$

An example of this [conflict resolution] is the wiccan community in ottawa, which was rife with feuding until very recently. People from several different tradit ions who were not on speaking terms before have begun to gather for a regular monthly event that they call a yeet and Greet, where political differences are left at the door.

The change in managers also served to create a perceived difference between the occult shop and the wCC, thereby increasing the shop's role as a drop-in centre and gossip focus. ${ }^{121}$ The perception of a difference between the shop and

119 Charles Lewis (1988) interviewed Khaled and Adrienne. Previous citizen interviews on Witchcraft in ottawa revolved around Richard and Tamarra James (e.g. McFarland, 1987).

120 Marr :. joes not specifically mention Dobhran and Khaled in this instance. Indeed, it is likely that he was unaware of the political machinations that led to the founding of the Meet and Greets. However, he interviewed both Dobhran and Khaled extensively.

121 And, incidentally, increasing the profitability of the Occult shop. 
the wCC tended to reduce tensions between the WCC and the nonWCC parts of the community. ${ }^{122}$ This reduction in tensions was also marked by the increased use of the ritual space at the occult Shop by non-wCC groups. ${ }^{123}$ Before Dobhran, the shop ritual space was solely for wCC events.

The period of intertraditional cooperation (middle communitas: see section 2.2 .1 , saw the occult shop acting as the single most important gossip and information cer ce in the ottawa community. People from every group and tra ition in ottawa would frequent the shop and spend large amounts of time talking. ${ }^{124}$

The current isolationist tendencies of the wCC Priest have, in part, been frustrated by this division between the Shop and the Temple. ${ }^{125}$ The Occult shop is still viewed as a

122 This apparent paradox, perceived difference leading to greater cooperation, arose because people felt "safer" when they visited the occult Shop. Differences were accepted and encouraged. One of the mz $n$ outcomes of this perseptual shift was the performance of WCC sunday Night Circles by non-WCC initiates (e.g. Marios, Adrienne, Sekhet-Sophia, Serenity and Magnus).

123 For example, the Wymyn's Spirituality group. See open Circle, *4 (November), 1988

124 The subjects of the discussions varied extensively from who is fighting with whom, to technical information, to requests for ritual services. Many discussions that started at the Occult Shop, later moved to Bumpers Restaurant three doors north. Discussions have been know to last for over ten hours and involve up to 15 people.

125 Indeed, there are numerous repurts that corliss has started a "feud" with the occult shop staff. 
gossip forum by many community members. And, while WCC isolationists actions have tended to keep a number of people away from the occult shop, these same actions are a favourite subject of slanderous gossip both at the shop and at postritual social gatherings. This frequent gossip serves to prejudice newcomers to the WCC and hamper attempts to create a stable wCC group.

\subsubsection{Oral Culture and Conceptual creation}

At the start of this section, I stated that the occult Shop is the primary focus for oral definition in the ottawa wiccan community. "Oral definition" is a problematic term. Ong (1982:24) notes that

In an oral culture, knowledge, once acquired, had to be constantly repeated or it would be lost: fixed, formulaic thought patterns were essential for wisdom and effective administration.

But modern Canadian society is not an ora: culture. Or is it? I would argue that while we may live and operate in an electronic, Sccond Industrial Revolution, technic culture, our primary mode of subjective reality creation is, for most people, oral. Everyday reality is orally composed, expressed and maintained. ${ }^{126}$ The performative "rituals" that recreate everyday life are, primarily, oral.

125 Sep Schutz and Luckman (1:73, 1989). 
This oral base becomes most readily apparent in those areas of society where stereotypes are not institutionally produced. To use Goffman's (1959) terms, in the absence of signs for an individual to give off (non-verbal presentation), verbal signs which the actor gives will take precedence. The actor in this situation, must then attempt either to create new stereotypes (thereby institutionalizing their presentation), or to acquire pre-existing stereotypes.

For example, members of the wCC have attempted to draw on categorical equations to acquire access to certain non-verbal meaning complexes. ${ }^{127}$ However, these actions have been hampered by non-wCC witches throughout Canada who reject the wCC categorical equations (Rabinovitch, 1991).

In Ottawa, the occult shop has served as the $p$-imary forum for the creation of certain meaning complexes. Concepts of "priesthood", "initiate", "ritual leader" and "functional elder" have been created or modified in this definitional arena. And, as with most creations in the ottawa community, these definitions draw on both the odyssean public tradition

127 By "categorical equations" I am referring to a logical argument in the form of $A=C, B=C$, therefore $A=B$. The concept of associated meaning complexes extends this argument as follows: all $A$ 's include $M$ (cultural meaning referents), since $A=B$, therefore $B$ must include $M$. This categorical equation is most readily apparent in the wCC's attempts to equate themselves with mainstream, hierarchical religions (see Rabinovitch, 1991; James, 1991; McFarland, 1987). The cultural meaning referents are the non-verbal meanings attached to the concept of "priesthood" (see Rabinovitch, 1991). 
and the Alexandrian private tradition.

The first concept, "priesthood", derives primarily from the wCC definition of "priesthocd". This definition opposes "priesthood" to "laity", a concept that is antithetical to the Alexandrian "priesthood of all believers" formulation (see Rabinovitch, 1991). "Priesthood" is equated with two primary functions: counselling and ritual leadership.

The second concept, "initiate", derives roughly evenly from both odyssean and Alexandrian formulations. "Initiates" are "priesthood", but there is also the connotation of a special skill with magic that is absent from the concept of "priesthood". In general, most Odyssean Initiates in ottawa are considered to be "priesthood" first, while Alexandrian and Herodian initiates are considered to be "initiates" first.

The concept of "ritual leader" emerged as distinct from initiate and priesthood during the period when the WCC Temple was without any local priesthood. "Ritual leaders" may be initiates or non-initiates. The important criterion is ihe ability of the individual to lead a public ritual.

The final concept, "functional elder", derives from a combination of the Gardnerian derived concept of "Elder" (2nd or 3 rd degree) and the public nature of large parts of the ottawa community. A "functional elder" is a person who acts as an elder within the community, regardless of whether or not 
they have the appropriate degree. ${ }^{128}$ A "functional elder" is a community resource; a teacher, administrator, counsellor, and ritual leader.

\subsubsection{Oral Concepts and Community Roles}

Several effects of these conceptual definitions are apparent. First, there has been the de facto degradation of the experience of non-initiates. This degrading of experiences arises from a logical either/or position. If the person has meaningful experiences, then they will be an initiate. Therefore, if the person is not an initiate, then they do not have meaningful experiences.

This position has led to the second effect. The adoption of these conceptual expectations has influenced the general requirements for initiation and elevation in several traditions. ${ }^{29}$ when an individual presents an image of possessing meaningful experiences, and of fulfilling certain expectational requirements, a conflict arises if they are not an initiate.

The best example of this is the case of spider. He was

128 There have been several case where Odyssean Neophytes (pre-Initiates) have acted as functional elders. other instances involve 1st degrees and Neophytes running groups. There are also examples of technical Elders who were not functional elders.

129 For example, the definition of a Merydian 2nd degree is the same as a functional elder. 
initially refused initiation by the Odyssean council in Toronto. This refusal provoked a generally negative reaction from members of the ottawa community. Spider was seen by members of the ottawa community as possessing meaningful experiences and of fulfilling all the functions of an initiate in the community. The refusal provoked several offers of initiation from non-WCC sources (e.g. Anahita-Gula and Marios) on the grounds that he "was" an initiate, and that this should be formally recognized. Spider was subsequently passed before a second council and accepted Odyssean initiation. ${ }^{130}$

Third, a form of counselling "industry" has grown up based on expectations of "priesthood". This industry centres on the oral relationships between people who are perceived as being "priesthood" and those who are not. Non-priesthood frequently take their emotional, as well as their technical, problems to the "priesthood".

This situation acts in a number of ways. First, it reinforces the concept of priesthood (see above). Second, it serves to reinforce a dependency relationship between priesthood and laity. Finally, it serves as a mechanism to force a change in status (see the example of spider above).

130 For more on this incident, see Rabinovitch (1991). 
3.2.3.3. The "Counselling Industry"

The development of a "counselling industry" appears to be a unique development in ontario, deriving from the interaction between the WCC and Alexandrian groups. In communities that are dominated by Gardnerian derived groups, such as England, communal emphasis is on harmonizing experience with Gardnerian derived cosmology (Luhrman, 1985, 1989). In many American communities, emphasis is placed on harmonizing experience with "politically correct" action (Adler, 1986; Starhawk, 1979, 1982). Gordon Melton (1983:25) has noted that

... it [American Witchcraft] fails to create a community of concern that can support individuals in crisis or reach out to people in need. I saw this clearly in a Pagan leader I met recently. He had returned to the christianity in which he had been raised. In answer to my probing, he spoke of alcoholism. He had turned to the Pagan community for help, only to discover it lacked the resources and finally the desire to give the needed assistance.

In contrast with the American situation noted by Melton, the ottawa community constantly provides resources to people. In one situation, an individual who was being physically abused by his parents was offered a place to stay, sympathetic people to talk with, and part-time employment.

Many of the people who come to local wiccans are not 
craft, and there is littie attempt to recruit them. ${ }^{131}$ Most of the people looking for help have little or no trust in the mainstream churches. They feel that Christianity in particular has denied their pain, and supported their "oppressors". They go to local witches because of the general cultural stereotype of witches being in opposition to the Church. 132

For the vast majority of people, finding a local witch means travelling to the occult shop. And, upon making enquiries, they are directed to whomever is available and deemed "appropriate". This "referral service" directly supports the previously formulated concept of "priesthood". It also reinforces the status of certain community members as "movement intellectuals". 133

\subsubsection{Conclusions}

The occult Shop is probably the single most important definitional arena in the current history of the ottawa wiccan

${ }^{131}$ In point of fact, every attempt is made by non-WCC initiates to discourage them from joining the craft. The WCC, however, subtly encourages these people to join by providing a supportive atmosphere.

132 Many of these people are "street kids" who have run away from their homes. For many of these people, Christianity is equated with the "establishment" and their parents.

133 For example, researchers interested in the wiccan community are directed to specific individuals, thereby ensuring that these individuals'formulation of wicca appear in dcademic and journalistic presentation. 
community. By acting as a communal "drop-in" centre, it has focused intertraditional and interpersonal discussions. By its general function as an access point to the non-Craft world, it serves as a gatekeeper. The close associations between the Occult shop and the wiccan Church of Canada have, in some measure, controlled the nature of the discourse on concepts such as "priesthood".

\section{$3 \cdot 2 \cdot 4$. Conclusions}

This section has examined four oral definitional arenas operating in the ottawa wiccan community: the OPC, the Meet and Greets, the O.V.P.D.G., and the Occult Shop. Each of these four definitional arenas has had a pronounced effect on the ottawa community. The OPC served to create a distrust of central bodies. The Meet and Greets reinforced the centrality of oral (verses written) definitions. The O.V.P.D.G. served as a foil to the general politically charged atmosphere of most of the community. Finally, the occult shop serves as a focal point for the community, and a locale where oral definitions could be constantly recreated.

\subsection{Conclusions}

This chapter has examined the development of the ottawa Wiccan community. Section 3.1. examined print and electronic communications media used by the community, whereas section 
84

3.2. concentrated on oral definitional arenas. Of the seven definitional arenas examined ( 2 print, 1 electronic, 4 oral), the role of the occult shop is pre-eminent.

While the driving force of haled (see section 2.2. and 3.1.) cannot be denied, most of his work has served to spread ideas and concepts developed in the occult shop forum. It will be interesting to see if haled's proposed reformulation of M.A.G.S. into a Pagan Federation model (see section 3.1.1.) will materially influence occult shop developed concepts. 
Chapter 4:

\section{Definitional Arenas}

The structures of linguistically established intersubjectivity - which can be examined prototypically in connection with elementary speech actions - are conditions of both social and personality systems. Social systems can be viewed as networks of communicative actions; personality systems can be regarded under the aspect of the ability to speak and act. If one examines social institutıons and the action competence of socialized individuals for general characteristics, one encounters the same structures of consciousness.

Habermas $1979: 98-99$

Changes in general social reality, and in religious realities in particular, may arise through a number of avenues (e.g. war, plague, famine, environmental shifts, internal changes, etc.). While a general theory, and concomitant methodology, of the institutionalization of religions should be able to explain and, to some degree predict, changes in religious realities, I am concerned primarily with internal, "peaceful" changes in religious realities. Thus there is a methodological bias towards examination of "non-violent" forms of reality change. ${ }^{134}$

Joel Best has argued that the process of change in social definitions is rhetorical (1987). This process involves the

134 Thus, while the Vietnam war appears to have had an effect on the evolution of modern Wicca in North America, and World War II plays a seminal role in both the creation of Gardnerian Wicca, and in the mythography of modern wicca (see, for example, Kurtz, 1983), 'hese roles will be considered only peripherally. 
use of certain socially avallable are zas for a number of purposes, namely:

* as vehicles to spread new definitions (e.g. radio, television, newspapers);

* as arenas of definitional conflict where it is assumed that the changes wrought in the arena will influence general society; and

* as mediums whereby definitions may be instilled in the next generation of society. ${ }^{135}$

Best, together with a number of others, has analyzed the process of constructing social problems. ${ }^{136}$ However, the Constructionist "school" has done little work on the broader area of why a definition is seen as problematic. Also, most Constructionist work has focused on "objective" action within certain readily observable, pre-existing arenas. However the process of social change is limited. In order to utilize the constructionist model, we must expand it.

Schutz and Luckmann (1973:3) argue that any analysis of human action must start by examining the "foundational structures", the natural attitude, of those examined. This was

135 This is the process of "enculturation" or socialization. If culture may be viewed as a web of communicative action, as Habermas $(1984,1987)$ argues, then this may be seen as the replication process of cultural definitions. And, since communicative action is dependant on the definitions of what is being communicated, changes in definition will also be replicated, albeit with a temporal displacement during which time a "new" definition is accepted.

136 See, for example, Best (1989), and Richardson, Best and Bromley (1991). 
done in chapters 2 and 3 . It is now necessary to develop an analytical frame that a) allows for the multiplicity of roles played by individuals in community development, and b) shows the limiting factors of this development.

\subsection{From Idea to Institution}

Institutions do not simply "exist". Every institution that is has, at some point in time, been created by people. Furthermore, each institution thus created has been accepted by people as valid and legitimate. And, in the course of human interaction, these institutions are recognized as a part of "lived reality".

But recognition does not automatically procuce acceptance and agreement. Conflict between differing groups over recognition, acceptance and agreement appears to be a human norm. And this conflict arises from differing perceptions of "what is" and "what should and should not be". Perceptions which, in turn, are formed by the definitions of "reality" that are part of an individual's natural actitude.

Definitions do not appear full formed in arenas. As with institutions, definitions must be created by humans. The process of communicating these new definitions gives rise to new arenas where definitions may be formed. Sometimes, as in the case of open circle, these arenas are not accepted and definitions presented in them gain no recognition. 
What then are the conditions whereby a new public arena is formed? From our previous analyses, four conditions are readily apparent, each with two modes (internal and external), namely:

* Creation - a new definition (or definitions) of the given socio-cultural concept (in this case witchcraft) must be created, and this new creation must meet certain social and/or individual needs.

* Communication - ideas and, most importantly, definitions must be communicated both to the people involved in the internal process of institutionalization, and to the gereral social body. ${ }^{137}$

* Legitimation - the "proto-institution" must be able to establish internal and external legitimacy.

* Validation - the "proto-institution" must be able to establish both internal and external validity.

Several of these points have already been considered from the Constructionist perspective, namely external communication, legitimation and validation. However other points, such as internal validation and creation, are generally not considered. ${ }^{138}$ There is also an assumption that social

137 This process, inevitably, gives rise to a new "class" of people within the social movement. These people may be termed, after Eyerman and Jamison (1991), as "movement intellectuals".

138 For example, the entire Constructionist analysis of Satanism (Richardson, Best and Bromley, 1991) which concentrates on the external definitions applied to satanists by "experts". There is little or no attempt to gain an understanding of the internal construction of satanism from its practitioners. This methodological bias, however, is (continued...) 
movements are unified, or are composed of readily identifiable interest groups. ${ }^{139}$ while this assumption may be justified in the case of the construction of social probiems, it is unjustified when we consider the breadth, diversity and syncretistic nature of the neo-pagan witchcraft. ${ }^{140}$

The ottawa wiccan community makes use of a variety of social arenas:

* arenas constructed within the community (e.g. the Meet and Greets and open Circle);

* arenas constructed by the movement (e.g. Podnet);

* arenas constructed by other social groups and general Western society (e.g. the press).

But this diversity necessitates a relativistic analysıs. We must consider who is acting, where they aze acting, and how

138 (....continued)

inherent in the Constructionist approach as it is currently theorized.

139 It should also be noted that these interest groups are themselves institutions.

140 For an examination of the diversity of the neo-pagan movement, see Adler(1986), Marron (1989), Luhrmann (1989). I am also indebted to $S$. Rabinovitch for access to her preliminary research on neo-pagan groups in Canada. Eyerman and Jameson $(1991: 55)$, ncte that

"A social movement is not one organization or one partirular special interest group. It is more jike a cognitive territory, a new conceptual space that is filled by a dynamic interaction between groups and organizations. It is through tensions between different organizations over defining and acting in that conceptual space that the (temporary) identity of a social movement is formed." 


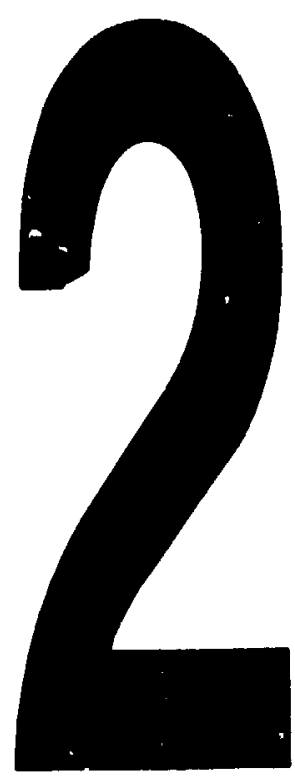

PM-1 31/2"X4" PHOTOGRAPHIC MICROCOPY TARGET NBS 1010a ANSI/1SO \#2 EOUIVALENT

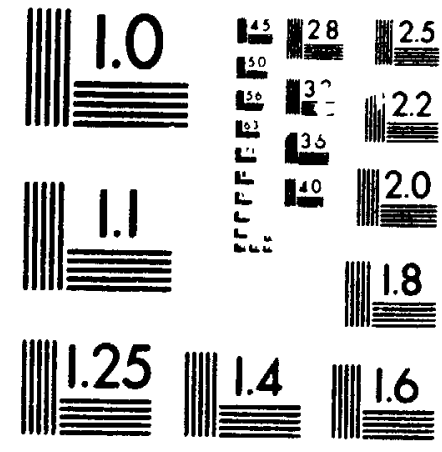

PRECISIONSM RESOLUTION TARGETS

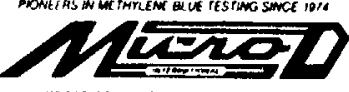

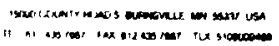


they view their actions. Are these actions viewed as internal (creative) or external (imposed)? Who (or what) is being acted upon?

Let us consider each of these eight areas in turn. 1. Interual creation: The process of internal creation contains five main audiences:
a) the self (the individual);
b) the other (deity, teacher or group) ${ }^{149}$;
c) the identified community (and/or the Tradition) ${ }^{142}$;
d) the Self's other realities ${ }^{143} ;$ and
e) general society.

The process of creation varies with each intended audience, as does the expression of the process.

2. External creation: The process of external creation involves the actions and reactions of other individuals,

141 The "Other" may also include the Divine (however it may be perceived) and/or any other supernatural beings. And, since the primary diadic relationship is between the practitioner and the Divine, this inclusion has given rise to a number of movement "authorities" considering the case for "self-initiations" and developing a rationale to support them (e.g Crowley, 1989:52-53, Farrar and Farrar, 1984:244-250). But while the demand for recognition of self-initiations inay well have arisen from local isolation from lineage sources, there is still a notable lack of acceptance on the part of lineage groups.

142 This may be either the local Wiccan, Neo-Pagan, and/or Magical communities, and/or the Tradition (if any) in which the individual chooses to operate.

143 i.e. family, friends, work, etc. In other words those bonds which the self defines as "non-wiccan". 
groups and institutions. These individuals, groups and institutions are the "audiences" referred to above. Their actions and reactions are attempts to create and maintain their own realities, as well as to impose those realities on other groups. 144

3. Internal communications: The process of internal communications (i.e. communication within an individual, group, institution, or movement) will depend on
a) the audience (see under Internal creation);
b) the communicator;
c) the communication medium; and
d) the communicative symbology.

These communications may be further divided into a) informative messages, ${ }^{145}$ b) inquisitive messages, ${ }^{146}$, c) sensory messages, ${ }^{147}$ and c) rhetorical messages. ${ }^{148}$

144 In this area, the social constructionists have provided a very flexible methodology for examining the actions and reactions of institutions and interest groups. They are, however, weak on the smaller scale (individual, small group).

165 A message dealing with "fact". Such messages presuppose a common interpretive framework or, at the minimum, a recognition of the interpretive framework in which the "facts" are situated.

146 A request for information, or "facts". Once again, this presupposes a common interpretive framework or understanding of what is being requested.

167 A "sensory message" is a message that does not demand a common interpretive framework, it just "is". This type of message frequently appears when one deals with the Divine, and

(continued...) 
4. External communications: External communications may be analyzed using the same criteria as internal communications. However, it should be noted that the style of message will depend on the degree of validity and legitimacy which the external audienc: accords to the producer of the message and the "institution" which s/he is assumed to represent.

5. Internal Legitimation: the process of internal legitimation is dependent upon the perceived source of legitimacy sought. And this source of legitimacy is, in turn, dependant upon an underlying set of axiological assumptions.

6. External Legitimation: External legitimation, or the recognition of legitimacy by other individuals, groups and institutions, also relies on perceived sources of legitimacy. However, the axiological assumptions invoked may be "operational", dependant upon a perception of what is, rather than a perception of what should be. In other words, group A may recognize the existence of group $B$, but may also be dedicated to eradicating group $B$.

7. Internal validation: Internal validation (i.e. validation

${ }^{147}($. . . continued)

entire symbolic languages have been developed in an attempt to understand these "l.essages".

168 A rhetorical message attem.sts to change the interpretive framework of a given audience. See Best's (1987) analysis of rhetoric in claims-making for a more detailed examination. 
within an individual, group or institution) depends upon the criteria set by each individual or group for the verification of truth claims.

8. External validation: External validation is the recognition and/or acceptance of a group's (or individual's) truth claim. This recognition and/or acceptance does not necessarily imply the recognition of all claims made by the individual or group. 149

Each definitional arena may be characterized as serving one or more of these areas. In effect, each definitional arena provides its users with opportunities for one or more actions leading to creation, communication, legitimation and/or validity.

\subsection{The Institutional Ground of Being}

Hilgartner and Bosk (1988) have argued for a public arenas, model of social problems which stresses the primacy of definitional arenas. While their work has focused on the creation of social problems there are, as $I$ have already noted, direct correlations with the institutionalization process of new religions.

By extending their concept of definitional arenas to

149 For example, many Christian churches recognize modern neo-pacan witchcraft as a religion. However, while granting this recognition, they withhold recognition of any other claims made. 
include the internal definitionul debates within a social movement, we can more effectively examine the process of institutionalization among new religions. ${ }^{150}$ The model proposed by Hilgartner and Bosk has six main elements, which may be extended to the process of institutionalization. This model, however, is incomplete for our purposes.

Their model is based on the assumption of preexisting channels of communication. ${ }^{151}$ As I showed in chapter 3 , most communication channels in use in the ottawa community were created there. And, while many of the factors that allowed these communications channels to develop were already in existence, the impetus to create them was required. The model lacks an examination of the process whereby new arenas, both for communication and prescription, may come into existence. In order to extend their modei so that it reflects the

150 This conceptual extension allows us to proceed beyond the boundaries of the "life history" models proposed by stark and Bainbridge (1985) and Wallis (1984). Hilgartner and Bosk (1988) argued for a similar extension beyond the Life History models of earlier social problems theorists, and their arguments are equally valid for the process of institutionalization.

151 A "channel of communications" is defined as any formalized series of conditions that allows for the interaction of two or more individuals and/or groups. Thus, this definition would include everything from two people having coffee together to a television network. The primary consideration is the ability for the people or groups involved to engage in a "meaningful" dialogue. The intersibjective nature of the dialogue does not, of necessity, have to be that of an equal exchange. 
development of the ottawa Wiccan community, we must consider the development of communication channels. Furthermore, this extension must consider technological, linguistic, and informational factors. ${ }^{152}$ But communications channels are also def initional arenas. And, as such, they are in turn subject to the process of institutionalization.

When we consider the early "life history" of an institution. It breaks down into three main stages:

1. The initial grouping together of people to form proto-institutions, and the creation within the members' natural attitude of a "group mind".

2. The acceptance within the natural attitude of movement members of the validity and legitimacy of the proto-institution as an institution and/or as a definitional arena.

3. The development of bureaucratic superstructures within the institution which replace the foundational ("traditional") power relationships and definitions of the institution, and the concommitant loss of individual freedom and flexibility within the confines of the institution. ${ }^{153}$

152 In this instance, an "informational" factor refers to the knowledge of the existence and location of a potential user of the communication channel, as well as that potential users technological and linguistic limitations. For example, it does little good to establish a Craft electronic bulletin board system such as Pandora's Box if you are unaware of any craft people who have access to computer communications.

153 This process has been examined by Max Weber (1947). It should also be noted that this condition refers solely to the institutionalization of "grass roots" movements, and not to the development of externally constructed movements (e.g. Intercessors for America), or the expansion of previousiy constituted bureaucratic organizations (e.g. the Moonies).

The developmental model used here derives both from Max Weber (1947) and from Thomas Kuhn (1970). 
This "life history" model, when applied to the development of channels of communications, takes on a new, nondeterministic form. Each stage is not "predestined", rather each stage is, in some sense, voluntary. ${ }^{154}$ The first stage consists of three main phases:

1. the decision to create a channel of communications;

2. access to the technology necessary to create the chosen form of communications channel; and

3. the reification of the proposed channel of communications in the natural attitude of the founders. 155

The second stage involves the reification of the created channel of communications in the natural attitude of the rest of the movement (or at least a significant section of the movement). 156 However, the choice to extend access to the rest of the movement is voluntary. ${ }^{157}$ Finally, the choice to transform the channel of communications into a bureaucratic

154 see Lippert (1990) for a similar argument about the importation of claims relating to satanism into Canada.

155 This reification presupposes an emotional investment on the part of the founders in their creaticn. This emotional investment, when combined with a unity of purpose on the part of the founders, is the "group mind" of tise proto-institution.

156 For example, the O.V.P.D.G. (see section 3.2.2.) is reified in the minds of its members, but not in the minds of most of the ottawa community.

157 See, for example, the limitations placed on membership in the Messenger (section 3.1.1.) 
Pigure 4.1 Interlocking Factors Affecting Channels of Communications

\begin{tabular}{|c|c|c|c|}
\hline Pactor & $\begin{array}{l}\text { Frect on... } \\
\text { echnology }\end{array}$ & Incuistics & ence \\
\hline Technology & - & $\begin{array}{l}\text { form and type } \\
\text { of communic- } \\
\text { ation (e.g. } \\
\text { written, oral, } \\
\text { visual, etc.) }\end{array}$ & $\begin{array}{l}\text { physical } \\
\text { access to } \\
\text { arena }\end{array}$ \\
\hline Linguistics & $\begin{array}{l}\text { cost of } \\
\text { appropriate } \\
\text { technology }\end{array}$ & - & $\begin{array}{l}\text { ability } \\
\text { to use } \\
\text { linguistic } \\
\text { form }\end{array}$ \\
\hline Audience & $\begin{array}{l}\text { access to } \\
\text { technology }\end{array}$ & $\begin{array}{l}\text { appropriate } \\
\text { linguistic } \\
\text { form }\end{array}$ & - \\
\hline \multicolumn{4}{|l|}{ Notes: } \\
\hline \multicolumn{4}{|c|}{$\begin{array}{l}\text { 1. "appropriate" as defined by the desired linguistic } \\
\text { milieu. }\end{array}$} \\
\hline \multicolumn{4}{|c|}{ 2. "access" in the sense of physical, economic and } \\
\hline
\end{tabular}

administrative form is voluntary. ${ }^{158}$

Channels of communication depend, as has been already stated, on technology, linguistics and an audience. Both the technological and linguistic requirements will act as determinants on the audience. And the choice of a specific audience will determine both the technology used and the linguistics. Figure 4.1 shows the particular constraining

158 This choice may well be the subject of intense debate. The movement towards bureaucratic form arises from the increasing complexity of the channel of communications. If the people who control the channel do not wish to expand its complexity, the transition may well prove unnecessary. 
relationships of these three factors.

Our second extension of the Hilgartner and Bosk model requires the addition of three phrses to account for the emergence of and recognition of new movement arenas. The first of these phases should consider the emergence, ex nihilo, of new movement proto-institutional arenas. ${ }^{159}$ The second phase should acrount for the creation of tailored protoinstitutional arenas. ${ }^{160}$ The third phase should account for the recognition process of these new arenas by members of the movement.

All three of these phases are necessary to our consideration of the institutionalization of the wiccan movement in ottawa. The movement itself may only be said to have institutionalized in toto once the recognition phase is controlled by institutionalized bodies. In essence, institutional bodies, including channels of communication, wjll emerge in a grass roots new religious movement. However, the movement itself will not become institutionalized until recognition of arenas is a function of institutional groups, rather than individual members of the movement.

\footnotetext{
159 These "proto-institutional" arenas develop from the "grass roots" of the movement, hence their designation as ex nihilo.

160 A "tailored" proto-institutional arena is an arena that is created by an already established institution as a movement forum. For example, the ottawa Member Temple of the wCC is a "tailored" arena, as are their sunday Night circles.
} 
The main elements of this restructured model now appear as follows: ${ }^{16:}$

A. Creation and Recognition of Arenas

1. the ex nihilo development of movement protoinstitutional arenas (e.g. the O.V.P.D.G.);

2. the emergence of "tailored" proto-institutional arenas (e.g. the wCC Ottawa Temple);

3. the recognition of proto-institutional arenas as "valid" and "legitimate" (see section 4.1.);

B. The Process of Institutional Evolution

4. a dynamic process of competition among the members of a very large "population" of potential definitions (see section 2.2. and chapter 3 ); 162

5. the institutional and proto-institutional arenas that serve as "environments" where definitions (and arenas) compete for validity, legitimacy and acceptance (see chapter 3 ) $i^{163}$

161 I have reworded Hilgartner and Bosk's six elements from their original emphasis on social problems towards our present emphasis on institutionalization. Also, the letter section headings (A. to $D$.) have been added for clarification purposes only.

162 The "population" of the movement is frequently "selfidentified" since there is no central bureaucracy to confer and/or control movement internal legitimacy. A similar situation appeared when the Church of Jerusalem attempted to control Paul's conversion of the gentiles (Gal 11-21).

163 It is always possible for a definition (or protoinstitutional arena) to be considered valid and legitimate, but not supported or accepted. For example, the Pagan Data Archives is considered both valid and legitimate by many people. It provides a large electronic data base of pagan resourses (ca. 17MB of information) for any donation. Currently, the amount of donations averages $\$ .50$ which does not even cover the cost of the distribution disks, let alone the upkeep and maintenance of the archives (personal communication from Joseph Teller, Archivist). 
C. The Characteristic Environments of Arenas

6. the "carrying capacity" of these arenas, which limit the number of definitional debates (and debaters) that can gain widespread attention at any one time;

7. the "principles of selection" that influence the probability of survival of competing definitional claims within a given arena;

D. The Inter-Arena Environment

8. patterns of interaction among the different arenas, such as feedback and synergy, through which activities in each arena spread throughout the others; and

9. the network of operatives who promote and attempt to control particular definitions and whose personal channels of communications crisscross the different arenas (e.g. Khaled, Adrienne, Marios, Merydydd, etc.).

I believe that this reformulation and extension of the model initially proposed by Hilgartner and Bosk reflects the process of constructing the ottawa community.

4.3. Conclusions

In chapters 2 and 3, I presenteci a background outline of the developmert, both historical and of communicative forums, of the Ottawa Wiccan community. The purpose of this chapter was to develop an analytical model that would reflect this development.

In section 4.1 . concentrated on examining the functions of communicative forums and the actors within them. Section 4.2. concentrated on expanding the social ronstructionist 
model of Hilgartner and Bosk. This expansion was required for two reasons. First, the Hilgartner and Bosk model assumed tile pre-existence of communicative forums, and this was cleariy not the case in the ottawa cominuity. Second, their model assumed that definitional arenas were already in existence. Again, this was not the case.

As I have already shown, rituals have played a major part in the development of the ottawa community (e.g. the Beltaine Grand Sabbat). In the next chapter, I will examine the role and effects of ritual on community formation in ottawa in greater detail. 


\title{
Chapter 5:
}

Ritual and Experience

\begin{abstract}
When we act in everyday life we do not merely react to indicative stimuli, we act in frames we have wrested from the genres of cultural performance. And when we act on the stage, whatever our stage may be, we must now in this reflexive age of psychoanalysis and semiotics as never before, bring into the symbolic or fictitious world the urgent problems of our reality. We have to go into the subjunctive worli of monsters, demons, and clowns, of cruelty and poetry, in order to make sense of our daily lives, earning our daily bread.

$$
\text { Turner, 1982:122 }
$$
\end{abstract}

Modern witchcraft is not, primarily, a philoscphy: it is a "craft", or practice. ${ }^{164}$ And while there are certain cosmological and "religious" beliefs common to the movement (see chapters 6 and 7), the primary emphasis is on practice. However, the word "practice" has certain connotations that are inappropriate. "Practice" in many religions lneans formalized

164 In some ways, it is possible to argue that wicca, or certain branches of it, is a form of experientidl philosophy based on the phenomenological (ritual and experiential) manipulation of "meaning symbols" which are assumed to represent certain "elementary intentionalities". As Husserl (1970:168) notes, "The being of these intentionalities themselves is nothing blit one meaning-formation operating together with another, "constituting" new meaning through synthesis". While this argument might apply to some of the more advanced schools of Western Ceremonialist magick (e.g. certain modern ordo Templis oriental groups), it is at variance with the everyday reality of most wiccars. This variance is apparent in the linguistic construction of wiccan deities who are considered to be both "powers" ("meaning symbols") and people (individual actors). 
or liturgical observances. ${ }^{165}$

In modern witchcraft, "practice" has more "tribal" connotations (see Turner, 1977; Williams, n.d.). Even in the most "iiturgicai" Wiccan traditions (i.e. Gardnerian derived traditions), there are frequent instructions such as "Cakes and wine, and any other games you like" (Kelly, 1991:70). Ritual leaders in the ottawa community will frequently include instructions such as "wing it", "improvise", and "blither on" in their ritual outlines.

The practice of the "Craft of the Wise", varies significantly between groups and individuils in the ottawa community. ${ }^{166}$ Ritual practice also varies dependant on the "audience", the "theatre of operations", and the "purpose" and "technique" of the ritual. These terms may be problematic since they derive from different sources. ${ }^{967}$

165 This is especially true in religions of "The word". Consider the liturgical prescriptions in Christianity, Judaism and Islam. Prayers, duties and obligations are all listed, formalized and have the strength of "divine law".

166 The phrase "Craft of the wise" refers to a general wiccan mythographical belief that "witchcraft" derives from "wicca/-e", "to bend" or "to shape" (see Adler, 1986:11; Valiente, 1989:81).

167 The tern "audience" derives from the theatre, specifically from the Latin "those who hear". The term "theatre of operations" derives from military strategy and refers to the broad landscape of a campaign of operations. "Purpose" presupposes the reflexive creation of a ritual event. "Technique" includes both the technology necessary to create and stage the event and the "style" or "elan" of the presentation of the event. 
An audience is the sum of individuals represented in a ritual. This includes not only those individuals who are physically present, but also those who are believed to be present. ${ }^{168}$ For example, if a deity is invited into a circle, that deity would be considered as part of the "audience". This inclusion of discarnate (or sometimes physically absent, but incarnate) individuals is important in a number of rituals.

The theatre of operations includes not only the named individuals in the audience, but also the sum of what these individuals represent. For example, an elemental Guardian ("called in" at the various cardinal points of a circle) is, as an individual a member of the audience. They are also representatives of a particular order of beings and, as such, they bring that order of beings within the "theatre of operations" of the ritual. 169

The purpose of the ritual is its function. This function may be perceived as taking place in any number of different, but connected, "worlds" or "realms". The purpose of the ritual

168 The audience may be further divided into the cast and the non-cast members of the audience based on who participates and who observes. However, this distinction is of use only in large rituals since there is an assumption of cast membership of all present in most wiccan rituals. Ritual is considered to be a process of internally creating a "reality" (see section 4.1.).

169 "Theatre of operations" is a technical term that I have borrowed from the military. It refers to the strategic conduct of a campaign in a specified geographical or political area. 
is frequently stated at the start of the ritual. For example, in the Alexandrian 1st degree initiation ritual (Farrar and Farrar, 1981:17),

The Initiator leads the Postulant to each of the cardinal points in turn and says:

"Take heed, ye Lords of the East [South, West, North] that is properly prepared to be initiated a priest [priestess] and witch.

This statement of purpose at the beginning of a ritual serves to reinforce the underlying assumptions that require the existence of the ritual. ${ }^{170}$

The technique of a ritual is both the technology used and the method of application of that technology. For example, a specific state of consciousness, or emotional state, may be

170 For example, at the start of the Anglican Solemnization of Matrimony (BCP), the Priest says

Dearly beloved, we are gathered together here in the sight of God, and in the face of this Congregation, to join together this man and this woman in holy Matrimony; which is an honourable estate, instituted of God in the time of man's innocency, signifying unto us the mystical union that is betwixt christ and his church.... and therefore is not by any to be entered upon, nor taken in hand, unadvisedly, lightly, or wantonly; but reverently, discreetly, advisedly, soberly, and in the fear of God; duly considering the causes for which Matrimony was ordained.

Matrimony was ordained for the hallowing of the union betwixt man and womani for the procreation of children to be brought up in the fear of the Lord; and for the mutual society, help, and comfort, that the one ought to have of the other, in both prosperity and adversity. [emphasis mine ] 
required for a ritual to achieve its desired purpose. These states may be invoked through the use of sensory "props" (e.g. incense, candles, blindfolds), meditational or psychological techniques (e.g. visualization), and physiological "manipulation" (e.g. drumming, dance)..$^{171}$

In general, ritual practice may be divided into two main categories: spell crafting and soul crafting. This division is based on a purposive dichotomy.

The category of "spell crafting" deals with the induction of substantive change in the material world. Rituals in this category would include healing rituals, money spells, binding and loosing spells (curses and exorcisms), love spells, job spells, etc. Their primary purpose is the attainment of some specific material goal (e.g. money, a job, health, etc.). 172

"Soul crafting" rituals are concerned with the induction of substantive change in the social and spiritual worlds. These rituals are frequently rites of passage (Van Gennep, 1960; T.Turner, 1977) that mark a specific change from one "state" to another "state".173 These "states" may be either

171 See Farrar and Farrar, 1981, 1984, 1990; Howes, 1987; Luhrmann, 1985, 1989.

172 For an examination of the ethical problems arising from this form of ritual, see section 7.3 .

173 By "state" I do not mean a static condition. Rather, "state" is taken to mean a continuing process of flow that is predictable. The term "rite of passage" refers to a shift from (continued...) 
social (e.g. single to married; laity to priesthood), spiritual (e.g. novice to Initiate; "shadow questing"), or cosmoloyical (e.g. summer to winter; life to death). While "soul crafting" rituals make use of altered states of consciousness, the intention behind these rituals is to change the everyday reality of the individuals, rather than to achieve an altered state of consciousness.

Frequently, rituals in the ottawa community will involve components of both of these categories. For example, prosperity spells are an integral parts of most Handfasting (Marriage) rituals.

This chapter will examine use of ritual in the Ottawa Wiccan community. First, I will briefly consider a crosssection of rituals (section 5.1.). Next, I will examine the various "occult" skills developed in the ottawa community (section 5.2.). Finally, I will consider the effects of this variance of skill development (section 5.3.).

$$
173(. . \text { continued) }
$$

one state, to a liminal condition, to another state ( $T$. Turner 1977). However, this shifting from state to liminal to state is a hallmark of wiccan ritual action. The circle in which most wiccan rituals take place is in itself a limisal state in which anything is possible. The "process of flow" referred to above is viewed as a continual shift between static state, liminal, static state; a calculus of the life process. Many wiccan soul-crafting rituals are designed to bring about an awareness of this "calculus" and to counteract any blockages in the process of flow. 
5.1. Ritual Types

As I noted above, there are two broad categories of ritual: spell crafting and soul crafting. spoll crafting rituals aim at changes in the material and/or social world through the manipulation of certain "natural laws" (Farrar and Farrar, 1990). Soul crafting rituals attempt changes in the social and spiritual worlds through the use of certain "natural laws"174, the application of meditational technologies, and via interpersonal relationships between the cast of the ritual and the theatre of operations.

\section{Figure 5.1: Rituals in the ottawa wiccan Community}

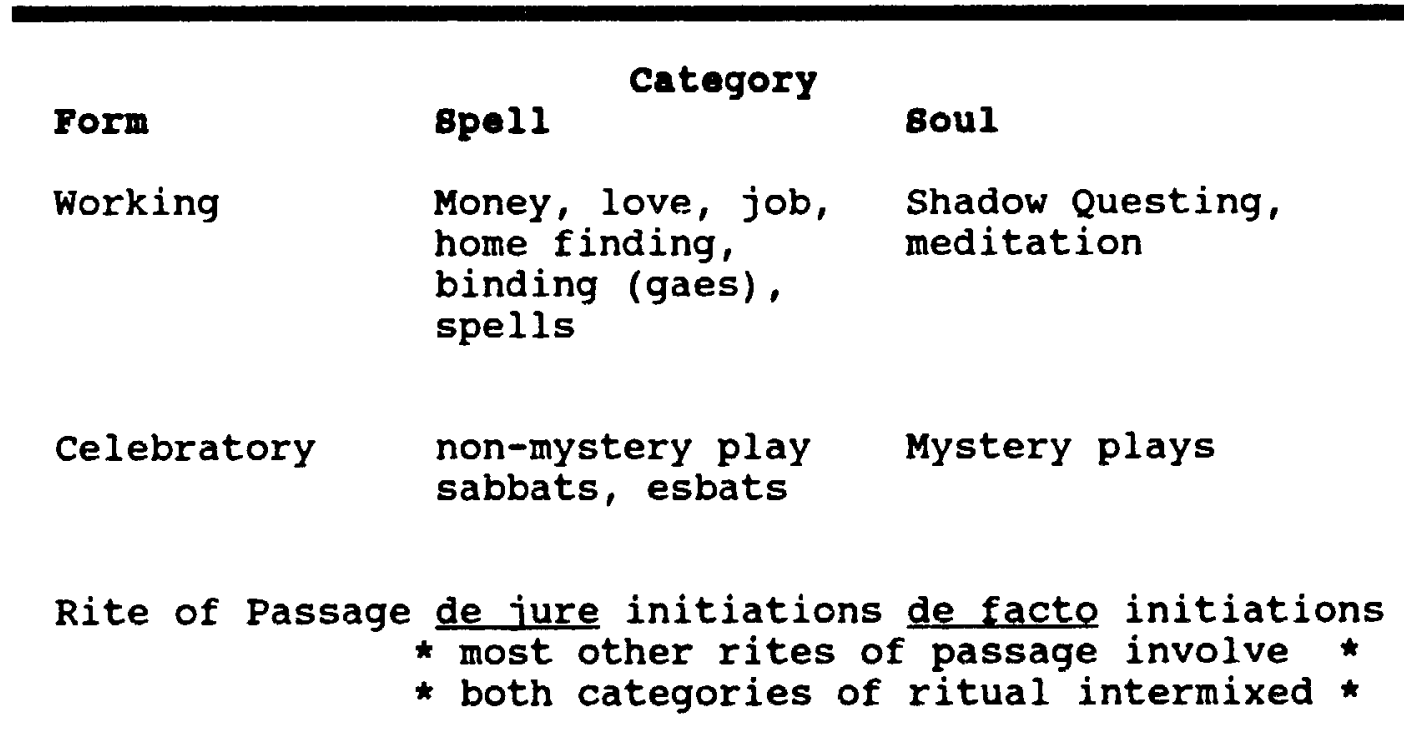

In general, there are three, broad forms of rituals in

174 Most notarle, through the application of Hermetic axioms, e.g. "As above, so below". 
the ottawa community: working rituals, celebratory rituals, and rites of passage rituals. Figure 5.1 gives examples of each of these forms.

As can be seen, the category distinctions are clear during working rituals, become less clear during celebratory rituals, and practically disappear during rites of passage. This convergence is due to the intimate linkage between "magic" and rites of passage.

While spell crafting may induce the transitions to and from the liminal stage of a rite of passage, the purpose is soul crafting. It is only with the de jure recognition of an event that spells are used solely to formalize the changes that are already considered to have taken place.

For example, at the Handfasting of Marios and Kelpie (August 3rd, 1991), the couple were ceremonially handed a number of symbolic objects.

(Handing chalice) "May you never know thirst" (drink). (Handed cakes) "May you never know hunger" (eat). (Handed coal) "May you never know cold". (Handed silver coin) "May you never be poor".

These actions are an example of both sympathetic magic in a ritual of social and spiritual transformation. The objects themselves are symbols of specific cures to certain "ill" states (thirst, hunger, cold, and poverty).

The action of accepting the symbols, and their retention, symbolizes the interdependence of the community represented at 
the event. The "audience" of the ritual was composed of the family and friends of the two main participants. The theatre of operation included the far vaster audience of Ancestors, Deities, Elementals, Brethren, and general society. While the "event" to place at a specific point in time (August 3rd, 1991), it also took place at a specific place outside of time where "the community" extends to include those who are not currently incarnate. ${ }^{1 / 3}$

Celebratory rituals (e.g. Sabbats) tend to utiiize spell crafting techniques to allow the participants to experience the "flow" or "process" represented by the Sabbat. Frequently, this process is represented in the form of a mystery play. This form possesses certain characteristics.

First, the audience is presented with a myth, which is a personification of the "mystery" of the sabbat. This presentation allows the incarnate audience to become familiar with the exoteric symbology of the "mystery".

second, the individuals acting out the parts gain an experiential understanding of their particular role. This act of "role playing" serves to actualize a mental pattern in which the actor "becomes" the role. ${ }^{176}$ This actualization allows the actor to experience the emotions of the role. And, 6.

175 For more on wiccan constructions of time, see Chapter 176 See Highfield, 1984:9-25; Stanislavski, 1961:1-106. 
by gaining an experiential knowledge of the role, the actor may gain a knowledge of the "mystery"; the esoteric "meaning" of the event.

Celebratory rituals are, for the majority of the audience, a celebration. For example, most sabbats are followed immediately by a feast. ${ }^{17}$ Many sabbats are also followed by Bardic "circles", complete with songs, dances, jokes, and stories. In many groups, seasonal games are part of the rituals. ${ }^{178}$

The categorical distinctions are clear cut when we consider working circles. This is by far the most common form of ritual in the ottawa community. Forty-four of the fifty-two weekly sunday circles run by the wCC temple in ottawa are working circles (the other eight are Sabbats). Many of the ad hoc rituals in the ottawa community centre around working circles (e.g. house blessings, exorcisms). The vast majority of solitary rituals are working circles (meditations, spells, Shadow Questing, etこ.).

In addition to their explicit purposes, rituals also have itself.

177 In some cases, the feast takes place in the circle

178 This inclusion of seasonal games in the Sabbat rituals goes back to Gardner. See Kelly, 1991; Farrar and Farrar, $1981,1987 \mathrm{a}$. 
latent effects. ${ }^{170}$ Rituals may enhance, maintain or degrade individual and/or group statur and legitimacy. ${ }^{180}$ Attendance at rituals also allows for oral interaction. For exanple, wcc Sunday Night Circles are frequently followed by "gossip sessions". Finally, public rituals (WCC and invitational) serve as performative forums to make political, social and cultural statements. ${ }^{181}$

The role of ritual in the ottawa community is multifold. Ritual events mark changes in the individuals/groups'/ community's relationships with each other, and the various "worlds" in which community members operate (ecological, material, social, and spiritual). Rituals are both "magical"

170 The Mertonian distinction between latent and manifest functions. However, in a number of casses (e.g. the Beltaine Grand Sabbat of 1987) the latent effects were consciously known by most participants.

180 For example, it is a requirement that wCC priesthood perform public rituals. If these are not up to the expectation of the audience, then the individual may well lose status in the community. Likewise, individuals who are not perceived as required to perform public ritual may gain status through the performance of "successful" public rituals. Another example is the Beltaine Grand Sabbat of 1987 where the OPC lost legitimacy as a result of a poor ritual.

181 For example, at Mini-Fest, 1990, the main ritual included a Drawing Down the Moon ritual. This ritual, and the Goddess invoked (Aradia), allowed the presenters (Marios and Sekhet-Sophia) to make certain political and cosmological statements. First, the ritual "announced" to the community the general cosmological beliefs of the Web of Herodias. Second, the ritual made a political statement of support for the Drawing Down the Moon ritual, which is frequently derided by the WCC. For more on the use of ritual as performative forums, see Turner 1974, 1982, 1986. 
and "religious" in Durkheim's (1915) sense of the words. In point of fact, the distinction between the "magical" and the "religious" becomes nonexistent at a certain level of ritual. The "sacred" and the "profane" are inextricably intertwined. And the division between sacred and profane is seen as a functional illusion. The sacred is everywhere, and in every thing. An item or event which is profane is merely a sacred event from which the illusion has not been stripped.

\section{2. "Occult" skills}

It would be as misleading to assume the unity of "occult" skills as it would be to assume the unity of sociology. I use the term "occult skills" to refer to a constellation of interrelated skills, technologies, and practices. Many of these skills have been labelled as "deviant" by general society (Ben Yehuda, 1985:74-105; Knight, 1991; Luck, 1985; Tambiah, 1990). In general, these skills break down into 7 areas: Divination, Healing, Mystical and Shamanic techniques, Theatrical and Bardic techniques, Folk magic, Ministerial skills, and Psychic skills.

Divination techniques are as old as humanity. Ginzburg (1980:13) argues that techniques of divination arose from attempts at inductive reasoning based on signs in nature.

...there are undoubtedly striking analogies between the model we have developed for hunters [tracking], and the model implicit in the texts of Mesopotamian 
divination, which date from at least 3000 years $B C$.

Divinatory techniques come in a bewildering variety of forms. The classical Tarot deck is probably the most popular form of divination in the Wiccan community. One also finds Norse Runes, I Ching, Geomancy, Astrology, Scrying, and reading the Akhasic Records. ${ }^{182}$

Healing techniques include herbalism, magicai herbalism, and the so-called "alternative nedicines". Herbalism is the most popular, and has long had an association with Witchcraft. ${ }^{183}$ Magical herbalism includes both the use of herbs in magical spells, and the use of the doctrine of signatures. 184 "Alternative medicine" includes homeopathy, aromatherapy, massage therapy, Reiki, and the whole complex of "new age" medical treatments. Of the three major categories,

182 The Norse Runes are the Futhark system (named after the first six Runes), see Blum, 1982. The I Ching derives from the Chinese practice of divining by cracks in tortoise shells. Later it developed into a sixty-four character set of oracles; see Wilhelm and Baynes, 1967. For Geomancy, see King and Skinner, 1976. Scrying refers to a collection of techniques involving mirrors, bowls of water, fire, etc.: anything that can unfocus the conscious mind (see Butler, 1979). The Akhasic records are the sum total of all that has happened. They are roughly the equivalent of Jung's collective unconscious.

183 For the associations between witchcraft and Herbalism, see Klaits, 1985; Sawyer, 1988; Russel, 1972.

184 See James, n.d., for a modern wiccan view. For medieval and early modern views on the doctrine of signatures, see Kieckhefer, 1990. For a general introduction to magical herbalism, see Cunningham, 1983. 
herbalism is the most common, followed by alternative medicine.

Mystical and shamanic techniques include both the cosmologies involved and the actual techniques. Examples of mystical cosmologies would include Qabalah, Hermetic philosophy, Theosophy, Tibetan Buddhism, Sufi and radical Christian mysticism. ${ }^{185}$ The vast majority of techniques are trance and/or ecstatic techniques (see Crowley, 1989; Duerr, 1985; Eliade, 1964; Farrar and Farrar, 1984). These include dance, drumming, constriction (binding with cords), cirugs (e.g. alcohol), scent, visualization, meditation, ritual movement (gesture), and neuro-electric stimulation. ${ }^{186}$

185 On the Qabalistic content in modern witchcraft, see Farrar and Farrar, 1984, 1990. In general, wiccans use Western Ceremonialist, primarily Golden dawn derived, interpretations of the Qabalah (e.g. Butler, 1978; Highfieid, 1984). Hermetic philosophy and Theosophy also enter into modern Wicca via Western ceremonialism. The links with Tibetan Buddhism are more tenuous, and appear to derive more from literature and individuals who have trained in both systems. For the links with Sufism, see Graves, 1964. Radical Christian mysticism as expounded by Matthew Fox, Hildegarde of Bingham, and the unknown author of the cloud of Unknowing has entered into the ottawa community via individual Wiccans who appropriate them (e.g. Marios and Meredydd) : Radical Christian mysticism also enters into modern wicca via Western Ceremonialism (e.g. Butler, 1990; Fortune, 1987c).

186 I have chosen the term "neuro-electric stimulation" to desj.gnate the "flow of power" experienced during a ritual. The feeling may best be described as a constant or alternating current of electricity "flowing" along the sympathetic nervous system. Activation of the parasympathetic nervous system, is produced through a technique known as "grounding and centering". Activation of the central nervous system uses the (continued...) 
Theatrical and Bardic skills include both the ability of the practitioner to cast an "illusion" into which they may draw other people, and the skill to design "effective" rituals. Skills include body movement, voice projection, singing, liturgical design and small group dynamics. These skills serve to enhance the "charisma" or "magretism" of the individuals by controlling the presentation environment.

Folk magic consists of the use of siecific techniques from popular culture. Few American witches outside of the Appalachiar. mountains use indigenous folk magic, whereas many British and Canadian witches do. Frequently, folk magic "recipes" will be taken from folklore and/or anthropological literature and melded in with local practice.

Ministerial skills are primarily counselling skills. Outside of coven settings, there are few set forms for these skills, although the wCC is attempting to create them. In the Ottawa community, most Wiccan ministerial skills derive from non-Wiccan sources (e.g. volunteer counselling). ${ }^{187}$

Psychic skills include both the skills considered by

${ }^{186}($. . . continued)

Western Ceremonialist variants of the Yogic Chakra system. For more on the general interconnections between ritual and the nervous system, see Laughlin et al., 1983.

187 A similar situation has been noted by Danny and Lyn Jorgenson in their research in the occult community in Southern California (Jorgenson and Jorgenson, 1982). In England, there are very close ties between the psychiatric and wiccan communities (e.g. Vivianne crowley). 
parapsychology (e.g. telepathy, telekinesis, etc), and those known in scotland as the "Second sight". Little emphasis is placed on the parapsychological skills with the exception of psychometry which is considered a basic requirement for talismanic work. ${ }^{188}$

The primary development of psychic skills is around the "Second sight". This is both for historical reasons (i.e. a continuity with "witches" of the past), and because the development of the second sight is necessary for power moving in ritual and awareness of discarnate beings. The second sight is developed primarily through visualization exercise. ${ }^{189}$

In this section I have tried to show some of the varied skills and techniques used by witches in ottawa community. As can easily be seen, there is a bewildering array of sometimes contrasting, sometimes complementing skills.

\subsection{Effects of Differential Skill Development}

As I showed in the previous section, the range of skills which may be developed in the ottawa community is huge. No

188 The construction, identification and maintenance of magical Talismans ("talismanic work") is examined by skelton (1991).

189 The term "Second Sight" is also sometimes referred to as "clairvoyance". This second usage is, however, problematic since the same term is used to refer to viewing at a distance in parapsychological circles. 
single person can hope to become an expert in every area. ${ }^{190}$ This has naturally led to group and individual specialization. And, along with specialization, there are status values attached to each of these skills. However these status values differ from group to group dependant on the valuation accorded to different skills.

The wcc tends to place heavy emphasis on the early development of two main areas. First, the Theatrical and Bardic skills necessary to run public rituals. Second, the Ministerial skills necessary for a public priesthood. The other skills are picked up over a general ccurse of study, although Healing (herbalism) and Divination (mainly Tarot) are emphasized.

Quicksilver (and most of the other Gardnerian derived groups and individuals) tends to place a heavy emphasis on Mystical and Shamanic techniques, Psychic skills, Divination, non-traditional "folk magic" (i.e. intentionally developed techniques) and general research. Theatrical and Bardic skills are not considered as primary, since Quicksilver operates within the Gardnerian derived liturgy system. Herbalism is generally neglected ("Why use herbs when we have OHIP?"), although other forms of healing are taught (e.g. massage,

190 on of the "rule of thumb" definitions of an Elder in the community is a person who is a specialist in a few areas, knows something about several more, and knows where to find information about the rest. 
"psychic hands", etc.).

The Web of Herodias tends to place heavy emphasis on Mystical and Shamanic techniques, Psychic skills and Theatrical and Bardic skills. Healing and Folk magic are generally neglected. Divination is used rarely but is a training item. Ministerial skills are developed outside of the tradition at individual discretion. ${ }^{191}$

The Merydians tend to place an emphasis on Mystical and Shamanic techniques (although they generally do not use magic), and on Ministerial skills. Divination and Healing are also emphasized, but they are secondary to the "religious" aspects of the tradition.

Hecate's Web appears to emphasize Theatrical and Bardic skills, and Mystical and Shamanic techniques. They concentrate primarily on the production of mystery plays at sabbats. Healing, Divination and Ministerial skills are all developed at the discretion of the individual members.

As might be expected, the three indigenous traditions (the Web of Herodias, the Merydians, and Hecate's Web) are somewhere between the two earlier, non-indigenous groups:

191 The Herodians justify this individual choice on Ministerial skills by appropriating the Catholic concept of a "vocation". 
Figure 5.2: Skills Development

\begin{tabular}{|c|c|}
\hline Group & Emphasis \\
\hline WCC & Public religious \\
\hline Quicksilver' & $\begin{array}{l}\text { Private group (coven) } \\
\text { Magico-mystical }\end{array}$ \\
\hline $\begin{array}{l}\text { Web of } \\
\text { Herodias }\end{array}$ & $\begin{array}{l}\text { Individual/ad hoc } \\
\text { group Magico-mystical }\end{array}$ \\
\hline Merydian & $\begin{array}{l}\text { Group/communal } \\
\text { religious }\end{array}$ \\
\hline $\begin{array}{l}\text { Hecate's } \\
\text { Web }\end{array}$ & $\begin{array}{l}\text { Public/group religio- } \\
\text { mystical }\end{array}$ \\
\hline \multicolumn{2}{|c|}{$\begin{array}{l}\text { 1. Includes other Gardnerian derived } \\
\text { groups and individuals in the ottawa } \\
\text { community. }\end{array}$} \\
\hline
\end{tabular}

Quicksilver and the WCC. ${ }^{192}$ All three local traditions have limited contact with the wCC, although this situation is fairly recent and arises out of interpersonal conflict. There is slightly more contact with

Quicksilver.

When we consider the various emphases of these groups, it is possible to see where much of the intergroup conflict comes from. The early conflict between Quicksilver and the WCC follows the same pattern as the early conflicts of the Gnostic and orthodox Christian Churches: esoteric verses exoteric. And the indigenous responses to this tension are also similar to those of early Christianity. The web of Herrdias is a

192 While Quicksilver did evolve in 0:tawa, it has become practically indistinguishable from certain English Gardnerian derived covens. This evolution appears to be parallel, since there was no contact between Quicksilver and the English groups until 1990. However, while Quicksilver itself may be counted as indigenous, the Gardnerian derived Wiccans not, hence the exclusion of quicksilver as an incigenous group. 
collection of individuals who might be equated with the early wandering monks. The Merydians are also similar to a monastic order in that they wish to withdraw from general communal conflict. ${ }^{193}$ Hecate's Web is similar to the early Marcionite movement with its emphasis on large rituals and on speaking directly to the divine.

So far in this chapter, I have not mentioned the local Asatru group. This is because they are not Wiccan. However, they are considered to be part of the community. In general skills terms, they are similar to the Gardnerian derived groups (e.g. Quicksilver) except that they have a heavy emphasis on Folk magic and Folk lore in general. 194 Their interactions with the other groups in the area are limited to one personal contact with the Web of Herodias, and to the wcc. There are significant tensions between them and the wCC, based in part on personal animosity.

\subsection{Conclusions}

In this chapter, I considered the use and effects of rituals in the ottawa wiccan community. The vast array of differing rituals and their generally non-repetitive nature

\footnotetext{
193 Although this is the only way in which they are similar to monks!

194 specifically, they have a heavy academic interest in Norse and Germanic folk lore.
} 
has made it impossible to analyze individual rituals in detail. Rather, my examination has concentrated on the categories of rituals (section 5.1.), the skills developed (section 5.2.), and the effects of varying skills development (section 5.3.)

Unlike liturgical religions (e.g. Christianity), modern Wicca in the ottawa community is primarily improvisational. Rituals axe modified, changed and invented depending on circumstances. Liturgical development tends to be in the area of individual ritual construction, rather than on the formation of specific rituals. Even in the most liturgical groups, large sections of "set" rituals are subject to improvisation and change.

Rituals are oral, performative, and interactive. There is a general emphasis on achieving a ritual balance between "mirth and reverence". A sense of "play" is encouraged, as are laughter and song. And this sense of play is the strength of modern Wicca in ottawa. While no ritual leader has been hit with a pie in the face, there have been occasions where ritual leaders have broken into paroxysms of laughter during "serious" parts of public rituals. This quality appears to have been suppressed in many English and American groups. ${ }^{195}$

195 Personal communication from Janet Farrar to Magnus (Magnus, 1992). The Dionysiac quality is more apparent in American groups, but is increasingly being channelled to accord with politically correct goals. 
However, the Dionysiac quality and individuality are the core qualities of modern wicca. As the Farrars note (1987a:179)

If institutionalisec: Wicca groups do arise, as they are already doing in America, they will always have to stand up to comparison with other groups, and to the voices of autonomy and individualism, which are the essential voices of witchcraft. 
Chapter 6:

Constructing Time

"We think that we need a landscape as a ground to
sustain us. If we study the patterns moving on the
surface of a river, we need a bank or a bridge to
keep us suspended in meditation. And even at the
shore of our tidal breath in less topological forms
of meditation, we find ourselves coming back to a
certain body of knowledge that is the landscape of
our world, a world with, perhaps, a few new
territories added to its map." (Thompson, 1989:130)

History, as the story of "that which was", contains in it the form of "that which is" and "that which will be". But these stories, "Myths", are constructions; a piecing together of "objects" and "facts", many of whose very existence depends on the interpretive framework which they, in turn, support. And the universe of other, non-interpretive, "facts" is effectively unlimited thereby rendering any interpretation "tentative". In addition, a shift in the social definition of the "good" may well serve to delegitimize certain "facts", interpretive schema, and/or technologies of discovering the "possible". 196

Mircea Eliade (1958) has argued that "Myth" and ritual are returns to a sacred time. Ritual is the re-creation of the primordial mythic event that creates the "world". As such,

196 Consider, for example, the case of spiritualism. Spiritualist technologies (i.e. trance mediumship) have been attacked as late as the $1950^{\prime} \mathrm{s}$. This is in direct opposition to the earlier acceptance of spiritualist research as "legitimate". 
these myths contain the template for understanding time, space and purpose: the primal "trinity" of social myths. They answer the existential questions of "Why are we here?", "What am I?", "Where am I going?" and "What is here?".

In the "modern" world, science has replaced religion as the source of myth and ritual. ${ }^{197}$ Rituals, termed "experiments", re-create the world in schools and laboratories. Learned journals and conferences discuss the origin of "the world": Cosmology replaces theology and assumes a mystical quality of its own. ${ }^{198}$ Finally, science comes full circle and presents its results in mythopoetic language.

"The advent of the spirit, as the evolution of matter towards spirit, is part and parcel of the movement of being in the process of becoming, implying the possibility, in principle, of the surpassing of the self which breaks the bounds of the essence, an essential, active transcending of the self, aspiring towards the very life of the Absolute -- self-possession, freedom and truth. This is the sense of the cosmic process of which Man is a part, finding therein the sense of his own existence and his own dignity, and the meaning of his suffering." (Zatti, 1988:155)

197 While there can be no exact dating of when the "modern" world ended and the "postmodern" world began, certain key events do appear to indicate a division. These are: the student revolts in the 1960's (primarily 1968); the invention and rapid dissemination of the personal computer $(1979+)$; the introduction of television (late 1950's); and the polarization of attitudes towards mainstream religious traditions, possibly dating from the Scopes "Monkey Trial".

198 Consider, for example, the works of william Irwin Thompson (1981, 1989) 
While Zatti's mythopoetic expression is further than many scientists would go, it is by no means unique. ${ }^{199}$

Religions, regardless of how they identify themselves, must be able to answer these existential questions. And while their answer need not hold true for all of existence, these answers must be true for their members.

The purpose of this chapter is to examine how modern neopagan witches, both in the ottawa community and in the movement as a whole, answer these questions. While there are few formalized answers, many are implicit in the presentation of the questions.

This examination involves an analysis of how witches formulate Time. These constructions of Time, with their implicit constructions of space (section 6.2. and 6.3.), answer the question of "What is here?" The questions "Why are we here?", "What am I?", and "Where am I going?" are answered by the concept of Evolutionary time (section 6.4.).

\subsection{Metaphors of Time}

"Today we think of time as a linear chain of events, a sequence that began billions of years in the past and is likely to extend for an indefinitely long period into the future. But if we look a little more closely at the way we really use time in the everyday world, we may not be so remote

199 See, for example, the works of Margulis (1987). Perhaps the best example of mythopoetic expression is in the works of William Irwin Thompson (1981, 1989). 
from our ancestors." (Aveni, 1989:63-64)

Time, for many witches, is presented paradoxically. It is a spiral, a line, a circle, and a cycle (Farrar and Farrar, 1981). How one views time is dependant upon one's current place in the cosmos, and it is assumed that this place will change as the individual evolves and changes.

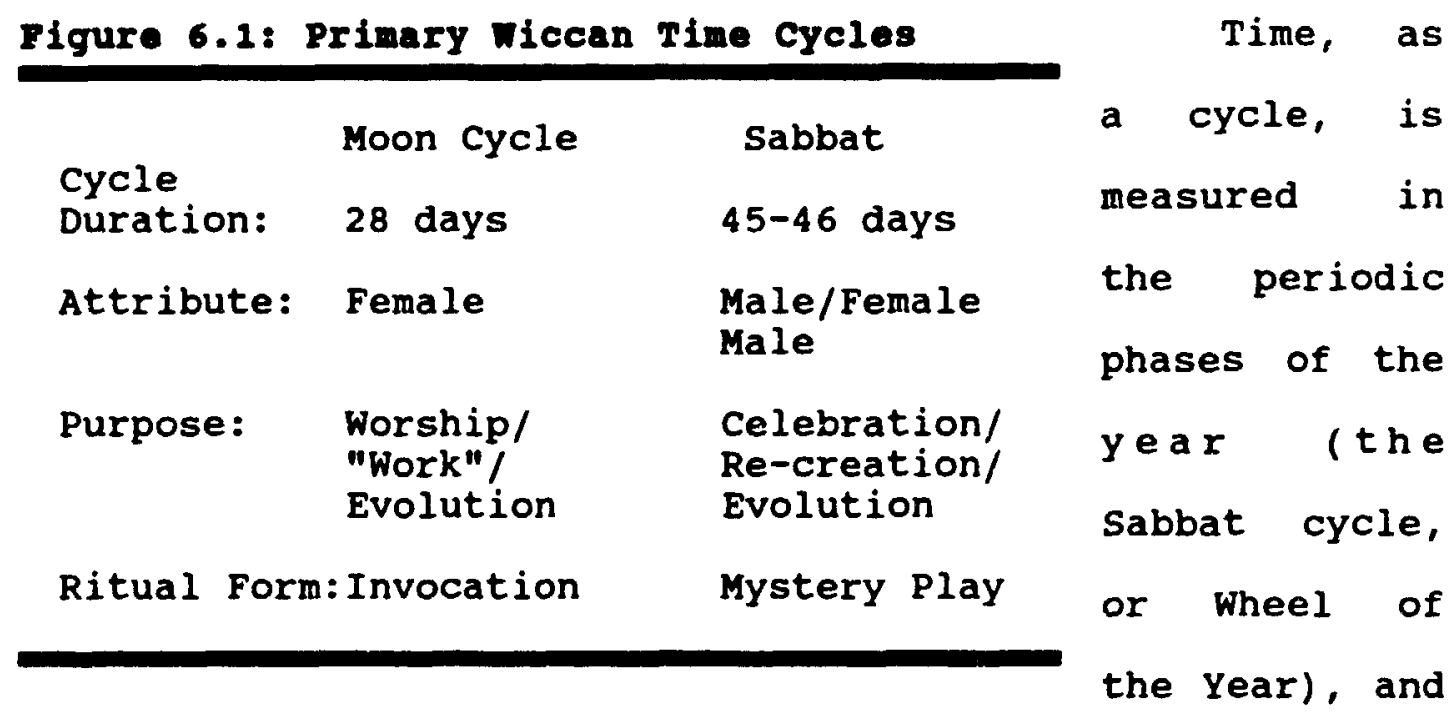

by the changes of the moon (celebrated at Esbats). These perceptions of time are based on perceptual "reality". They derive from the waxing and waning of the moon, from the shifts in the agricultural "year", and from the changes in the Earthbased perceptions of the sun. 200

However, these perceptions of time, grounded as they are in material (or sensory) reality, are expanded to describe

200 These time cycles are by no means "new". For an examination of other cultures that use similar cycles, see Eliade, 1958. 
cosmological truths-claims, and to prescribe the use of certain technologies. The two primary wiccan time cycles, the moon cycle and the sabbat cycle, are shown in Table I.

The sabbat cycle may also be broken down into two complementary cycles: one agricultural, and one solar. Let us consider eavh of these cycles in turn.

\section{2. the Moon Cycle}

The lunar cycle is, possibly, the oldest form of time reckoning created by humanity (Aveni, 1989:106-109). It appears to predate the invention of agriculture. Part of the deep rooted symbology of the lunar cycle is based on the relationship between a woman's menstrual cycle and the Moon (Shuttle and Redgrave, 1978).

The introduction of a lunar time cycle into modern witchcraft can be traced to two main sources: the "command" in the Vangelo of Aradia (Leland, 1990), and the medieval and early modern equation of the full moon with the witches Sabbat. 201

The command for the witches to meet is given in Aradia as

201 For more on this equation, see Ginzburg (1985, 1991). Earlier examples of the equation of the lunar cycle with Witchcraft can be found in classical Greece (Luck, 1985) and ancient Babylon. 
"... once in the month, and when the moon is full,".202 This was retained during Valiente's 1954 reworking of the Charge of the Goddess: "...once in the month, and better it be when the moon is full."

The purpose of these meetings is twofold: first to worship the Goddess, and second to learn "sorcery". It is worth examining the two forms of the Charge in detail, since there are profound changes from Aradia to the current version.

The most striking difference between the two versions is the speaker. In Aradia, the speaker is Aradia, daughter of Diana and Lucifer. Her voice is promissory and reminiscent of the words of Jesus to his disciples in the Gospel of John. ${ }^{203}$ Aradia is promising an event (or series of events) that will take place in the future ("When I shall have departed from this world...").

This speech is an anticipatory command for future meetings that will commemorate this promise. The speech takes place in Eliade's in illo tempore. It is the words of a divine exemplar who creates, rather than recreates, a ritual form. And the speaker's emphasis is on the "adoration" of Her mother (Diana), not Herself. Aradia speaks with the voice of a

202 The original Italian (Tuscan dialect) reads as follows: "una volta al mese quando la luna e piena" (Leland, 1990:5)

203 John 16, especially verse $22-23$. 


\section{Aradia}

When I [Aradia] shal! have departed from this world,

Whenever ye have need of anything,

Once in the month, and when the moon is full,

Ye shall assemble in some desert place,

or in a forest all

together join

To adore the potent spirit of your queen, My mother, great Diana.

She who fain would learn all sorcery yet has not won

Its deepest secrets,

my mother will

them

Teach her, in truth all

trings as yet unknown.
Charge (Current)

Whenever ye have need of anything,

once in the month, and better it be when the moon is full.

Then ye shall assemble in some secret place and adore the spirit of Me who am Queen of all witcheries.

There ye shall assemble, ye who are fain to learn all sorcery, yet who have not won its deepest secrets.

To these will I teach things that are yet unknown.

prophetess and priestess, not as the Goddess Herself.

In the modern Charge of the Goddess, the voice is that of the Goddess in all Her multiform aspects. ${ }^{204}$ The charge is

204 "... the words of the Great mother, who was of 0 also called among men, Artemis, Astarte, Dione, Melusint Aphrodite, Cerridwen, Diana, Arianrhod, Bride, and by many other names." (Tntroduction to the Charge of the Goddess). 
made by a priestess who is "possessed" by the Goddess. 205 Frequently, the actual wording of the charge changes, depending on the trance ability of the priestess and on the needs of the group. ${ }^{206}$

Once the invocatory part of the Drawing Down the Moon ritual has been completed, the Priestess is considered to be the Goddess. She (the Priestess) speaks with Her voice and hears with Her ears; she is the Goddess incarnate for the duration of the ritual.

There are three main points that I wish to focus on. First, any Initiated Priestess may be the focus of a Drawing Down the Moon ritual. 207 Second, the Goddess is seen as multiform; the sum of all Goddesses past and present. 208

205 The actual strength and form of the "possession" varies due to a number of factors. The depth of trance which Priestesses enter into during the Drawing Down the Moon ritual which precedes the charge varies from none (acting only) to full deific control. I have observed a similar range of trance states (none to full possession) amongst charismatic Christians.

206 of the numerous "Drawing Down the Moon" rituals I have observed, most $(80 \%+)$ have varied from the "script". On a number of occasions, once the "Goddess" is in the circle, she has completely discarded the charge with such phrases as "You've heard all this before anyway, and its not why I'm here", or "My, my. So many people?" (Mini-Fest, 1990).

207 As any Initiated Priest may be the focus of the Drawing Down the Sun ritual. See, Farrar and Farrar, 1984:6770 .

208 This may well derive from either Murray (1963), or from Dion Fortune's frequently quoted saying "All Gods are one

(continued...) 
Third, the "teaching" takes place in the no-time/present time of the circle. ${ }^{209}$

The first point, that any Initiated Priestess may be the focus of a Drawing Down the Moon ritual, demonstrates both the ubiquity of the Goddess, and Her immanental (as well as transcendant) nature. ${ }^{210}$ The Goddess may (and is assumed to) live in any Priestess (or woman) and, by extension, lives in all things. This ubiquity and immanence has profound social ramifications, and is the source of much of the environmental activism of a number of witches. ${ }^{211}$

The second point, the multiform nature of the Goddess,

$$
{ }^{208} \text { (... continued) }
$$

God. All Goddesses are one Goddess. And there is but one Initiator." For more on the multiform nature of the (modern) witches Goddess, see (Farrar and Farrar, 1987b).

209 For more on the no-time/present time nature of the witches circle, see section 6.4. following:

210 This is also shown in the charge itself in the

"... for behold; I have been with thee from the beginning, and I am that which is attained at the end of desire."

The transcendant nature of the Goddess is shown in Her speech act (the charge) to the other members of the group.

211 The principles of ubiquity and immanence are the justification for the Dianic position that any woman may declare herself a witch by saying "I am a Witch" three times. 
derives in part from the principle of ubiquity, ${ }^{212}$ and in part from the tripartite perception of the Goddess as Maiden, Mother, and Crone. This tripartite perception of the Goddess derives primarily from the three main phases of the moon: Waxing (Maiden), Full (Mother), and Waning (Crone). ${ }^{213}$ Thus the primary aspect invoked at Esbats (full moon rituals) is the Mother. ${ }^{214}$ However, by changing the time of the Esbat from the full moon to a different moon phase, a different aspect of the Goddess may be invoked. ${ }^{215}$

The final point is that teaching takes place in the notime/present time of the circle. Teaching is viewed as a continuing process of both revelation (knowledge) and

212 If the Goddess is in all things, and if we perceive all things as different forms, then we must perceive the Goddess in different forms. Forms that are appropriate to the moment of perception.

213 The fourth phase of the moon, the dark moon, is usually not integrated into wiccan thealogies, although there are exceptions. In the ottawa community, this phase is usually considered to be the transformation from the crone to the Maiden phases, rather than the destructive "face" of the Goddess.

214 This equation is further pointed out in the invocation of the Drawing Down the Moon ritual:

"I invoke Thee and call upon Thee, Oh Mighty Mother

of us All, Bringer of all Fruitfulness."

215 This appears most frequently, in my observations, in a shift to the dark moon for divinatory or shadow Questing purposes, where the Goddess appears as Queen of the Underworld. One other use, mentioned in a number of places, but which I have not observed, is the invocation of the dark Goddess for curses (Luck, 1985). 
evolution (wisdom). One enters into the circle and leaves it changed forever. The circle becomes a spiral, with the $z$ axis being wisdom and knowledge. In Aradia, the $z$ axis was knowledge of sorcery. In modern circles, it is both knowledge of sorcery (spell crafting) and wisdom.

In conclusion, for modern witches, lunar time is the time of the Goddess. ${ }^{216}$ It is a time of continuing revelation about the nature of the cosmos, the individual, and the Goddess. It $j$ - ut so much a recreation of an in illo tempore event, as. = a part in the continuing spiral path back to the once and future state of union. This state of union existed before time, exists now, (although we have forgotten it), and will exist in the future. ${ }^{217}$

\subsection{The Sabbat Cycle}

The Sabbat cycle breaks down into two distinct parts: the "agricultural cycle, and the "solar" cycle. Of these two, the agricultural cycle is probably the oldest, developing as a myth (celebration/explanation) cycle along with the development of agriculture. The solar cycle appears to develop with

216 Rarely does the Horned God appear. And, while there is some evidence that Gardner originally proposed them to be equal during Esbats, this has not happened, at least in the Ottawa community.

217 And in this belief, we can see a resonance with earlier Gnostic beliefs about the purposes of reincarnation and the nature of the Fall into matter. 
the emergence of astronomy/astrology (Eliade, 1958).

6.3.1. The Agricultural Sabbats

The agri- Pigure 6.3: Agricultural sabbats

cultural sabbat sabbat Date Event

cycle derives * Samhain october 31 Final Harvest

from the celtic (animals)

fire festivals Imbolg February 2 "In the belly"

(Table o.3). * Beltaine May 1 Summer

Each of these

festivals re- Lammas August 1 First Harvest

festivals reughnasad)

lates to a

major event in the yearly life of an agricultural people.

The two main festivals, Samhain and Beltaine, are festivals of Death and Life respectively. Samhain (pronounced "sow-'een") derives its nature as a festival of Death from the harvesting of animals that took place at this time (Farrar and Farrar, 1981). Beltaine derives its nature as a festival of Life from the appearance of summer. Samhain and Beltaine mark the prime turning points of the year. According to one mythos, the Horned God, as the Lord of Death, takes rulership of the year from the Goddess at Samhain (Farrar and Farrar, 1981). Samhain is also a time when the Legend of the Descent of the Goddess is portrayed in public (at least in the ottawa and 
Toronto communities).$^{218}$

In the ottawa community, Samhain is a time of remembering the dead. This may take the form of throwing a party and inviting the Dead to attend, or it may take the form of saying goodbye to friends who have died during the past year. With the single exception of two KCC public Samhains (1988 and 1989), no two rituals are the same. ${ }^{219}$

Beltaine, the Feast of Life, is probably the most popular Sabbat amongst the newer members of the ottawa community. ${ }^{220}$ It is viewed as the time when the Goddess gains rulership of the year. It is also seen as the time when the God and Goddess are married (Farrar and Farrar, 1981).

In the ottawa community, Beltaine is a time to "PARTY!" The feast coincides with the ending of the university school

218 However, the public Legend of the Descent of the Goddess is not the version that appears in the Gardnerian Book of Shadows. Rather, the public version is usually a retelling of the Persephone/Hades myth, or the Descent of Innana (e.g. Samhain, 1989), both modified to fit the individual tastes of the ritual organizers.

219 These two $x$ ituals were run by the same people, Tamarra James and Marios. And neither ritual was seen as their own private "Samhain" (personal communication). Public Samhains are often viewed as a performance that is expected by the public, and are treated accordingly.

220 This popularity has been expressed in the ditty "Hurray, hurray for the first of May, outdoor f\#cking begins today." There is also a somewhat disparaging comment heard frequently to the effeci that the "kids" (newer members of the community) tend to divide the year into pre-Beltaine and postBeltaine. 
year, giving a number of community members an added incentive to celebrate. 221 While the ottawa community Beltains do not partake of some of the more orgiastic practices of parts of the Toronto community, they are far from sedate. ${ }^{222}$

The festival of Lammas (August 1st) is the height of power for the God in the world. Tamed into marriage at Beltaine, He becomes the grain that is harvested at Lammas. He is the ultimate hero figure who dies that His people may live on His now dead body (the grain). And, while this theological position may sound Christian (and bear overtones of the Christian Mass), it is derived from the pre-christian myth of the sacrificed God (Eliade, 1958). 223

The festival of Imbolg (aka Brighid, Oimelc) literally means "in the belly". It is the height of the Goddesses retreat into the world of Death. And what is "in the belly" is

221 A least one ritual burning of school notes has taken place (WCC Beltaine, 1990).

222 This does not mean to imply that the Elders and Initiates of the ottawa community support or endorse indiscriminate sexual behaviour, or that they are unaware of STD's. However, Beltaine is viewed as one of the two nights outside of time (the other is samhain), and anything is possible. For example, at the WCC Beltaine of 1990 , six dozen condoms were blessed and made available for general use. To the best of my knowledge, only two couples used them (all the other couples either brought their own, or were monogamous).

223 There is a secondary interpretation of Lammas, as Lughnasad, the wedding day of Lugh the God of Light. This is the interpretation that was used during the wedding of Marios and Kelpie (August 3rd, 1991). 
the life that springs forth at Beltaine. This festival is a traditional time for first degree initiations, although few in the ottawa community have been initiated then. ${ }^{224}$

Figure 6.4: Agricultural 8abbats II

$$
\text { Lady of Life }
$$

Lammas

God at height in the world

First Harvest

Beltaine

Festival of Life

Beginning of Summer

winter
Samhain

Festival of Death

Beginning of

New Year

"in the belly"

Goddess at height out of the world Imbolg

Lord of Death

Figure 6.4 encapsulates the agricultural sabbat cycle. This cycle is an even polarity between the God (the Lord of Death) and the Goddess (the Lady of Life). And, while there are other interpretations of these sabbats (e.g. the use of

224 Khaled, open Circle \#6 (February, 1989). However, both Marios and Merydydd received their second degrees around Imbolg (and their firsts around Samhain). 
the Greek Persephone/Demeter myths by the WCC and Hecate's Web), this interpretation appears to be fairly acceptable to many members of the ottawa community.

This interpretation stands in contrast to the Goddess centered Sabbat cycle common in the United States, and to the eightfold Sabbat cycle of English wiccans (Farrar and Farrar, 1981:11-32).225 The reasons for this interpretive difference appear to stem from three main factors: climate, the wcc, and the academic environment of the ottawa community.

It is readily apparent to anyone who has spent a full year living in ottawa that there are two main seasons: winter and summer. With temperatures ranging from $-40^{\circ} \mathrm{C}$ in January and February to $+40^{\circ} \mathrm{C}$ in July and August, the year divides fairly well into winter (Death/Ice) and summer (Life/Fire). And the turning points in the local climate equate sufficiently well with the times of Beltaine and Samhain. These local climactic conditions make the division appear sensible. 226

225 The primary difference between the English interpretation and the ottawa interpretation appears to be based on a God theology. In the English groups, at least according to the Farrars (1981), the God is splintered into a number of competing aspects that are apparently unreconciled (e.g. the Lord of Deatr, the Holly King and the Oak King, the God of the Hunt, and the God of the sun).

226 In both meanings of the word: a) available and perceptible to the senses, and b) logical. A similar climactic effect on cosmological interpretation has been noted by (continued...) 
The second factor, the WCC, has been insufficiently studied. However, one main observation that has been made is their public use of gender polarity. The wCC, at least in the Ottawa Temple, will not perform an open ritual unless both the God and the Goddess are invoked. This insistent use of polarity has spread to other groups in the ottawa area, at least in the realm of public rituals. ${ }^{227}$

The final factor, the academic influence in the ottawa community, appears in two forms. First, members of the ottawa community have access to large amounts of academic (including folkloric) data on pre-Christian beliefs. Second, due to the large number of Wiccans involved in the academic study of religion, there is a tendency to produce theologies that are consistent. 228 This academic influence also serves as the

$$
{ }^{226} \text { (....continued) }
$$

Ashleen O'Gaea (from south-eastern Arizona), Another Look at the Wheel in Sacred Hart, 6(1) Imbolg, 1992.

227 Most academic investigation of the effects of the WCC on wicca in ontario have been limited to undergraduate course papers. To the best of my knowledge, only one Graduate course paper (Rabinovitch, 1991) has considered the influence of the wCC. Their apparent effect on witchcraft in southern ontario deserves serious, in depth, investigation.

228 The number of academics and scholars in positions of high status in the ottawa Wiccan community is abnormally high. of the functional Elders in the community, 12 of 16 have undergraduate (or equivalent) degrees, and three are involved in graduate research. These degrees are in: Psychology, Folklore, Comparative Religion, Biology, Philosophy, Political Science, Sociology, English and Indo-European Studies. While movement statistics indicate that the educational level of 
focus for symbolic syncretism. Individuals will frequently use academic sources of information in constructing symbol systems and in the ritual presentation of these symbol systems.

In summation, the agricultural sabbat cycle, at least in the ottawa community, is polarized between the Lord of Death and the Lady of Life. It reflects the gender polarization that marks Southern ontario from the rest of Canada (and large parts of the United States), but is not the unified eightfold cycle of English Wiccans. ${ }^{229}$

\subsubsection{The Solar Sabbat Cycle}

The solar sabbat cycle (see Table 6.5) centers on the apparent phases of the Sun. As with the agricultural sabbat cycle, the solar sabbat cycle is gender polarized, although it is primarily male oriented. It relies on precise observations of the sun, and may have derived from the practice of

$$
228 \text { (...continued) }
$$

neo-pagans is significantly above the norm (Green Egg, 22(88), Oimelc 1990), interview data (Magnus, 1992) points to the uniqueness of the academic core in the ottawa community.

220 This summation is, of necessity, a broad generalization of beliefs that would not be rejected out of hand by a significant proportion of the ottawa community. However, any attempt to gage a unified, positive response on general beliefs is impossible due to the individualistic expressions of each group (and many individuals).

For more information on the gender polarization effects, see Marron (1989) for Canada, Luhrman (1986, 1989) for England, and Adler (1986) and Starhawk (1979, 1982, 1987) for the United States. 
astronomy/astrology (Aveni, 1989).

There are three main ritual expressions of the solar Sabbat cycle in the ottawa Community: Celtic, Egyptian and Greek. The Celtic form derives from the myth of the Holly king and the Oak King (Farrar and Farrar, 1981). It has been used by a number of groups in the ottawa community (e.g. Seafire, Ouroborous), but is

currently only in use by one group sabbat Date Event (Quicksilver). Yule December 21 "Death" of the

The Egyptian form, stemming from the Western Mystery tradition and Egyptian radical theology (the Ra cycle), has been used in a small number of open rituals, and is currently used by $t h e r$ o $\quad r e$ Ceremonialist inclined wiccans (e.g. Marios). There are some indications that this fora is used in the English craft communities, however, it does not appear to be a highly 
popular form (Farrar and Farrar, 1987b).

The Greek form derives its popularity from three main sources. First, it is the pantheon "of choice" of the WCC. Second, the Greek myths are fairly well known in Western society and, as such, are more comprehensible to the general public. Third, the Greek pantheon, and their mystery plays (in particular the Eleusinian Mysteries), successfully survived the shift from a rural, mono-cultural social system (i.e. Greek city states), to an urban, multi-cultural social system (the Roman Empire). Thus, it can be assumed that they will serve well in today's urban, multi-cultural environment. 230

The solar sabbat cycle is viewed, when viewed at all, in three main ways. The "Celtic" ritual form, derived from the English Gardnerian understanding, presents the solar Sabbats as part and parcel of a continuing story about the Gods. However, this story is based on perceptions that are peculiar to the British Isles, and do not translate well to ottawa.

The Egyptian ritual form, derived from the Western Mystery Traditions and radical Egyptian theology, views the solar sabbats as the life cycle of Man and God. This form is more complex than the celtic form, and draws of the four aspects of a single God (Ra). It also makes an explicit

230 This point was first brought to my attention by Tamarra James (personal communication). 
equation between a day, a year, and a life.231

The Greek ritual form appears in two main areas. First, the WCC uses a sequence of eight Sabbats that are loosely tied around the Greek mytrss. ${ }^{232}$ The presentation by the ottawa temple, however, is not uniform and consistent. Hecate's Web also uses the Greek myths for semi-public rituals. Their usage appears to be more consistent, and to be more in the line of re-creation than presentation. ${ }^{233}$

In summation, the solar sabbat cycle, in the ottawa community, is poorly developed. I suspect that the usage of the Greek ritual forms will increase, although it will be modified by concepts from the agricultural sabbat cycle.

\subsubsection{Conclusions}

The Sabbat cyrle is not an integrated, consistent series of ritual practices in the ottawa community. Conflict between ritual forms, and between theological and thealogical inter-

231 The riddle of the Sphinx is an example of the equations made by this ritual form. The first Initiatory experience in this form is the shifting of perceptions from that of one who observes the Sun, to that of one whose core is the sun. It is a specific statement about the core, the soul or spirit, of the individual.

232 Although many other myth cycles are presented by them: Egyptian, Celtic, Aztec, Germanic, etc. This use of multiple myth cycles has led more mono-cyclic wiccans to occasionally refer to the WCC as "the gods of the month club".

233 And the members of this group are more experienced than the local wCC Initiates. 
pretations will probably increase as the community grows in size. At the present time, these conflicts are held in check by the majority of Initiates and Elders who tend to share similar experiences of the Sabbats.

Recent actions of the local wCr: priesthood are likely to lead to a WCC/non-WCC split in the ottara community similar to that which happened in Toronto in 1985. However, unlike the Toronto community of 1985 , the ottawa community has certain resources to contain this division. First, is the knowledge of the split in Toronto. Second, there are a number of non-wCC groups and Initiates who are quite capable and willing to perform public rituals. Third, there are several strong, nonWCC groups and networks, which keep in fairly constant communication with wCC members. Finally, the local wCC Priesthood lacks the charisma of the Toronto Priesthood, and is incapable of maintaining a self-contained religious organization. 234

${ }^{234}$ This incapability arises from several sources. First, the uttawa Temple is a "branch plant" style operation dependant upon the home organization in Toronto for doctrine and dogma as well as initiations. Second, the high turn-over rate of attendees at the ottawa Temple makes the construction of a stable core of committed individuals difficult to achieve. Finally, the priesthood/laity split encouraged by the WCC, coupled with the local reliance upon Toronto for initiations and teachings, leads to a longer wait time between expressed interest and teachings or initiations. This increased wait time, in turn, leads to a general dissatisfaction with the ottawa Temple both in reference to Toronto based members of the WCC and to other ottawa groups. 
When we consider what this means in terms of the ottawa communities' construction of time, certain conclusions are apparent. First, experiential constructions and understandings of time will continue to flow from the non-wCC groups to the wCC. Second, while wCC ritual forms may flow to the non-wCC groups, they will be modified, integrated, and returned with new understandings. In effect, the polarity set up between the WCC (performance/faith) and the non-WCC (experience/gnosis) groups will generate a constantly changing and expanding conception of time in the ottawa community.

\subsection{Linear and Evolutionary Time}

"Myth, as a history of the soul, is still a history, and each stage of the evolution of consciousness generates its appropriate story. As the spiral of history turns, one archetypal story becomes the recapitulation of the old, the performance of the new, and the overture to what is to come." Thompson, 1981:251

"The work of an initiate, and consequently the task the aspirant has to undertake in order to prepare himself for that work, cannot be fully realized unless it be understood in connection with the process of evolution, of which it forms an integral and very vital part." (Fortune 1982:46)

The construction of time as a linear, ordered (and planned) sequence of events, stems primarily from Western (Indo-Aryan) conceptions of Fate. The two primary forms of this concept currently appear as science and Western 
Ceremonialist magic. ${ }^{235}$ And, while there are links between science and modern witchcraft, there are stronger linkages with Western ceremonialist magic. ${ }^{236}$ And it is from Western ceremonialist magic, that modern witchcraft derives most of its concepts of linear and evolutionary time.

The linkage between Western Ceremonialist magic and modern neo-pagan witchcraft has been noted by several authors (e.g. Kelly, 1991). This linkage is readily apparent in the English wiccan communities (V. Crowley, 1989), and in many American wiccan communities. It is also observable in both Montreal 237 and in Toronto. 238

However, this is not the case in the ottawa community. In ottawa, there are no functioning Lodges, and little cross training such as may be seen in England (Luhrmann, 1989) or

235 In particular, from Gnostic cosmology, and from certain radical interpretations of the Gospel of John (Pagels, 1973). More modern extrapolations of these concepts include Hegelian philosophy, Marxist political ecoromy, the cosmology of Theosophy and the spiritualist movement, and the theology of Teillard de Chardin and Matthew Fox.

236 Links between science and modern witchcraft are apparent in the attitudes of wiccans to computers (Adler, 1986:447-449; Farrar and Farrar, 1987a:154-161).

237 Links between the silver wheel and the 0.T.O., primarily in cross membership.

238 Links between both WCC and non-WCC initiates and Golden Dawn derived Lodges (e.g. Silver Sword). 
the United States (Adler, 1986). ${ }^{239}$ what little Ceremonialist influences there are in ottawa stem from books and from ceremonialist links into the Alexandrian tradition.

This situation, which may well be unique, has had a number of profound effects on the construction of Time in the Ottawa community. Unlike England and the United States, the Ottawa wiccan community has been required to develop its own, internal conceptions of linear time. And, while these conceptions derive from western Ceremonialist magic, they are being formulated and articulated by people who self identify primarily as witches, not as Magicians (i.e. Western Ceremonialist Magicians).

In order to understand the construction of Time in the Ottawa Wiccan community, we must first examine and compare the concepts of linear and evolutionary time. We must then consider how these concepts have affected the ritual praxis of the ottawa community. Finally, we must consider how these concepts affect the internal construction of witchcraft, as a religion, in ottawa.

Linear time may be defined as $T_{1}=E_{1}+E_{7} \ldots E_{n}$ : time is the summation of a "linked chain of events". Linear time is both "causal" (event $E_{1}$ leads inextricable to event $E_{2}$ ) and

239 of the ottawa Initiates, only one has an 0.T.O. initiation, and none are currently members of Lodges. 
"objective" (subject to determination by natural laws ${ }^{240}$ ). Evolutionary time may be defined as $T_{e}=E_{1}+E_{2} \ldots E_{1 a}$ : time is the summation of a linked chain of events which return to their starting point in a changed condition. Evolutionary time is both "causal" (event $E_{1}$ leads inextricable to event $E_{2}$ ), "objective" (subject to determination by natural laws: [predestination] ${ }^{241}$ ), "subjective" (subject to modification and/ or selection through individual choice, [free will]), and "purposive" (the subjective experience of time/event has both immediate and ultimate purpose and meaning).

Linear time assumes that the shortest distance between two stable event spaces $\left(E_{1}\right.$ and $\left.E_{2}\right)$ is a straight line. There is also an assumption that while $E_{1}$ and $E_{2}$ may be similar, they cannot be the same. Evolutionary time assumes that the shortest distance between two stable event spaces ( $E_{1}$ and $E_{2}$ ) is a spiral. Furthermore, it is assumed that $E_{1}$ and $E_{2}$ share at least one dimension which is equal. ${ }^{24}$ ?

240 It is these "natural laws" that sociology attempts to discover, define and codify.

241 These natural laws are metaphysical rather than sociological. They include reincarnation, "karma", and the "laws" derived from the maxims of Hermes Trismesgestus (Three Initiates, 1940).

242 In the song, Hymn to Her (Get close, the Pretenders, Meg Keene, WEA Records Ltd, Scarborough), this concept is expressed as:

She will always carry on, 
Linear time may also be considered as "pragmatic" time. If one desires an event, "X", to take place, what precursor events and/or conditions are necessary? The concept of linear time is used for three main purposes: a) actions in the material and/or social world; b) the formulation of spell crafting; and c) the formulation of "rites of passage" rituals. ${ }^{243}$

Evolutionary time may also be considered as "purposive" or "meaningful" time. If an event, "X", is taking place or will take place in the foreseeable future, then:

a) what precursor events and/or conditions have "created" it; ${ }^{244}$

b) what pattern of events is revealed by this situation; ${ }^{245}$

c) is this pattern necessary and/or desirable for and to the actors involved; ${ }^{246}$

242 (... continued)

Something is lost, something is found. They will keep on speaking Her name, Some things change, some stay the same.

243 For a discussion on "rites of passage" rituals and spell crafting techniques, see chapter 5 .

244 "How did this situation come into existence?".

245 What are the natural laws underlying the specific events and situation.

246 Does the pattern show a fault in the actors which should be corrected (personal), or is it a culmination of events that must happen for a "greater good" (social). 
d) what options are available for the resolution of this pattern. ${ }^{247}$

of the conditions listed above, a) and b) are linear time considerations; the "what" and the "how" of an event. Condition c), the "why" of the event, is based on the assumption that all events take place for a purposive reason, even if that reason is curreitly incomprehensible to the incarnate beings involved. ${ }^{248}$ condition d), the response to the perceived event, is dependant on the "why" of the evert, and with the perception of options, the time focus returns to linear time.

So far, I have presented the concepts of linear and evolutionary time as if they were static models. We should now examine how these models of time have changed over the years and how they have affected ritual praxis in the ottawa community. In order to do this, I wish to examine the concept of Initiation and how the concept of evolutionary time was

247 How can damage from the pattern be minimized, and the growth potential inherent in the pattern maximized.

268 It is important to remember that the ottawa Wiccan community, as with most religious communities, is composed of both "incarnate" members and "discarnate" members. In cases where knowledge is not available to the incarnate members, it is generally assumed that the discarnate members possess it. This may lead to a reliance on the discarnate members of the community to the detriment of action in the general social world. This tendency frequently manifests as a reliance on divination techniques which serve as a communications link between the incarnate and discarnate members of the community. 
developed and deployed in order to solve problems of initiatory access.

During the early years (pre Beltaine 1987) of the ottawa community, initiation was considered a linear time concept. If the person seeking initiation met certain qualifications (a "checklist"), then they could be fairly sure of being initiated. And, while initiation standards varied between groups, the standards were fairly uniform. These standards consisted primarily of proving to one's potential initiators that one had a) the desire to be initiated, b) a certain body of knowledge, and c) a certain range of skills. 249

The period from Beltains $\$ 937$ to the present has seen a shifting in concepts of initiation. This has been due to a number of factors. First, the corcept of initiating a person who was not part of the group appeared. ${ }^{250}$ second, the concept of cross-training between various groups (and individuals) appeared, and was reinforced by most community leaders. Third, certain individuals began to specialize in areas of occult knowledạe, and to make this specialized

249 Most of the variance between initiatory "checklists" appeared in the types of skills required. The wcc emphasized public ritual and "priesthood" skills, while most other groups emphasized "magical" skills.

250 The earliest case I can find of this was Meryddyd's initiation, oct. 19th, 1986. However, similar ones do not appear again until 1989/1990, when they become fairly common. 
knowledge available to the general community. 251

The question of extra-coven initiations raised a number of questions in turn. First, what was initiation? The initial answer to this was that extra-coven initiations were a de jure recognition of a de facto condition. In other words, the candidate for initiation had already been initiated "by the Gods". Tne "initiation" performed was merely a "confirmaticn" of an existing condition: a legalistic recognition designed to make life easier for all concerned. ${ }^{252}$

The second question raised by extra-coven initiations was "What is the candidate being initiated into?" This question became particularly acute once individual seconds ${ }^{253}$ began to be asked to initiate people. While the "recognition" aspect still played a large part in the decisions to initiate individuals, there was a growing concern with what these people were being initiated into. ${ }^{254}$

One answer was a five point checklist centering around

251 This specialization stemmed from both the concept of cross-training, and from the fracturing of the community.

252 For the initiators, the initiation would preserve the necessity of lineage based initiations. For the candidate, the legal "recognition" would make their status clearer in the community.

253 "Seconds" or "Second Degree's". The second degree is the operational degree in most Gardnerian derived systems. At second, an initiate is considered to be functionaliy able to initiate and elevate others.

256 Sekhet-Sophia, personal communication. 
the questions of "Is tnis initiation good for the individual, the community and the Brethren?"255 $A$ second answer centered around the question "Am I [the Initiator] led by the Gods to perform this initiation?"

All of these questions require the inclusion of evolutionary time in order to answer them. ${ }^{256}$ First, a pattern termed as "pre-Initiate", was recognized by most elders in the community. However, the scope of tine pattern, the number of separate "paths", was such that it was beyond inclusion in any single Tradition. At least five separate "pre-Initiate" paths have been recognized: "Priesthood", "Magician/Initiate", "Mystic", "Shaman", and "Devote". 257

However, in order to answer the questions 1 isted above,

255 "Brethren" is a term sometimes used to refer to the entire Gardnerian derived, craft movement. It does not usually include Dianics, Eclectics, and Solitaires.

256 It should be noted that these answers were not developed by the wCC, which, at present, has no initiatory power in ottawa. These answers have also been a source of tension between the non-wCC initiates in the ottawa community, and the WCC hierarchy in Toronto.

257 The "Priesthood" path refers to public service, and is concerned with public ritual and counselling. It is exemplified, in the ottawa community, by the odyssean Tradition (WCC). The "Magician/Initiate" path refers to the path of hidden service to the nation, culture, and race (see Fortune, 1982). The "Mystic" path refers to the union or joining of wills between a God/dess and Her worshipper (see Underhill, 1956). The "Shaman" path, refers to a "walker between the Worlds" and is more in keeping with Indo-Aryan versions of shamanism (Ginzburg, 1991) than with Amerind versions (Eliade, 1964). The "Devote" path is described by the sanskrit term, Bhakti. 
it is necessary that the Initiator have access to "Divine" knowledge. In short, the Initiator must be able to know whether or not they should offer, or support, an Initiation request, and whether or not they should perform it. In order to get such information, the initiator must consult with their Inner Plane contacts (Guide, Patron/ess, or God/dess). In Christian terms, they would pray for guidance.

But such requests for knowledge, presuppose the existence of a divine working or plan. For, if the Divine contact is assumed to know what should be done, then it is logical to assume that this "should" is based on a comparison with a desired goal, and that the answer will further the fulfilment of that goal. However, the choice to actuaily follow the answer is up to the individual, thus maintaining the individual's free will.

In England and in many parts of the United States, these considerations are based on individual elders operating in a Western Ceremonialist environment (Luhrmann, 1989). In Ottawa, however, the development and inclusion of evolutionary time into Wiccan cosmology comes through a wiccan framework. The framework of wicca itself has been expanded through the recognition of individual specializations, and through the prevalence of cross-training. Thus, while the source of ideas may be Western Ceremonialist (e.g. Books, inclusions in Traditions, etc.), the development is uniquely ottawan, and 
uniquely wiccan. 25

\subsection{Conclusions}

This chapter set out to examine how the neo-pagan wiccan movement, and the ottawa wiccan community in particular, construct their conceptions of time. For inherent in these constructions were the answers to certain existential questions that all religions must answer.

This examination first considered how the metaphors used to examine time (section 6.1.). This was followed by and examination of the two temporal forms that witchcraft, as a religion, inherited during its initial construction: the Esbat, or Lunar cycle (secticn 6.2.); and the Sabbat cycle(s) (section 6.3.). Finally, I examined the concepts of linear and evolutionary time that define purpose, meaning, and the nature of becoming (section 6.4.).

While the ottawa community has certainly drawn on movement wide concepts in all of their constructions of time, certain particular emphases were noted. In the sabbat cycle, I noted that the agricultural sabbats were more developed than the solar sabbat, and that this arose from local conditions. Finally, it was noted chat the absence of Western

258 For example, tr.e concept of "Spiritual Ancestors" has been elaborated fairly fully in the Web of Herodias. While the concept is also used by Dianics, it is more of an ideological statement than an Inner Plane contact. 
Ceremonialist Lodges in the ottawa community has allowed the production of certain unique understandings and articulations of evolutionary time. 
Chapter 7:

Mythic structures

"I use the term cullture for the stock of knowledge from which participants in communication supply themselves with interpretations as they come to an understanding about something in the world" Habermas, $1987: 138$

Several theoreticians have argued that language preconditions our understanding of "reality". 259 Limitations in terminology and conceptual presentation control not only how we interpret something, but also what we are able to interpret. 260 when our linguistically determined understanding is surpassed by our experiences, our "reality" is shaken. ${ }^{261}$

259 Most notably, Gusdorf (1965). Sapir (1961:6) argues that

"... language is felt to be a perfect symbolic system, in a perfectly homogeneous medium, for the handling of all references and meanings that a given culture is capable of, whether these be in the form of actual communication or in that of such ideal substitutes of communication as thinking."

While the position of language as sole definer of a given reality is indefensible, it can be safely argued that language and linguistic categories, will precondition the comprehension of a given reality. And, while these comprehensions may well change, they will involve changes in the linguistic forms as well.

260 However, this is in the form of preconditioned expectations. If descriptors of reality are relational, then language may be said to contain the relational codes of a given group.

20 inclzner termed this a "reality shock" (1968:1113). 
But the concept of culture not only includes linguistic definitions. It also contains a valuation of situations and concepts. ${ }^{262}$ And while valuations of situations and concepts may (and do) change, they are retained in the cultural stock of knowledge and are available for future generations. ${ }^{263}$

Weber (1963:52) has argued that all new religious movements start as "reform" movements. This reformation may be either a return to a "pristine state" of an existing religion or a process of continued revelation. ${ }^{264}$ Regardless of the

262 See, White (1990).

263 See, Connerton (1989). Language, as a continuing act of creation (Gusdorf, 1965:37), continually re-creates the essential relational codes of the group. These codes contain the categorical polarities that define and delimit perceptions of reality. These categorical polarities may be continually unfolded, with the consequent "creation" of new linguistic terms to describe the results of this unfolding. As Sapir notes $(1961: 6-7)$

"New cultural experiences frequently make it necessary to enlarge the resources of a language, but such enlargement is never an arbitrary addition to the materials and forms already present; it is merely a further application of principles already in use and in many cases little more than a metaphorical extension of old terms and meanings."

Cultural valuations are retained through the linkage of previous concepts to currently emotive terminology. e.g. the "nasty, old" witch. But, even had the categorical term "witch" been linked to the emotive concept "good" or "kindly", this would still demand the existence of its opposite. For an examination of the process of linkage, see Jonson (1989).

264 And, hence, the current revelation will supersede all previous revelations. While this certainly appears to account for most religions, there should be a further cateyory which (continued...) 
form involved, there is a redefinition of the basic axiological assumptions of a religious cosmology. There is also a continuity with religious conceptions of the past and, horizontally, with religious expectations for the present and hopes for the future.

This continuity is very important in the Neo-Pagan movement as a whole. Numerous "traditions" are involved in "reconstructing" the "Iost" religions of particular cultures. 265 In addition to "reconstruction" attempts, there are also numerous claims to a continuity of current traditions (e.g. Gardner, 1959; Leek, 1971), as well as invocations of mythic charters (Huson, 1970).

These claims of continuity, whether they are via mythic charters, physical continuity or "reconstruction", are readily evident in the melange of magico-mystical techniques that appear in the seminal books on Wicca. For example, Aidan Kelly's (1991) analysis of the sources for the Gardnerian Book of Shadows reveals elements from Kipling, the Goetia, the Keys

$$
264 \text { (...continued) }
$$

allows for religions that were founded either by accident (e.g. The Church of All worlds; Robert Heinlein: A Correspondence, Otter G'Zell, Green Egg, 22(89):10, Beltane, 1990) or as jokes (Adler, 1986:319).

265 For example, Tra Mycenean Tradition (Teller, 1990); Asatru (Magnus, 1992); and ADF (Bonewitz, 1990). 
of Solomon, C.G. Lelande, and Aleister Crowley. ${ }^{266}$ This melange is also apparent in the ottawa wiccan community.

A number of sources are apparent in the magical practices of members of the ottawa wiccan community. These include: Qabalah 267 Santeria 268 , Ceremonialist Magick ${ }^{269}$, "mainstream" neo-pagan witchcraft 270 , Hermeticism,

266 This melange of sources (folklore, medieval magic, Hermetic philosophy, alchemy, folk magic, and anthropology) is fairly standard for craft books. Other sources include Gnostic mythography (Huson, 1970:9-18) and Masonic Rituals (notably the initiation rituals. Compare, for example the Initiation rituals in Ronayne (1917) with those of Gardner (Kelly, 1991)). It is also apparent that classical Greek mythography is becoming closely entwined with certain parts of modern witchcraft (Crowley, 1989; Farrar and Farrar, 1987b).

267 More properly, from the Qabalistic practices evolved by ceremonialist magicians since the mid 19th century. The primary source appears to be the Hermetic order of the Golden Dawn, and the ordo Templis oriental. There is little connection with Jewish mystical Qabalism.

268 This can be traced directly to the involvement in Santeria by Tamarra James. Her influence, both in the ottawa community and via her ownership of the occult Shop, has served to validate the santerian system to a number of community members.

269 Derived from the Hermetic Order of the Golden Dawn. There is little O.T.O. influence in the ottawa community other than in published form.

270 Stemming primarily from England, although there are several American and Australian sources. Examples from England are: Farrar and Farrar, 1987a; Gardner, 1959; Valiente, 1964. From the USA: Stahawk, 1979; Morwyn, 1988. For Australia, warren-Clarke, 1987. 
Gnosticism 271 , folk magic 272 , mysticism ${ }^{273}$, as well as numerous academic disciplines. ${ }^{274}$ The syncretistic tendencies of the members of the ottawa community are heightened by the academic core of elders. The use of various techniques and data sources from numerous academic disciplines encourages a syncretistic, relational and sceptical overview of craft, and religion in general.

In addition to these specifically spiritual and magical disciplines, there are also certain mythic elements present. These mythic elements provide the foundational structure for most craft activities. They also serve to provide both a temporal linkage with religious conceptions from the past, and with religious visions of the future. ${ }^{27}$ In effect, these mythic structures are the definitional arguments within the

271 Primarily via the Nag Hamadi Library. There is little later Gnosticism (e.g. Catharism) present in the ottawa community, although it is evident in England (Huson, 1970; Kurtz, 1983 (as part of wiccan mythography]).

272 Both from published sources (e.g. Evens-Wentz, 1966) and from local folk magic traditions, primarily Québécois.

273 Primarily Buddhist, Taoist and Christian.

274 Notably Psychology, Comparative Religion, English Literature, Anthropology and Sociology

275 There are interesting parallels between wiccan beliefs and certain forms of Christian theology. These are most evident in the works of Teillhard de Chardin, and Matthew Fox. There are also strong links between the "magical movement" and the works of mythico-magical works of C.S. Lewis (Knight, 1990). 
"arena" of Western religion. 276

The three most pervasive mythic structures in the craft are a) the Quest motif 277 , b) the continuance motif, and c) the Empowerment motif. Elements of all three are present in each craft Tradition, and it is their proportions together with specific practices that appear to define traditions. Each of these motifs is present within western culture, ${ }^{278}$ and each motif appears to have continuing relevance to niodern people.

\subsection{The Quest}

Probably the best known exposition of the Quest motif is the sagas of the Quest for the Holy Grail. From the Gnostic "Hymn of the Pearl" and the early tales of cerridwen, 279 through the troviere sagas of Cretien de Trois and Wolfram von

276 The mythic structures chosen as definitional arguments serve as a gage of the validity of the movements' belonging to the stream of Western religions. This is one of the primary arguments within the Western magical movement against the importation of religious movements from the "East", that they are not part of our "Western" heritage (Fortune, 1987c).

27 See Von Franz (1980), and Jung and Von Franz (1986).

278 By this I mean that expressions of each motif are part $c$ our Western Cultural heritage. These expressions appear in tulk tales, songs, plays, mythic images, literature, etc.

279 While neither the Hymn of the Pearl, nor the early tales of Cerridwen as specifically oriented to the Holy Grail, both are considered to be precursors to the sagas of cretien de Trois (Squire, 1975). On the early tales of Cerridwen, see Rees and Rees (1961:229-230). 
Eisenbach's Parsifal, to Robin williams in The Fisher King, the Quest motif has shown its lasting power to enthral the hearts of auciences. The motif itself may well be earlier going back to Greece $e^{280}$ or Sumoria.281 It has also been inextricably entwined in western culture with Alchemy, Hermeticism, and Gnosticism. ${ }^{282}$

The Quest motif enters into modern Neo-pagan wicca via a number of routes. First, it appears in condensed form in the prose version of the "Charge of the Goddess" as follows:283

And thou who thinkest to seek me, know that thy seeking and yearning shall avail thee not unless thou know the mystery, "That if that which thou seekest thou findest not within thee, thou wilt never find it without thee," for behold; I have been with thee from the beginning, and $I$ am that

280 The Capture of Persephone. A similar Quest motif is apparent in the Odyssey of Homer. and Kramer (1983).

281 The Descent of Innana. See, for example, Wolkerstein

282 For the connections with Alchemy, see waite (1926), Mclean (1989), Thompson (1990), and Yates (1964). The Gnostic connections appear primarily through the concepts expressed in the Hymn of the Pearl and through the close connections between the troviere and the Gnostic cathar movement in Provence. The Hermetic connection stems from early Gnostic/Hermetic interchange (1st-3rd century) and later (14th-17th century) Hermetic/Alchemical interchanges. For more information, see Atwood (1960). Also, there are certain characteristics of the Social Justice movement in Canada that parallel the Quest motif; most notably the equation of social injustice with "evil" which the proponents of social justice must overcome in order to save the "Land" (see, for example, Klassen, 1977).

283 The prose version of the Charge of the Goddess was composed by Doreen Valiente in 1954 (Valiente, 1989:60-62). 
which is attained at the end of desire. ${ }^{284}$

The focus of the quest, then, is inside the individual. This internal focus is also apparent in mystical alchemy, where the process of turning base metals to gold is seen as a metaphor for the purification and refinement of the soul. However, unlike alchemy, the terrain of the quest is the internal "fantasy world" of the individual as expressed in mythic imaginings. ${ }^{285}$ This internal, "fantastic", focus is also apparent in the modifications made by practitioners in externally oriented systems such as the Qabalah. ${ }^{286}$

A second example of the Quest motif in Neo-pagan Wicca appears in the Legend of the Descent of the Goddess (Farrar and Farrar 1984:29-30). This mystery play appears only in 2nd Degree initiations, and may be seen as the external, mythic

284 From Kelly (1991:115), italics in the original. Kelly has traced this quotation to the title page of an obscure book in Gerald Gardner's library (Magnetic Magic, by L.A. Cahagnet, privately printed, 1898; 47 pages paper bound) where the provenance is given as "Alipilli".

285 The use of internal mythical images, and the construction of and navigation in internal "fantasy worlds", is evident in a number of ways. First, there is the concept of "pathworking" elaborated on by a number of authors (e.g. Ashcroft-Novicki, 1990). Second, there is the use of guided meditation in shared "fantasy worlds" (e.g. Mathews and Mathews, 1990). Third, there is the conscious "naming" of parts of the subconscious (and hence of the "fantasy world") for the purpose of "unification" and/or "purification" (e.g. Tyson, 1988; Starhawk, 1979).

286 See, for example, Tyson (1988) and Kraig (1988). 
rendering of an internal change which takes place in the Initiate. The exact sources for this "Legend" are unclear. There is some similarity between it and both the Descent of Innana (Wolkerstein and Kramer, 1983), and the Legerd of Persephone and Hades. However, there are key morphological differences between the Legend of the descent of the Goddess and the other two legends. These differences are the source of an ongoing debate within the ottawa community.

Vivianne Crowley (1989:212-213), a Jungian influenced Psychologist and Wiccan High Priestess, describes the message of the Legend of the Descent of the Goddess as follows:

"In descending to the Underworld the Goddess enters the realm of death, but she does not die. Although she loves and becomes one with Death, and thus overcomes any fear of him, she is also given back the symbol of life, the necklace of rebirth, for her place is not to remain in the Underworld, but to return to the world above bearing with her the necklace symbolic of the knowledge of which she has gained."

This emphasis to "return to the world" is very much in keeping with Western forms of mystical Quests. ${ }^{287}$ The purpose of the Quest is to achieve a specific goal in the material (social) world. And this goal is seen as achieving a step

287 This emphasis is in stark contrast with certain eastern mystica? craditions where the emphasis is to leave the "illusion", maya, that is the material (social) world. 
forward in a divine plan. ${ }^{288}$ For example, in the earliest form of the Charge of the Goddess (Leland, 1990:6-7), Aradia, Queen of the Witches, tells her servants

"... She who fain would learn all sorcery yet has not won its deepest secrets, them my mother [Diana] will teach her, in truth all things yet unknown.... this shall last until the last of your oppressors shall be dead;"

And, while this last line has disappeared from the Charge of the Goddess (post 1954), its spirit has been kept through the adaptation of certain Western Mystery Tradition ideals. Most notably through the concept of the "Inner Temple" and the extension of the concept of "Lodge continuity" to coven practice. 289

288 Once again the similarities between the social justice movement in Canada, and the "Quest" motif are apparent. The "Quest" becomes focused on the "Land" and its people. This form is in stark contrast to the United states Craft movement which is rapidly becoming politicized to "causes", where the cause becomes the focal point. It is also interesting to note that there are a number of philosophical similarities between a significant fraction of the ottawa craft community, and the radical theology of Peter Morin and Dorothy Day (The Catholic Worker).

289 The concept of the "Inner Temple" postulates that the "true" core of a group is on the "Inner Planes". In other words, it is not part of the material world. The principle of "Lodge continuity" refers to the passing on, on the Inner planes, of the teachings, knowledge and guidance from this Inner Temple. There is no requirement that physical teachings take place. For more on these concepts, see Fortune, 1987c 


\subsection{Continuance}

This brings us to the continuance motif. In its earlier forms, continuance appeared as British nationalism. When Gardner and his associates first started to produce modern "mainstream" witchcraft, they drew heavily on the theories of Margaret Murray, which emphasised the connection between witches and the Land (Nation). ${ }^{200}$ Continuity was provided not only through the (false) belief that Gardner's group was a physical continuance of Medieval witches, 291 but also through the grafting on and interpretive ordering of folkloric

290 This assumes that the Witchcraft assembled by Gerald Gardner was not a survival of the "Old Religion". Kelly (1991) offers a fairly detailed reconstruction of Gardners' development of modern Wicca. The connection with the now discredited Murryite thesis is readily apparent in the introduction to Gardners'(1954) Witchcraft Today by Dr. Murray, the copresentation of papers by Murray (1955) and Gardner (1955). Evidence for an earlier acquaintanceship between Murray and Gardner appears in an Article by Gardner (1939) in which he claims that certain artifacts in his possession were examined by Murray.

291 There do appear to be several groups which have a continuity going back at least several hundred years, but their ritual practice and beliefs are at variance with Gardners' reconstruction. (personal communication from Khaled and others). The specific items that vary with Gardnerian derived practice differ with each group. One group of covens around Exeter draws heavily on Western Ceremonialist traditions (pre Hermetic Order of the Golden Dawn), while one group on the Devon/somerset border appears to practice folk magic exclusively (see Ryall, 1989) and bear a resemblance to the Ozark witches (Randolph, 1947). For other examples, see Kelly, 1991:21-26. 
events. 292 with the end of World War II, this nationalistic fervour appears to have shifted more towards the Land (i.e. ecological considerations) and historical continuity. ${ }^{293}$

The period of the $1960^{\prime}$ s brought about a large expansion in the spread of the craft. In Britain, the actions of Alex Sanders, coupled with a great interest from the tabloid press, combined to spread "information" about witchcraft throughout the nation. ${ }^{294}$ In the United states, Gardnerian derived witchcraft met with the youth counter culture and fragmented into dozens of "Traditions". 295 It was also in the United States that Feminism "discovered" Wicca. This discovery led to the creation of "Dianic" Witchcraft. 296

continuity in these newer traditions was through a

292 A similar grafting and ordering can be seen in the rise of Weish nationalism in the 18 th and 19 th centuries (Morgan, 1983).

293 See, for example, the mythologizing of the Grand Sabbat of Lammas (August 1) 1940 (Kurtz, 1983), and the continuing interest in the character of Drake (Kurt2, 1983; Luhrman, 1989).

294 For a biased account of Sander's actions, see Sanders, 1976 and Johns, 1969. For a more objective, albeit briefer, account see Valiente, 1989:163-177.

295 The number of "Traditions" operating in the USA is impossible to determine with any exactitude, and new ones appear almost very month. Their size may range from a couple of dozen up to several thousand.

296 Dianic witchcraft derives primarily from feminist thealogy. It is a separate development from Gardnerian derived witchcraft, and there is little overall similarity between the two (Jade, 1991). 
resonance with personal empowerment, and questing through the ages. 297 This "resonance" allows individuals to feel that they are part of a continuing tradition of empowerment. ${ }^{298}$ It is the individualists counterpart to the continuance via the Land.

As Wicca continued to develop in the United States, it stagnated in England. ${ }^{299}$ In Canada, Wicca developed along different lines. Major centres of craft activity appeared in Toronto and Victoria/Vancouver in the late 1960's and early 1970's. These centres were primarily Alexandrian, although there appears to be some evidence :or the spread of certain Famtrad ideas and 1 ines. 300

297 The primary exception to this is Dianic witchcraft which draws its continuity from feminist reconstruction of history. This situation probably arises frum the academic roots of Dianic Craft (e.g. Mary Daly). While there are early connections between Dianic Craft and Gardnerian Craft (e.g. Z . Budapest), continuance derives from Women centered Herstory (Jade, 1991).

298 And also a continuing tradition of martyrdom ie.g. the rabidly anti-christian polemics of the edrly Gardnerian iaws). It should also be noted that several of the figures who are touted as historical precursors died horribly (e.g. Joan of Arc). There are also interesting parallels draw between the historical persecution of witches and the persecution of homosexuals (see Evans, 1978).

299 This situation is slowly changing with the development of the Pagan federation, and with the importation of North American craft ideas.

300 The term "Famtrad" derives from "(Fam)ily (Trad)ition". It refers to individuals from families with a historic connection to earlier forms of witchcraft. A number (continued...) 
Indigenous Traditions have arisen in a number of Canadian centres.301 These indigenous traditions are frequently blendings ("creolizations") of Gardnerian derived Wicca with either Ceremonialist magic (e.g. the silver wheel, Alexandrian), classical mystery religions (e.g. the odysseans), or non-Christian mysticism (Merydian, Web of Herodias). 302

Continuity for these traditions arises out of a belief in the continuity of the "mysteries" held by the tradition. In other words out of the gnostic experiences provided by the tradition. And this continuity is a major source of the validation for each group.

This form of continuity, the continuity of a "mystery", j.s present in the charge of the Goddess in most of its forms. And, while the Charge is not a universal piece of liturgy, it is probably the closest that modern wicca comes to a "scripture" or creed. Consider the passage previously quoted

$$
{ }^{300} \text { (....continued) }
$$

of Fantrads have become involved in Gardnerian derived witchcraft, although there are always questions as to the authenticity of these "family traditions".

301 For example, the odyssean Tradition in Toronto, the Merydians and Web of Herodias in Ottawa, and the silver Wheel in Montreal.

302 While this derivation is a simplification, it serves to provide a general idea of the sources of certain canadian traditions. The actual beliefs of each group vary righiy, as do their practices, and each makes frequent use of the other groups'sources (mainly mystery plays and meditational forms). 
And thou who thinkest to seok me, know that thy seeking and yearning shall avail thee not unless thou know the mystery, "That if that which thou seekest thou findest not within thee, thou wilt never find it without thee," for behold; I have been witr thee from the beginning, and I am that which is attained at the end of desire.

The openly stated mystery (in italics) is only the external mystery. It is the mystery which allows the resonance between a modern individual and their "historical" (mythic/ archetypal) counterpart. The mystery drawn on by many of the traditions operating in the ottawa community is summed up in the last sentence: "I have been with thee from the beginning, and I am that which is attained at the end of desire."303 This mystery acts as the "ground of being" for further action. It also serves to tie the modern practitioner closer to all previous practitioners (real or hypothesized), regardless of their tradition. 304

In addition, this mystery provides an trans-tempore locus

303 It should be noted that the odyssean tradition does not use the charge of the Goddess, at least in their public rituals. Nor do they use the ritual of Drawing Down the Moon which incorporates the Charge. Their public rituals are almost exclusively mystery plays and working rituals.

304 This specifically includes Christian mystics and magicians. By its very nature in much of North America, the Craft is essentially a monotheistic polytheism based on the beliefs in an infinity of "Truths" all leading to the same ultimately knowable, but presently incomprehensible, Truth. Thus the Gods and Goddesses of the craft are both absolutely "real" and also merely facets of the Divine. See, for example, Lipp (1990). 
from which action and being spring, and to which they return. ${ }^{305}$ The speaker (the Goddess or Lady) speaks from a space that contains all time and is all time (the ground of being), through a chosen vehicle (the Priestess), within a space that is a threshold to all times (the circle) ${ }^{306}$, to a chosen people (the coveners ${ }^{307}$ ) who operate in a space bound by time (the world). The continuity provided by this mystery is that of being a part of the flow from the ground of being, through the material world, and back again; the continuity of a cycle of beingness and action. ${ }^{308}$

It is quite probable that one of the major sources of conflict in the ottawa community stems from the lack of use of the Charge of the Goddess (and the associated ritual of Drawing Down the Moon) by the WCC. Not only is the ritual not

305 It may also be the source of one of the epithets of the Goddess, "the Womb and the Tomb".

306 on the nature of the circle as a gate to all time, see Farra: and Farrar, 1981.

307 The more traditionally minded Gardnerian derived wiccans sometimes refer to themselves as the "secret children of the Goddess". This term derives fror craft Law (see footnote \# on the origin of the craft "Laws") \#78, which reads as follows:

Ever remember that ye are the hidden children of the Goddess so never do anything tc disgrace them or Her.

308 The concept of cycies is highly important in Gardnerian derived craft. Its importance, at an exoteric level, may be seen in the wheel of the Year, the cyclical celebrations of the Sabbats (see Farrar and Farrar, 1981). 
used in their public cirzles (except by non-Odysseans), it has also been referred to as a "museum piece" by a number of their Initiates. This lack of use only serves to push the attendants at a wCC open ritual further away from the Goddess, and to impose a layer of "priesthood" between the circle member and the divine. 309

\subsection{Empowerment}

The final motif under consideration is empowerment. Of all three motifs examined, this is the most problematic for the Neo-pagan movement. "Empowerment", as a concept, deals with the gaining of "power". However, exactly what power is is considered problematic. The questions surrounding power come from a) its source, b) its locus, c) its form, and (1) its limits.

Starhawk (1982), in her analysis on power, divides it into three main forms: power over, power to, and power with. Power over is the ability to create and enforce a definition of reality (and hence possible action and meaning) on others. Power to is the ability to internally create definitions of reality which allow the individual to modify their own realities. Power with is the ability of a group to cooperate in the mutual redefinition of their realities. The process

309 This is in direct opposition to the "priesthood of all believers" thealogy expressed in Gardnerian derived wicca. 
whereby an individual gains these powers i; "empowerment".

In many traditions, the source of power (of any type) is the individual acting in concert with the cycle or flow. 310 Individuals may also act in accord with others towards the same goal, with the group acting as the locus of power. Also, what is drawn on is not the full ground of being. Frequently, the source is a facet of the ground of being (e.g. a deity, a "force", etc.). The individual, or group, "taps into" a particular force or draws on personal relationships with a "divine being". The "power" from this conjunction is then "patterned" and "directed" by the individual towards the desired goal.

The ability to tap into a facet of the ground of being is dependant on the technology available to the individual and/or group. This technology is composed of

* collections of physiological manipulative techniques (e.g. dance, chant, etc.), and

* correspondence systems designed to symbolicly manipulate, and make intelligible, the mental and emotional states produced by the physiological techniques.

Each technology comes with its own forms, conditioned by the correspondence systems of the given technology. And each technology also contains a series of preset limits on its

310 See chapter 6. This view of the source of power is similar to the Taoist concept of power. 
effectiveness. Finally, each technology contains environmental limits deriving from the natural laws it invokes. ${ }^{311}$ and, furthermore, each technology includes moral constraints on its use. 312

I stated earlier that the concept of empowerment was problematic to Neo-pagan Wicca. This concern derives, in part, from the conflicting moral constraints of the various technologies employed by members of the movement. ${ }^{313}$ Another source of conflict is the ethical limits of the use of magic. The primary ethical statement in the craft, known as the

311 Magical practitioners firmly believe that "magic" is the manipulation of poorly understood natural laws. The primary difference, subjectively, between a practitioner of folk magic ("low magic"), and a magician ("high magic") is the degree to which they attempt to comprehend these same natural laws. In contrast to this, mystics are viewed as apprehending, rather than comprehendir:, natural laws. These distinctions bare little relationship to the anthropological concepts of "sorcery" and "witchcraft" (Evans-.Pritchard, 1976; Malinowski, 1954). This appears to be due to the assumption of the nonexistence of supra-physical reality. The assumption of the existence of supra-physical reality is, however, the basis of magic, mystical relizion, and many branches of physics.

312 This is true even of such "amoral" magical technologies as "positive thinking". In most cases, each natural law will include constraints and/or descriptions of what happens if that law is broken. Where these are not stated, they may frequently te inferred by reversing tne understanding of the natural law.

313 For example, folk magic money drawing spells conflict with many Ceremonialist systems, as do the use of most rituals involving sex (e.g. the Great Rite, Farrar and Farrar, 1981). However, these conflicts are resolved through the partitioning of areas of use. The theoretical work necessary to produce unified systems has, instead of producing a single dominant system, produced a relativistic view of all systems. 
Wiccan Rede, is "an it harm none, do what ye will" (Farrar and Farrar, 1984:135-144).

However, the wiccan Rede is not a simple injunction. Continual debate and discussion has complexified it, as has the addition of numerous other concepts (e.g. Karma). Debates continue over the meaning of "harm" and "will". While many craft practitioners take the Rede to be a personal operating code, ${ }^{314}$ others (such as starhawk, 1987) take it to be a call to political action. ${ }^{315}$ still others take it to be a statement of the operational realities of the world. ${ }^{316}$

314 Usually this is combined with a fairly refined understandirig, either conscious or intuitive, of the concept of karma. It is also usually found amongst people who have more understanding of ceremonialist magical systems. When the Rede fails, as in there are no actions that cannot produce harm, the practitioner can still fall back on the existence of a divine plan which requires harm (although every possible alternative must be examined first).

315 This "action" is usually action in the social world, and is typified by starhawks' spell casting against nuclear power (Starhawk, 1987). The Rede is usually combined with "politically correct" attitudes and causes. This "political correctness" appears to be more and more a hallmark of the American craft movement. As a contrast, there is only a single Canadian group (Pagans for Peace) which is heavily political, and their call to action takes the form of a request for aid, rather than a call for jihad.

316 In other words, some believe that any attempt to cause harm will be stopped by an outside agency. This belief is frequently used as a "safety clause" in spells (Weinstein, 1980, 1986). Thus, if a spell fails, the spell caster is free to believe that a "higher power" intervened because the spell would have caused "harm". This interpretation is very useful in shifting responsibility for an action away from the actor. It also leads into a "blame the victim" understanding of harmful events, and to a dissolution of the concept of evil. 
Empowerment, as a motif, deals with the gained ability to change reality in accordance with will. 317 This definition of empowerment is also Crowley's definition of Magick (1983:27). "Magic [or power] is the Art and science of causing change in conformity with will." The ability is, frequently, gained through the medium of a Quest and, sometimes, through the intervention of a God. ${ }^{318}$ And the question of how such power is used is one of the main debates amongst the wiccan movement.

At its simplest. level, the debate over the use of power may be expressed as a conflict over what circumstances justify its use. The "sides" in the debate break down into four main camps, namely

* Radical individualists who believe that power should be used solely for the benefit, and at the discretion, of the holder of that power. 319

317 When I say "gained", I am including the belief that the ability "gained" may be inherent in the individual. In this case, the person empowered gains a recognition of their inherent ability, rather than the ability itself. This form of empowerment is by far the most common form, at least amongst the elders of the ottawa community.

318 This form of empowerment is much more common in other religions. For example, Moses was empowered in this fashion by YHWH (EX 3). There are, however, instances of divine empowerment in the craft. These frequently take the form of "gifts" rather than the goal oriented empowering of prophets.

319 Extreme examples of this belief would be Anton Lavey (LaVey, 1970) and Michael Aquino. This belief is frequently considered to be evil and is generally referred to as "The Left Hand Path" (Fortune, 1987c:70-73). 
* Political activists who believe that power may be legitimately used to further a given cause. 320

* Moderates who believe that numerous craft technologies should remain hidden, but who believe that magic may, given certain circumstance, be used for limited personal gain. 321

* Traditionalists who argue that the use of magic must be kept secret and carefully guarded from misuse. Magic must never be used for personal gain, only to further the purposes of the Tradition and to help others. ${ }^{322}$

Further, the debate has been polarized in its consideration of which forms of power one is discussing. The main division is along the axis of "economic power" verses "magical power". ${ }^{323}$ By this division, a definitional dividing line has been drawn between the social world and the sacred

320 Starhawk and many other "politically correct" members of the wiccan movement in the United states fit into this category as do Pagans for Peace and many Dianic groups.

321 This category includes most of the elders in the ottawa community. The general consensus is that the use of magic is always a viable option, but should not be the first one considered, unless one is dealing with a magical problem. This consensus is not echoed by a large portion of the nonInitiate community (primarily those around the wCC) where magic is seen as a first resort for many actions.

322 This attitude is most readily apparent in the Ceremonialist Lodges and in the most Traditional Gardnerian covens (e.g. Fortune, 1987c). Few members of the ottawa community subscribe to it.

323 However, if magick is, as Crowley (1983:27) argued, "the Science and Art of causing Change to occur in conformity with will", then money (and other forms of economic power) are undoubtediy "magical". For an examination of this argument, see Tambiah (1990:80). 
world. In effect, the two are to be considered as separate, a view which is in direct conflict with one of the primary axiological assumptions of the Craft (i.e. the Unity of All).

The most visible form of this debate centres around the "question of paying for the craft". This question takes a number of forms with the question of a paid priesthood and charging for craft teaching being the most prominent.

The debate centres around a perceived conflict between Craft "Law" and "pragmatic realities".324 And, while the Craft "Laws" have little direct influence on non-Gardnerian derived practitioners, they have a large amount of indirect influence due to their early dissemination. The question of receiving payment for the practice of the craft is covered by Laws \#119 and \#120, which state:

[119] Never accept money for the use of the art, for money ever smeareth the taker. 'Tis sorcerers and conjurers and the priests of the Christians who ever accept money for the use of their arts. And they sell pardons to let men escape from their sins. [120] Be not as these. If you accept no money, you will be free from temptation to use the art for evil causes.

This argument is based on two main points. First, that

324 The "Laws of the craft" have appeared in a number of different publications. For an eye witness examination of where and when they appeared, see valiente (1989:70-72). The version I quote from is from a publicly available set of Laws from a "Generic Gardneroid BoSH", available on Pandora's Box. It was compiled by sekhet Sophia. 
money serves as a spiritual "temptation". Second, the falling to this temptation is seen as the hallmark of certain despised groups ("...sorcerers and conjurers and the priests of the Christians..."). The final sentence of law \#120 makes a causal connection between accepting money for the art, and using the art for "evil causes". While this argument appears to have a certain validity, 325 it does not account for other "temptations" that may cause one "... to use the art for evil causes. 1326

The counter argument, put forward by a number of "Big Name Pagans" (e.g. Isaac Bonewitz ${ }^{327}$ ), is that a community should feel ethically bound to financially support its priesthood. These speakers have used their influence and prestige in the wiccan movement to "professionalize" the practice of witchcraft and the role of "priest/ess" in neopagan religions. In effect, a number of movement intellectuals have decided that they should be paid for being movement

325 Especially in light of the PTL scandals of 1988 .

326 For examinations of different temptations in occult practice, see Fortune $(1976,1978)$ and Timlett (1974, 1976, 1977). Probably the best examination of temptations to the occultist (and mystic) is "The Cisud of Unknowing" (Underhill, 1956).

327 Isaac Bonewitz is the well know, highly outspoken, founder and "guru" of Ar nDraiccht fein, a neopagan, druid organization. He has expounded tis views on the desirability of a paid priesthood at a nunber of seminars at neopagan festivals (e.g. Wic-Can Fest and starwood). For more on ADF, see Adler (1986:325-328). 
intellectuals.

The "paid priesthood" argument has already gained some official recognition in the ottawa community. A sign on the Occult Shop bulletin board, which presents a financial breakdown of the cost of a wCC open ritual, incluies the following item:

"Childcare for $X \quad \$ 15.00$ (approximately, based on time for preparing as well as conducting the ritual) 328

While the WCC Ottawa Temple does not charge a fee for their Sunday evening open rituals, the fact that "childcare" is an accountable item is revealing. The costing of childcare had previously been refused by the wCC ottawa Temple steering committee. 329

328 This document is entitled "SO YOU WANT TO HAVE A PRIVATE RITUAL..." It concludes with the following "Note from your steering committee":

"Previously, most of the charges incurred in the performance of private rituals have been borne by the priesthood. However, this places a burden on the priestess and priest who serve us with such dedication. We would appreciate it if those asking for private rituals would take responsibility for meeting the expenses involved."

While the specific reference is to private rituals, the implication is a) to the cost of all rituals, and b) the priesthood are "professionals" who should be paid for their work.

329 The stated reason for refusing the costing of
babysitting was the ethical consideration that this would
entail "charging for the use of the art". The current costing
(continued...) 
7.4. Conclusions

In the previous sections (7.i. to 7.3.) I have attempted to show how the modern neo-pagan wiccan movenent, and the ottawa community in particular, draws on western mythicoreligious structures. These mythic structures are the "arguments" in a definitional debate. The debate resolution may be stated as

"resolved: that neo-pagan witchcraft is a religion
in the western stream of religions."

The arena in which this debate takes place is not in the "world of contemporaries", but rather in the Vorwelt of Western culture. ${ }^{330}$ The primary argument is the attempt to show continuity with the stream of Western religious thought. The prime exemplar in this argument is not scripture, but rather the mythic cycle of Quest and empowerment (as opposed to structure, doctrine, and dogma).

The primary argument technique is "gnostic", in that proof is experiential, rather than logical or rational. And

329 ( . . continued)

of childcare was agreed to by the High Priestess of the WCC (Tamarra James) (personal communication from Morwen).

330 I have borrowed schutz's terminology here to describe the culturo-temporal location of the definitional arena. possibly a more accurate description would be to say that the arena is in the collective unconscious of current western culture, the cultural "groupmind".. However, it is important to note that the debate includes not only those alive, but those who are dead as well (e.g. Church Fathers, Biblical authors, burned witches, dead academics, etc.). 
the primary technique of this argument is the use of magical and/or mystical technologies which allow individuals to experience the "reality" that supports these truth claims.

Given this a.gument technique, other arguments of continuity (lineage, physical continuity, etc.) are merely auxiliary, designed to ease the way into the primary gnostic argument. They are, in the words of Ignatious Loyola, a "composition of place" wherein the inner "truths" may be accessed. 
Chapter 8:

Towards a Theory of Institutionalization

The sciences that would interpret and explain human action and thought must begin with a description of the foundational structures of what is prescientific, the reality which seems self-evident to men remaining within the natural attitude. This reality is the everyday life-world. It is the province of reality in which man continuously participates in ways which are at once inevitable and patterned."

Schutz and Luckmann, 1973:3

The purpose of this chapter is to bring together the various strands that have composed my analysis of the ottawa wiccan community. In chapters $2,3,4$, and 5 I examined the roles and effects of various definitional arenas within the ottawa community. Chapters 6 and 7 concentrated on the links between the broader wiccan movement, Western religious culture in general, and the ottawa community. The time has come to tie these together into a broader theoretical picture.

First, it is necessary to examine role and effects of differing epistemologies. This is done in order to determine how truth claims are judged (section 8.1). Second, I will consider the role played by institutions in our society (section 8.2). This is followed by an examination of the socio-cultural web of "reality" (section 8.3.). Fourth, I will examine the broad definitional environments within the web of 

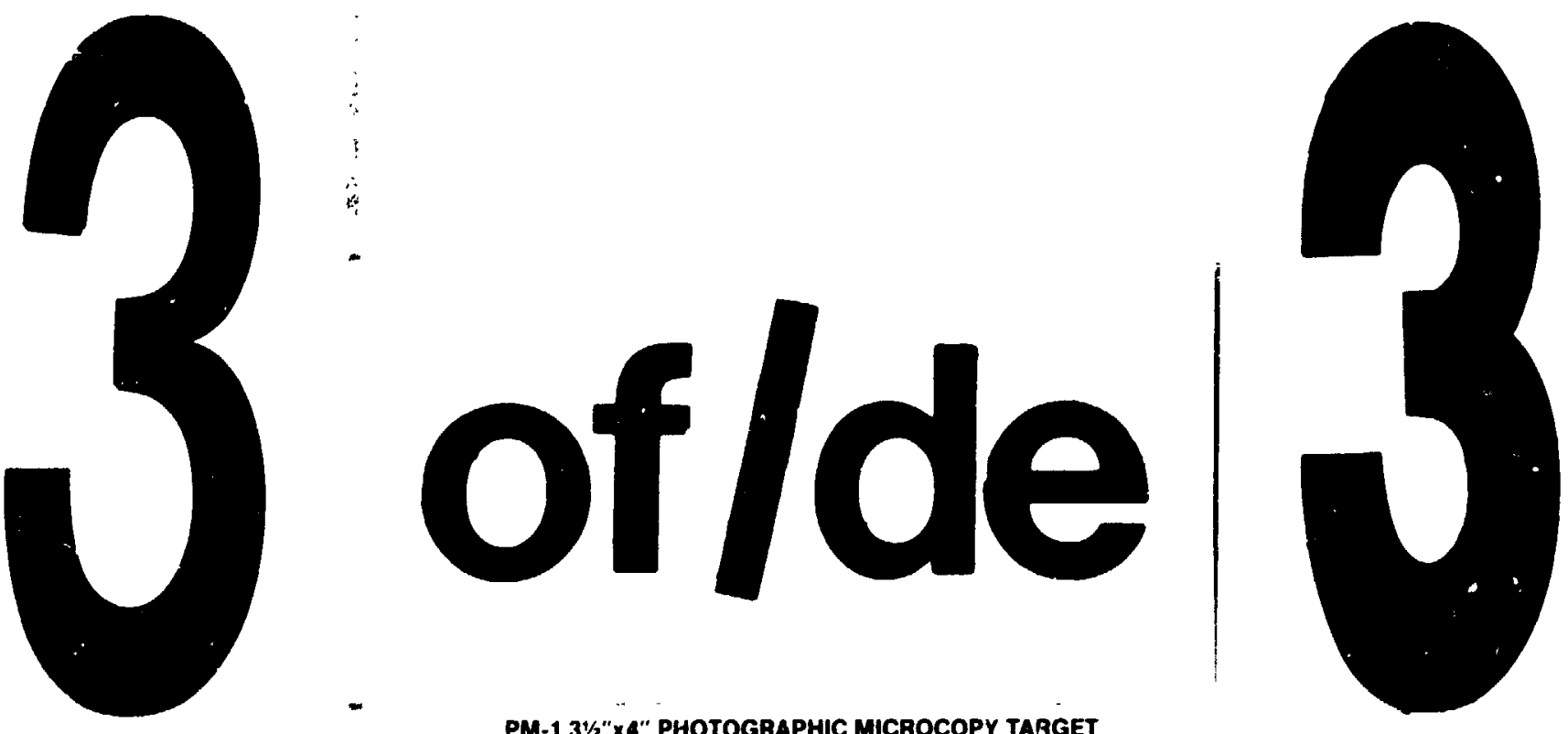

PM-1 31/2" $\times 4 "$ PHOTOGRAPHIC MICROCOPY TARGET NBS 1010a ANSI/ISO \#2 EQUIVALENT

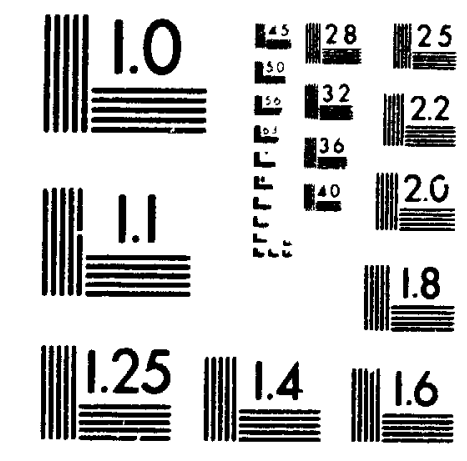

PRECISIONSM RESOLUTION TARGETS

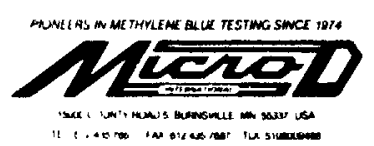


a model of several of the "natural laws" for the social world. And, while lt is impossible so construct similar models for the other three worlds due to space restrictions, it is desirable to consider the bases of each of them. Figure 8.1 shows the primary forms of epistemology for each of the four worlds.

In the social world, the main forms are Doctrine, Debate, and Definition". In the Material world, the primary forms are "Pragmatism and Functionality". In essence, the primary judge of a truth claim is functionality, "Does it work?". And the question "How do we know what we know?" is answered with "We know what we know because it works." The primary mode of action within the Material world is technology: the physical manipulation of the physical.

For neo-pagan witches, the primary forms of technology are magic and ritual. And the testing of the efficacy of magic and rituals is an ongoing affair. This appears to be a movement wide trait appearing in the l'nited states (Adler, 1986), the UK (Luhrmann, 1989), Australia (Warren-clarke, 1987), and Canada (Marron, 1989). And, while there is some tension between "traditional spell forms" 331 and syncretic

331 A "traditional spell form" would be a spell or ritual that has been recorded in the past, either in a grimoire or in a Book of Shadows (Farrar and Farrar, 1984, 1990). 
spell forms ${ }^{332}$, the general attitude, at least in the ottawa community, can be summed up in a current truism: "If it works, use it. If it doesn't, then pitch it."

Magic, as a technology, is becoming more popular in general society. ${ }^{333}$ However, as with all technologies, the general public usually has a very different idea from the professional of the capabilities, and limitations, of the technology. A similar state of incomprehension can be seen in current popular understandings of science.

In the psychological world, the primary forms are "intuition" and "lived reality".334 The term "intuition"

332 A "syncretic spell form" is a spell that is concocted from first principles and tailored to meet a specific situation. It relies on an invocation of "natural laws" (Farrar and Farrar, 1990).

333 This can be seen in, amongst other things, the rise of the self-help movement (e.g. Norman Vincent Peale). Other forms of magical thinking are apparent in the construction of group mind symbols and rituals (e.g. Nazi rituals), the development of advertising techniques (Tambiah, 1990), and the general use of talismans (e.g charms on charm bracelets, Italian "horns", st. Christopher medals, etc.; Skelton, 1991).

334 I have drawn heavily on the theoretical psychology of Ken Wilber (1977, 1983) and Carl Jung (e.g. 1953), and to a more limited degree on the neuro-anthropological ideas of Webber (1980), Webber and Laughlin (1979), Shearer, Laughlin and McManus (1983) (primarily on their concepts of "symbolic penetration" and for the links between neuro-biology and psyco-sensory experience). In addition, a number of concepts derive from Gregory Bateson (1991), Gareth Knight (1978, 1991), and Dion Fortune $(1957,1978,1985)$. It should also be noted that when I speak of the "psychological world", I am 
refers to the deep seated urgings of the unconscious. The term "lived reality" refers to the daily "patterns of action" created in the mind, the "sub-conscious". 335 In answer to the question, "how do we know what we know?", there are two answers. First, the answer from intuition is "I don't, but I have a hunch." It is a knowing, without knowing why we know. The second answer is "I know, because I perceive." It is knowing that flows through the senses and is interpreted by the recognition patterns in the subconscious. ${ }^{336}$

Modern neo-pagan Wicca, and the entire magical movement, have close ties with certain branches of psychology, mainly with the various psycho-analytic schools. 337 Historically, this arose from the cross-over interest between psychology and the occult, primarily via the Jungian school.

334 (...continued)

referring to the "software" of the mind, rather than the "hardware", although the two are linked.

335 If one were to use a computer analogy, then "intuition" would be the operating system and "lived reality" would be the individual programs. To carry the analogy further, the "hardware" would be the neuronal connections, neurotransmitters and bio-sensory interfaces. In addition, each symbolic language may be viewed as a programming language.

336 For a discussion of the::e patterns, see $c$. Thompson (1959), Friedman (1959) and Rado (1959). More general information can be found in the studies of behaviour reconstruction (e.g. Walker and Heyns, 1962).

337 For example, see Fortune, 1978, 1985; Crowley, 1989. 
In parts of the ottawa community, this linkage has been taken to an extreme where the community is viewed as a psychoanalytic forum (see section 3.3. ). This is most readily apparent in the expectational views of a number of newcomers to the community about the meaning of "priesthood". And these views are supported, in action if not in ideal, by the local priesthood of the wCC. In effect, the role of "priest/ess" becomes that of psycho-therapeutic counsellor.

In contrast, the less public groups and individuals tend more towards an emphasis on internal psychological development as a necessary process in spiritual evolution. Gareth Knight(1978:262), a well known British or zultist, describes this process as follows:

"This much can be said in general though, if particulars must be avoided: a student goes through a series of ritual dramas in which he is the main protagonis:. These rituals are a portrayal in colour, form and speech of an integration symbol, to use the Jungian cerminology. He is thus led onward, in the course of several years, through a carefully graded pathway of the soul, until, if he be found worthy, he is sufficiently integ ated and skilled in mental and emotional control to go on to psychical pioneering work and the help of others."

In the first, "public priesthood", model, the primary form of knowing is from perception. The pressures of constant attention to the needs of others often do not allow the individual the time necessary to complete their own, internal, 
integration. This may well account for the constant "burn-out" of peopie involved in this role. ${ }^{338}$

The second, "Lodge" or "Mystery", model is based on a combination of knowing via intuition, and by perception. Intuition and perception are seen as the twin "gates" that give access to the Inner planes. ${ }^{339}$ However, few groups in the ottawa community have a full set of ritual dramas that they can work with, and there is a fairly constant shifting around between mythic dramas. The primary exception to this is the Gardnerian derived dramas (Crowley, 1989). However, their effectiveness has become limited due to their wide dissemination.

Another factor influencing the lack of mythic drama cycles, is the lack of any functioning Lodges in contact with the ottawa community. This situation stands in stark contrast to England, where there is a very heavy connection (Luhrmann, 1989). Similar connections are apparent in the United States (Adler, 1986), Montreal and, to a more limited degree,

338 The "burn-out" of people in the role of public priesthood is an easily observed situation. Institutional protections have not, on the whole, been successfully deployed to insulate the individuals (e.g. payment for services, retreats, specialized training, etc.).

339 This intuition or knowing comes through the "Gate of Horn" and the "Gate of Ivory". See, Butler (1979). 
Toronto. 340 contact with Lodge ideals and concepts, in the ottawa community, is almost entirely through books. ${ }^{349}$

The question of the psychological motivation of people joining the craft is completely separate. Preliminary research appears to indicate a number of factors including

* a search for "magic" in the sense of "wonder" or "enchantment" (Adler, 1986)

* a search for the female as divine (Adler, 1986; Jade, 1991)

* a quest for personal power in the material and social worlds.

There also appears to be a fairly strong correlation between early childhood abuse and entry into the craft, however any definitive statement must await further research. 362

In the spiritual world, at least in western religicus conceptions of it, the two primary forms of knowing are

340 The "Silver Sword" Lodge (O.T.O. and Golden Dawn derived). Silver Sword makes a point of showing up en masse at wic-Can Fest and running rituals and workshops.

341 Especially the works of W.E. Butler $(1957,1975,1981$, 1986, 1990), Dolores Ashcroft-Novicki (1982), Dion Fortune (1957, 1982, 1987a, 1987b, 1987c), Gareth Knight (1978, 1991), and Caitlin and John Matthews (1985, 1986). There is limited interest in the works of Aleister Crowley, Israel Regardie, and Denning and Phillips. There is also little interest in Blavatsky ('Theosophy), steiner, and Gurdjieff.

362 This correlation had been noted by Isaac Bonewitz in a number of seminars, however he did not present sufficient proof. Current research by shelly Rabinovitch along similar lines has uncovered a strong correlation between early child abuse and entry into the craft. 
"faith" and "gnosis". "Faith", described in Paul's epistle to the Hebrews (11:1,KJV), "is the substance of things hoped for, the evidence of things not seen." It is both the projection and that which is projected: the beliefs, hopes, fears, desires and yearnings of the individual. When Durkheim (1915) analyzed the "function" of religion in society, he was analyzing the social expression or faith.

"Gnosis", the second form of knowing in the spiritual world, relies on direct experience. While gnosis is guided by faith initially, it is categorically different from faith. The projection of belief is used as a vehicle to carry the individual to a point where they may directly experience the spiritual reality they seek, rather than experience the social projection of it. ${ }^{343}$

In Christianity, this dichotomy is recognized through the use of the two baptisms of water and of fire. Later Gnostic

343 Possibly the greatest examination of the relation
between "faith" and "gnosis" is the Ihya' Ulum as-Din
[Revivification of the Religious Sciences] of Abu Hamid
Muhammad al-Ghazali who discussed the difference as follows:

Certainty reached by demonstration is knowledge ('ilm); actual acquaintance with that "state" is immediate experience (dhawd); the acceptance of it as probable from hearsay and trial (or observation) is faith (iman).

From Watt (1953:62; italics in the original). The first condition described is intellectual knowledge of, the second is gnosis, and the third is faith. 
thought would expand on this dichotomy even as the protoorthodoxy would attempt to limit it. 344 To this day, there is conflict amongst Christian sects and denominations over the role of the two baptisms. 365

In modern neo-pagan witchcraft, the faith/gnosis dichotomy appears in a number of formats. First, while many magic rituals are essentially aimed at producing a gnostic experience, 346 there are an increasing number of "social" rituals. ${ }^{367}$ It is also an unstated policy of the wCC to not perform gnosis inducing rituals in public (with the highly limited exception of certain mystery plays). Second, there is a vigorous debate over the legitimate uses of magic (see Chapter 7). Finally, there is the development of additional

364 This is most apparent in the Valentinian school of Gnosticism. See, for example, the account of Valentinian/ orthodox relations in Pagels (1988:70-76).

345 The latest expression of the Baptism of Fire has been in the Charismatic movement.

346 For example, Drawing Down the Moon (Farrar and Farrar, 1984:294-300), the Initiation rituals (Farrar and Farrar, 1984:9-39; Crowley, 1989), Shadow Questing (Starhawk, 1979), Pathworking, etc. Also see Gareth Knight (1978). These are soul crafting rituals (see chapter 5).

347 For example, Handfastings (marriage) and wiccanings (infant baptism) (see Farrar and Farrar, 1981:153-173); and Dedications (adult baptism). Other examples include the use of magical rituals for ecological and political purposes, and for personal gain. 
degrees to expand on the old Gardnerian tnree degree system. 360

However, on the whole, modern neo-pagan witchcraft seems to emphasize the gnostic rather than the faith element of proof. Tanya Luhrmann (1989) has noted that faith tends to be a post hoc proof system designed to posthumously rationalize and order the experiences achieved and perceived by British witches. This matches similar observations of most non-wCC Witches in the ottawa community. Gnosis, rather than faith, is the core around which modern neo-pagan witchcraft has been built up. And this core is reflected in the development of rituals, beliefs, and views which are expressed in the social world.

This section has focused on the influence of the material, psychological and spiritual worlds on neo-pagan wiccan action in the social world. It was argued that religion is not a purely social action, but also action in each of these other worlds. And thus, the bases of knowledge operating

348 For the links between the Gardnerian three degree system, and Masonic initiations, see Kelly, 1991. One additional degree, "Dedicant", appears to be fairly common in North America, although not in England. A second degree, "Neophyte", is in common usage amongst the WCC, but does not appear to have spread beyond it yet. The wCC Neophyte degree was created for the express purpose of denying one person initiation while retaining their loyalty (personal communication from Meryddyd). 
in each of these worlds would materially effect the presentation of witchcraft in the socia. world, both within the movement and to the general public.

\subsection{Institutions and General Society}

Mary Douglas (1985), drawing on the works of Durkheim and Fleck, has argued that institutions serve as collective representations which are able to affect social behaviour and, to some degree, override individual behaviour patterns. 349 This influence is based on a number of factors. The primary factor is control (or attempted control) over systems of classification and interpretive frames of reference. Douglas (1986: 69-70), commenting on the revision of history textbooks, argues as follows:

When we look closely at the construction of past time, we find the process has very little to do with the past at ali and everything to do with the present. Institutions create shadowed places in which nothing can be seen and no questions asked. They make other areas show finely discriminated detail, which is closely scrutinized and ordered.

349 This "ability" to override individual utility towards a greater cause is readily apparent when the military is examined. That the ability is also limited, can be seen in numerous cases of military mutinies (e.g., the creation of German workers' and soldiers' councils between Nov. 5th and Nov. 11th, 1918 which, in effect, caused the final collapse of the Central Powers in World War I). A similar change in "selfevident" realities may be seen in the classic "road-toDamascas" style of conversion where ore reality is shattered and another takes its place. 
History emerges in an unintended shape as a resu. $t$ of practices directed to immediate, practical ends. To watch these practices establish selective principles that highlight some kinds of events and obscure others is to inspect the social order operating on individual minds.

But the past, "history", is more than just a flat recital of temporally distant "facts". It is the source for many forms of legitimacy ${ }^{350}$, and serves to define how current and future events should be comprehended. ${ }^{351}$ Control of the past, or rather of interpretation of the past, gives an institution increased influence in both the present and, possibly, the future.

Control of the past gives controllers certain societal advantages. For example, it allows them to choose the terms of debate; to define the language of discourse, the "true" epistemology, and to control access to recognized definitional axenas. Control of the past also serves to lend legitimacy to current institutions by presenting their existence as "inevitable" or "fore-ordained". This function of the control of history can be seen from the earliest recorded writings to

350 See, for example, Weber, 1947:324-373; Trevor-Roper, 1983 ; Morgan, 1983.

351 See, for example, Ranger, 1983; Schutz and Luckmann, 1973:87-92; Cohn, 1983; Peneff, 1990. 
the present day. 352

But control of the past is not the sole activity of institutions. They also "control", in the sense of limit or define, the choices of individuals. This control is achieved through control of physical force, material wealth and opportunity, and belief patterns. Galbraith (1983) refers to these forms of control as condign, compensatory and conditioning power.

And yet our society is not controlled by a single institution. Institutional conflict may well be, as the social constructionists would argue, a survival of the fittest conflict. However, it is readily apparent that there are also various socio-ecological niches. And it is within the niches that institutions compete with each other.

\subsection{Institutions and the web of Socio-cultural Reality}

While institutions affect our thoughts, beliefs, and actions, these same thoughts, beliefs and actions also affect our institutions. I have already noted a number of different analytic schools and paradigms that examine how the individual

352 For example, consider the Babylonian creation epic Enuma Elish which presents Marduk's conquest of Tiamat, and the concomitant changes in the social order, as inevitable (Aveni, 1989:59-66). A modern example would be Hitler's Thousand year Reich or Trotsky's perpetual revolution. 
effects change in institutional reality (see section 1.2 ). Each paradigm constructs itself in such a way that it produces certain research problems, which it then proceeds to solve.

Each paradigm may be seen as a point of view inside a complex, multi-dimensional space (the "web" of reality). And each paradigm shift may be seen as a change in the observers' viewpoint from one place in the web to a new place in the web. Each viewpoint allows the observer to perceive different parts of the web. Thi observer may then construct a new model, complete with new properties, from these new perceptions.

In A Formal Approach to Explicit, Implicit, and tmbodied Idens and to Their Fores of Interaction ${ }^{333}$, Gregory Bateson remarked

"Conventional epistemology, which we call "sanity", boggles at the realization that "properties" are only differences and exist only in context, only in relationship. We abstract from relationship and from the experiences of interaction to create "objects" and to endow them with characteristics. We likewise boggle at the proposition that our own character is only real in relationship. We abstract from the experiences of interaction and difference to create a "self", which shall continue (shall be "real" or thing 2 sh) even without relationship.

Bateson's argument, and the earlier arguments of Schutz (1967), Husserl (1970), and Habermas $(1984,1987)$, points

353 Originally printed in Double Bind: The Foundation of the Communicational Approach to the Family, edited by Carlos E. Sluzki and Donald C. Ransom, Grune \& stratton, 1976. Reprinted in Bateson, 1991:185-190 
towards a unity of socio-cultural relations. This unity may ivill be conceived of as a set of webs or matrices ("environments") in which all actions take place, and which serve to constrain the limits of socio-cultural actions. These webs of socio-cultural "reality" are, in turn, anchored to other webs: physical or material "reality"; previous sociocultural webs; psycho-spiritual webs, etc. ${ }^{354}$

It is within these socio-cultural webs that we perceive the "objects" and "things" of the social world. ${ }^{355}$ The sociocultural webs provide us with the relationships that are the preconditions for the establishment of the properties that come to characterize "objects" and "things". 356 They provide

354 For a comprehensive analysis of a number of these "webs" and their interplay, see Jahn and Dunne (1987). I have chosen the term "web" rather than Jahn and Dunne's "vector" in an effort to more readily convey the circularity and linkages implied in the core concept.

355 one of the primary perceptible forms of these sociocultural realities is language. See, for example, ong (1982) observation:

356 Igor Kopytoff (1986:64) makes the following

From a cultural perspective, the production of commodities is also a cultural and cognitive process: commodities must be not only produced materially as things, but also culturally marked as being a certain kind of thing. Out of the total range of things available in a society, only some of them are considered appropriate for marking as commodities. Moreover, the same thing may be treated as a commodity at one time and not at 
their members with various frames of reference or viewpoints about the world. 357

Thomas Kuhn (1970:103), in his discussion of paradigm shifts, notes the following:

"Successive paradigms tell us different things about the population of the universe and about that population's behaviour.... But paradigms differ in more than substance, for they are directed not only to nature but also back upon the science that produced them. They are the source of the methods, problem-field, and standards of solution accepted by any mature scientific comnunity at any given time. As a result, the reception of a new paradigm often necessitates a redefinition of the corresponding science."

But the web of socio-cultural "realities" includes more than purely physical or "material" reality. William James (1902:53), in a lecture entitled "The Reality of the Unseen", remarks that:

All our attitudes, moral, practical, or emotional, as well as religious, are due to the "objects" of our consciousness, the things which we believe to exist, whether really or ideally, along with ourselves. Such objects may be present to our senses, or they may be present only to our

${ }^{356}$ (....continued)

another. And finally, the same thing may, at the same time, be seen as a commodity by one person and as something else by another. Such shifts and differences in whether and when a thing is a commodity reveal a moral economy that stands behind the objective economy of visible transactions.

357 See Schutz and Luckmann (1973, 1989), and Habermas (1984, 1987). 
thought. In either case they elicit from us a reaction; and the reaction due to things of thought is notoriously in many cases as strong as that due to sensible presences. It may even be stronger.

James' implication that the objects of "thought" are not real ("sensible") is, perhaps, unfortunate. "Reality", when defined solely as material sensation, is unacceptable to most people, as James admits when he says that reactions due to "thought" are as strong as those arising from sensation. 358

"Thought" cannot, however, be viewed as a unity; a "black box" into which we cannot peer. Nor can "thought" be construed as a non-sensible activity, for we have an easily recognizable organ of thought sensation, the conscious mind, and some understanding of the process of thought sensation. 359

When we consider "thought", we should view it as a) the action of thinking, b) the objects of the action of thinking, c) the perceptual environment in whicn thinking takes place, and d) the suurce of these perceptions. "Thought" itself becomes one of the "webs of reality" in which the individual acts. The conditioning of the perceptual patterns of thought

358 As is the concept of human sensory limits to comprehension of the physical world. We cannot "see" or "taste" an atom, or a quark, and yet we can accept their existence as "real".

359 The various schools of the Psycho-analytic tradition of psychology are paradigms for the comprehension of the process of thought perception and sersation. 
can be seen as one of the primary functions of many institutions in society. 360

Descarte's famous dictum, cogito ergo sum, might well be rephrased for the social world as cogitamus ergo id est; we think, therefore it is. Our thought, our recognition, whether in agreement, opposition or neutrality, creates and maintains our webs of socio-clitural reality. ${ }^{361}$ Goffman (1959) has noted this in his work The Presentation of Self in Everyday

360 Consider, for example, the role of "education" in society. Other terms used for the conditioning of sensible patterns of thought are "enculturation" and "socialization". Furthermore, the "natural attitude" of Schutz and Luckmann may be seen as the collection of primary recognized patterns of thought within a society, the base patterns from which social individuals derive social meaning. See also ong (1982).

361 There are, however, a number of dangers in this proposition. First, one may assume that existence derives solely from thought. This position has been taken by a number of Eastern religions and is exemplified by the concept of maya, or illusion. While this position may well be ultimately true, it constricts one's actions within the social and material worlds (this is a primary difference between Eastern and Western religions; escape from the world versus action within the world).

Second, there may be an assumption that social reality derives from a thought consensus (Social contract Theory). This position contains a number of unwarranted assumptions. First, conflict over definitions of reality exist and this would not be so if there were consensus. Second, different cultures exist, and their existence points to limits in any supposed racial consensus. Third, various processes of thought control exist, designed to enforce a supposed consensus.

By saying "we think, therefore it is", I am extending Kuhn's conception of "paradigms" to general society. And this extension includes the concepts of paradigm conflict and paradigm limits. 
Life.

It is within these socio-cultural webs of "reality" that institutions operate and exist. And it is within these sociocultural webs that the process of institutionalization occurs. This process, "institutionalization", involves a number of different sub-processes, namely,

* The naming, or defining, of a pattern within a socio-cultural web as an "institution";

* The proscription of the properties of that pattern (the institutions' sphere of influence);

* The acceptance by a significant portion of general society of both the definition of a pattern as an institution and of its proscribed properties; ${ }^{362}$

The actions of "naming" and proscribing are social actions that take place in various definitional arenas (see chapter 4). ${ }^{363}$ The process of acceptance of these definitions

362 This "acceptance" does not necessarily imply an agreement with the "institution". The entire field of "social problems" is concerned with the non-agreement by general society with a perceived institution. For an example of this, see Ginzburg (1985) on the "acceptance" of the Benandanti.

363 The process of "naming" may be controlled, as Whorf (1956:233-270) argued, by a set of "patterned relations" implicit in the language used by the individuals. However, the syncretistic adoption of meaning symbols appears to imply that at least partial sets of patterned relations may be imported (and modified) from one language to another (e.g. Kabbalistic glyphs into Western Ceremonialist magic). Furthermore, the development of "new" patterned relations due to the syncretistic adoption of meaning symbols would imply that language boundaries are 1) permeable and 2) parts of a (continued...) 
and proscriptions, both internally (by the groups involved) and externally (by the "general public"! may well lead to varying forms of social conflict.

\subsection{Definitional Environments}

A number of points derive from this definition of the process of institutionalization, and from various analyses of the socio-cultural web. ${ }^{364}$ These points may be stated as a series of propositions:

Proposition 1: existing institutions will protect their definitional control over parts of the socio-cultural web already in their sphere of influence. ${ }^{365}$

Proposition 2: discrepancies will inevitably arise between internal definitions and proscriptions and external

\footnotetext{
363 (... continued)

"complex" system and, hence, are susceptible to "fuzzy logic" and "chaos" analysis.

364 For examples of these analyses, see footnotes number 31-37.

365 See, for example, simmel on secret societies (1950). It must also be noted that institutions have both core definitional areas (those necessary to their existence), and peripheral definitional areas (those areas on which they make pronouncements which may or may not be taken as "definitional"). Attempts to redefine core areas will inevitably lead to a reaction by the current institution. Attempts to redefine peripheral areas may or may not cause reactions.
} 
definitions and proscriptions. ${ }^{366}$

Proposition 3: This tendency towards definitional discrepancy and institutional territoriality, combine to produce social conflict. 367

These propositions assume that the web of socio-cultural reality may be subdivided into a series of definitional environments or socio-ecological niches. Each definitional environment is composed of:

* a number of pre-existing institutions which exercise claims within a particular area of the socio-cultural web;

* a set of conflict resolution modes that are socially recognized as being operative within the definitional area $i^{360}$

* a set of access conditions whereby a new institution or group may attempt to enter into the

366 This form of cultural time lag has been noted by a number of authors, $e, g$, Ginzburg on definitions of witchcraft (1985, 1991), and Niccoli on definitions of prophecy (1990).

367 Tris conflict may be at a "peaceful" definitional level, i.e. conflict that takes place in socially constituted definitional forums (e.g. the news media, the law courts, etc), or it may be at a "forceful" definitional level, i.e. conflict that uses non-socially recognized definitional forums (e.g. assassination, terrorism, etc.).

368 For example, in the general definitional environment known as "religion", the conflict resolution mode of open warfare is not generally accepted in modern Canadian society. And, if such a mode of conflict resolution was attempted, it would inevitably lead to external entrance into the definitional environment. 
definitional environment. ${ }^{369}$

* a set of "operational" rules which constrain and limit actions within the definitional environment.

Definitional environments may be viewed as the archetypes of the social mind. In the Western world we tend to describe these with one word terms: "Politics", "Religion", "Science", "Magic", etc. Each of which is represented by some idealized, exemplary, figure. ${ }^{370}$ This pattern of sociai Archetypes is not limited to the Western world, nor to modern humanity. Rather, the mythologizing of "essential" cultural definitional environments appears to be a human universal. ${ }^{371}$

The primary areas of each definitional environment are

369 In modern Canadian society, in the definitional environment of "religion", access controls are held in a large part by various governmental bodies (e.g. the legal definitions of religions). However, in as much as there is more legal emphasis placed on multiculturalism than on religion, the legal access to the definitional environment is relatively open.

370 For example, the quintessential politician (e.g. Diefenbaker (exemplifying Canada's control by the USA), or Mulroney (exemplifying uncaring and perceived corruption)). The essential servant of God (e.g. Mother Theresa (exemplifying care) or Tommy Douglas (exemplifying social justice)). The ideal scientist (e.g. Copernicus (exemplifying the fight between "truth" and "superstition") or Einstein (exemplifying brilliant insight). The archetypal Magician (e.g. Faust (exemplifying the dangers of the unknown) or Houdini (exemplifying "magic as trickery")). (1964:449).

371 See, Eliade (1958, 1977), Campbell (1970), Jung 
the sectors which control environmentally specific definitions.372 These have been termed "Public Arenas" by Hilgartner and Bosk (1988; see chapter 4). Each arena, and there may well be several in a given definitional environment, is engaged in an ongoing debate about the taken-for-granted assumptions that operate within particular institutions, definitional environments, and general society. ${ }^{373}$ It is within these arenas that individuals, groups and institutions attempt to redefine the "self-evident" reality of their environments, their selves, and their society. And it is from the rhetorical debates in these arenas that specific social mythologies appear. 376

The definitional debates may, however, take place in arenas that are not part of the sphere of influence of any "competing" groups or institutions. Furthermore, it is quite feasible that certain definitional environments may be considered as axiomatic (i.e. not subject to redefinition)

372 It must be noted that many of these areas are not part of the definitional environment. For example, legislation regarding public religion in Canada is developed and implemented in parliament, rather than in a "religious" claimsmaking forum.

37 For example, Lippert (1990) identifies five main groups, each with their own public arenas.

374 See, Best (1989:xix-xxi), Ginzburg (1991), and Hobsbawm and Ranger (1983). 
during a particular debate. For example, the role of the press is frequently split into its presentation of a given debate, and its role as the presenter of the same debate (Rowe and Cavender, 1991). The role as presenter is considered axiomatic, while the presentation itself may be considered as subject to redefinition. The choice of which arena a debate will take place in is frequently dependant upon the cultural valuations placed on the given definitional environment.

When we look at modern neo-pagan witchcraft, we can see that it operates in two primary definitional environments: "Magic" and "Religion". ${ }^{375}$ However, both of these environments are currently valued less than "Politics".376 This valuation places limits on the potential actions of preexisting institutions in the environments of "Magic" and "Religion". For example, Christian organizations do not have the "freedom" to burn or kill self proclaimed witches. 37 A

375 For example, the Wiccan Church of Canada is currently involved in an attempt to gain recognition as a "religion" from the federal Ministry of Correctional Services (James, 1991; Rabinovitch, 1991).

376 This valuation may be seen from the reliance by society on political, rather than magical or religious solutions to general social problems.

377 However, there are cases, primarily in the southern United states, of systematic persecution of self-proclaimed witches. These cases involve violence against both persons and property, as well as legal action. In Canada, there are few (continued...) 
second example of the subservience of "Magic" and "Religion" to "Politics" appears in the "political correctness" of certain branches of the American Craft movement (Adler, 1986; Starhawk, 1982, 1987). The "politically correct" debate is currently ongoing in American and, to a lesser degree Canadian, craft circles.

\subsection{Relational Factors in the Socio-Cultural Web}

In section 8.3., I argued that all analyses of the sociocultural web are based on the relative starting positions of those analyses. Section 8.4. argued that the socio-cultural web may be divided into a number of definitional environments. In this section, I wish to examine the factors limiting an analysis of the process of change within definitional environments.

This exanination is based on the primary assumption that the socio-cultural web is generated, maintained and changed by the members of a given society and culture. If this is so, then it should be possible to analyze certain "laws" of social thought: or, in other words, to determine the limiting factors to changes in social thought. A certain amount of evidence in

\footnotetext{
37 (....continued)

reported cases of violence. In England, most conflict appears to be Iimited to the popular press.
} 
favour of this hypothesis has already been considered in reference to social Archetypes, and social mythologization (see section $8.4 \cdot$ ).

However, the socio-cultural web may also be viewed as the sum of what the given society and culture perceive as "possible" and "good". Change, and conflict, within the sociocultural web occur due to these perceptions. While we are primarily concerned with the methods of the production of these perceptions, it is useful to examine the essence of what is perceived.

The search for the "possible", has appeared in many forms, but its primary testing ground is the material world.370 The "possible" is not a statement of moral valuation, ${ }^{379}$ rather it is a perception of what actions can be performed in "reality". The "possible" also contains the "impossible", those actions that cannot be performed in "reality". And, when the "impossible" becomes overwhelming, the possible must change.

The search for the "good", on the other hand, is a search

378 or, to be more precise, in the paradigms' modelling and defining the perceptions of the material world (Kuhn, 1970). Of course, the nature of the material world, what is and is not "real" and part of "nature", varies from culture to culture.

370 Except as it pertains to the "foolishness" of attempting the impossible even through "possible" means. 
for moral and ethical valuation. It has appeared in religion, philosophy, and mysticism and its testing ground is the spiritual world.380 Unlike the "possible", which discusses what "can" and "cannot" be done, the "good" discusses what "should" and "should not" be done.

The tension, and debate, between these two produces the social definition of what "may" and "may not" be done. This tension, and the variance in "proofs" has a number of implications for our analysis of the limits of change in the socio-cultural web of reality. ${ }^{301}$ These limits may be viewed not as formulaic limits, but rather as processual limits. 382

From our initial analysis, four "limits" are readily apparent, namely:

* Connection - numerous factors affect every change, and no single factor may be viewed as the sole cause of a change.

* Fluidity - all definitions of a given "reality" are inherently fluid due to a) the interconnection of all factors, and b) the differential rate of change between many factors. culture.

380 However that may be defined by the given society and

301 For a more detailed analysis of the implications of various forms of "proof" see section 8.1 .

382 In other words, these limits are in the nature of process, rather than form. And, while there are limits in the form of change, these derive from a) the limits of the process of change and b) the limits defined by the social "possible" and "good". 
* Subjectivity - "self-evident" realities are subjective rather than objective (although they may be objectively viewed and expressed by the subject), and therefore any examination must begin and end with individuals. ${ }^{303}$

* Chaotic - changes in "self-evident" realities are chaotic, rather than linear. ${ }^{304}$

The first point, connection, has been called by Gleick (1987) "The Butterfly Effect". In essence, it argues that a) accuracy in prediction or explication is limited by the precision of the given model, and b) no predictive or explanatory model can include all factors that are relevant to a given result. In effect, we can never achieve a level of precision to match our desire for "complete" accuracy.

The second point, fluidity, stems in part from the first. If complete accuracy is impossible, then all definitions will, of necessity, be limited and to varying degrees, inaccurate. In addition to iimited accuracy, there appears to be a constant in operation, a socio-cultural equivalent to Plank's Constant in physics. This may be stated as we can know either the position (form) of a pattern, or we can know the velocity

383 "Self-evident realities" are also the basis of the social "mind". See section 8.3 .

384 By "chaotic" I mean that there is a regular pattern observable, but this pattern is not expressible through either binary logic or by linear mathematics. It is, however, expressible in part through chaos dynamics (Saunders, 1980; Young, 1991). 
(force/rate of change) of a pattern, but any attempt to know both at a given time will reduce the accuracy of both measurements.

This social constant becomes extremely important when we consider the two main roles of the social sciences: prediction and explication. In order to explain an event of change, we must be able to show a) how a pattern evolved, and b) why a pattern evolved. ${ }^{385}$ In order to predict a given event of change, it is necessary to understand both constant states and vectors of change. Since our comprehension of social states and vectors is limited by our accuracy, our predictions are, of necessity, of limited range, duration and accuracy. ${ }^{386}$

The third point, subjectivity, has been expressed

385 The "how" part of this process is frequently done using a selective model to choose historical "facts" that support the interpretive frame of reference supplied by a theoretical stance. The "why" part is frequently a supportive proof for a given theoretical prediction. This tendency in the social sciences may well be why, using Kuhn's (1970) model, the social sciences have not evolved beyond the level of "schools". It is also apparent that the social sciences evolved to serve ideological interests, as opposed to the physical sciences which evolved out of theological and cosmological interests.

386 It is not surprising that the "language" of statistics evolved out of attempts to predict and control society (Stigler, 1986:159-261). However, the precision of this "language" has been severely limited by its linear nature. This limit of accuracy may well be expanded with the introduction of fuzzy logic, genetic algorithms, and chaos mechanics (Younge, 1991). 
beautifully by Gregory Bateson (1991, 226-227):

There is the interesting possibility that we might attach meaning to the word "systematically". If the "self" as a perceiver were randomly fallible, then there would be no hope of any knowledge or understanding. But $I$ am (personally) sure that neither perception nor even dream or hallucination contains more than a very small random element -and that random component always only indeterminate within a limited subset of alternative possibilities.

What if:

(A) What we can perceive of self is our own metaphor; and

(B) We are our epistemology; and

(c) our inner world is that epistemology, our microcosm; and

(D) Our microcosm is an appropriate metaphor of the macrocosm?

What if "Truth" in some very large and, for us, overriding sense is information not about what we perceive (the green leaves, the stones, that voice, that face) but about the process of perception?

The process of institutionalization, when viewed through the criteria of subjectivity, becomes one of categorization and communication of internal metaphors. The "institution", or pattern in the web of socio-cultural reality, is created and compiled from the individual epistemologies of its definers, within the web of socio-cultural reality. And, once created, it is subject to evolutionary pressures (redefinitional debates) within that environment both internally by its 
members and externally. ${ }^{387}$

The fourth and final limit, is that changes in selfevident realities are "chaotic" rather than linear. This final point derives, in part, from the first two points. Also, as Saunders (1980:83) points out,

The data which are available [to the social scientist] are often not quantifiable. We can generally order our observations; for example, we can tell whether a person has become more angry or less angry. And we can usually say whether or not a variable is continuous and whether it changes smoothly. On the other hand, algebraic concepts such as addition and multiplication generally have no meaning: it makes little real sense to say that someone has become twice as angry. As a result, it is often very difficult to use differential techniques in the social sciences. In catastrophe theory, on the other hand, the variables are defined only up to diffeonorphisms, so that order, proximity and smoothness are all we need. If we have data which are qualitative then we generally expect conclusions which ire qualitative, and if we are going to go from one to the other by using a mathematical technique it seems natural that it too should be qualitative.

In effect, while quantitative data may be useful in an examination of a social change, it has many limits. In general, quantitative data may be used very effectively to describe a particular state or pattern. It may also be used to

387 External redefinitional pressure may come from other institutions, events in the web of "material" reality, or other changes in the socio-cultural web that are superficially unrelated to the institution. 
describe certain forms of change and to give the researcher a rough model upon which to base further investigations. ${ }^{388}$

However, there are also extreme dangers in assuming the c.bsolute accuracy of quantitative data, since quantitative data is based on a categorization model that may well have little or no bearing on the realities which it attempts to model. ${ }^{389}$ This danger is especially real when the changes being modeled are discontinuities and/or sudden shifts in behaviour and/or belief.

From the above points, we can see that there are many limitations and convolutions involved in any study of radical change in the social "mind". However, as Saunders (1980:3) has pointed out,

The number of qualitatively different configurations of discontinuities that can occur depends not on the number of state variables [the web of sociocultural reality], which may be very large, but on the number of control variables [definitions], which is generally small.

It is on these "control variables", the change and maintenance of definition, that my analysis of the ottawa wiccan community has been based.

388 See, for example, Hakim (1987) and Jackson (1988).

389 This point has also been examined in discussions of ethnocentricity. A good example of projection in a survey which renders the results meaningless is Ward and Beaubrun (1980). 
8.6. Conclusions

This chapter sought to bring together the varying theoretical strands that would allow us to develop a model of "institutionalization". In order to do this, I first examined different forms of epistemologies (section 8.1.). Next, I considered the social functioning of institutions (section 8.2.). I then proceeded with an analysis of the role of institutions within the web of socio-cultural "reality" (section 8.3.). This was followed by an examination of the concept of "Definitional Environments", and a discussion of their relationship both to the web of socio-cultural reality and to institutions (section 8.4).

In section 8.5 ., I examined the process of change within the web of socio-culturai reality. This examination concentrated on the limiting factors regarding change, which were found to be dependant upon the process of change, rather than the forms changed. 
Chapter 9:

Conclusions

Indigenous Canadian culture arises not from cultural policy, but from a series of biographic, cultural and structural forces acting on and coming into play with subjective experience. If cultural expression may be regarded as parole, the corresponding langue which governs it (the system of meaning) is likewise a highly personal creation.

Kingsman, 1990: 158

Caroline Kingsman's conclusions regarding culture in Canada could easily apply to the subculture of the ottawa wiccan community. It has been formed "from a series of biographic, cultural and structural forces acting on and coming into play with subjective experience."

The "parole" of ottawa witches comes in many forms; ritual and gossip, feasting and political infighting, ecstacy and petty mindedness. There is no single "cultural expression" that can typify the members of the ottawa community, and no "langue" that unites them. Rather, the ottawa community (and the Wiccan and Neo-pagan movements in general) is a composite of many meaning systems.

In communities where meaning is a "highly personal creation" and syncretism is the rule rather than the exception, differences are the norm. When we examine the process of institutionalization, we are examining not only how an idea or practice becomes part of the natural attitude: we 
are also examining the general social responses to these differences.

At the beginning of this work, I stated my research question as follows: by what means, and through what avenues, do the ideas, practices and beliefs of individual witches come to be formalized, regularized, and institutionalized in the minds and realities of a modern wiccan community?

In order to answer this question, I started with a tentative definition of institutionalization, namely:

Institutionalization is 1 ) the process whereby a consciously created thought pattern, 2) together with its concomitant action/response sequences and 3) categorization schemata, 4) comes to be a part of the natural attitude of an individual such that 5) it acts to control the actions of that individual.

In the initial chapters ( 2 to 4 ) I presented a descriptive account of the development of the ottawa wiccan community. This account was linked to the theoretical model of definitional arenas initially formulated by Hilgartner and Bosk. These descriptive chapters served a threefold purpose. First, they provided an ethnographic background of the community under examination. Second, they served to illustrate how "thought patterns" came to be created and/or adopted in the community. Finally, they highlighted certain key community characteristics, most notably the essentially oral nature of 
communal formation.

This oral nature does not, however, derive from an lack of more technologically sophisticated communications devices. Both print and electronic media are available and in use. The reliance on oral formulation appears to stem from a general predisposition towards experiential proofs for truth claims. oral rhetoric, (e.g. gossip, counselling, teaching, ritual, etc.) allows for the direct interpersonal interaction which is a necessary condition for the experiential proofs of others truth claims. It is not surprising that all local Elders, and most local Initiates, are quite charismatic in at least one form of oral rhetoric. ${ }^{390}$

Communal conflict arises from two main sources. First, when oral communications break down, as with the Beltaine Grand Sabbat or current WCC isolationism. Second, when the same terms are used with two completely different meanings such that the conflicting meanings are ascribed absolute values (e.g. Initiate, Priest, etc.).

Individuals may be able to operate in a number of meaning

390 In this instance, "charismatic" is used to refer to the quality of drawing an individual into an "illusion" cast by words. 
systems and "speak" a number of technical languages. 391 The ability to shift from one meaning system to another requires the ability to recognize the contextual clues that delimit each system. And the ability to identify these contextual clues varies considerably depending on the experiences and stock of knowledge of each individual.

Terminological meaning conflict also stems from assumptions of purposive order. The source of this conflict stems from the primary axiological assumptions of a group or individual. This form of conflict is most readily apparent in ritual presentation and in the differing valuation placed on various ritual skills. It derives from the mythic structure assumed by the group as presented in its temporal locus.

For example, the public ritual presentations of the ottawa Temple of the wCC focus on the temporal present. The public "present" is matched by an assumption that the "Priesthood" have a temporal locus in the future. This difference in temporal locus serves to differentiate the "Priesthood" (future oriented) from the "Laity" (present oriented). Thus people entering the wCC with a future orientation are subtly urged toward Priesthood training, while

391 For example, the "language" of Gardnerian derived wicca includes technical vocabularies from Western Ceremonialist magic, Kabbalah, early modern witchcraft, herbalism, astrology, and Jungian psychology. 
those with a present orientation are urged away from Initiation.

The acceptance of a particular mythic structure serves to define the temporal locus of the group or individual. But temporal loci tend to be inclusive. A future orientation usually includes both the past and the present. A past orientation usually includes the present. For example, the acceptance of the Quest motif includes past, present, and future.

My initial definition of institutionalization must now be refined in light of the data presented. Institutionalization is

1) the process whereby a thought pattern (together with its concomitant action/response sequences and categorization schemata) is first created (or adapted) ;

2) then communicated to other individuals and/or groups;

3) recognised by other individuals and/or groups as legitimate;

4) and accopted by certain individuals and/or groups as valid, such that it

5) comes to be a part of their natural attitude, so that

6) it acts to impel the actions of the individual and/or group.

Institutionalization is both intersubjective (communi- 
cative action) and intrasubjective (psychological action). 392 Each stage in the process is voluntary, although certain pressures may be brought to bear on individuals to conform. At a communal level, recognition is the key stage. Recognition of a thought pattern, and its concomitant terminology, allows definitional debate on the nature of the thought pattern rather than on its legitimacy. The recognition stage marks the difference between a deviant thought pattern and legitimate thought pattern.

Definitional debate is the process whereby each stage is achieved. These debates are both intersubjective and rhetorical, and intrasubjective. Acceptance of a thought pattern does not imply the use of a thought pattern. Frequently thought patterns will lie dormant until they are invoked by specific envirommental challenges (social, technological, etc.).

At a social level, these challenges are most apparent in multicultural states such as Canada, the United States, England, or Imperial Rome. At an individual level, these challenges are most apparent in situations of axiomatic diversity and personal crisis (see Holzner, 1968).

392 In this case, "psychological" refers to the sciences of souls, rather than psychotherapy, analysis, or neurobiology. 
Response to the challenge vary on individual and institutional levels from the development of syncretistic thought patterns to "fundamentalist" demands for a return to "purity" (see Berger, 1980). In the Ottawa Wiccan community the syncretistic option has proved to be the main response.

My initial research question was

by what means, and through what avenues, do the ideas, practices and beliefs of individual witches come to be formalized, regularized, and institutionalized in the minds and realities of a modern wiccan community?

This may now be answered as follows. Ideas, practices and beliefs are formalized, regularized and institutionalized through a continuing process of intersubjective and intrasubjective definitional debate.

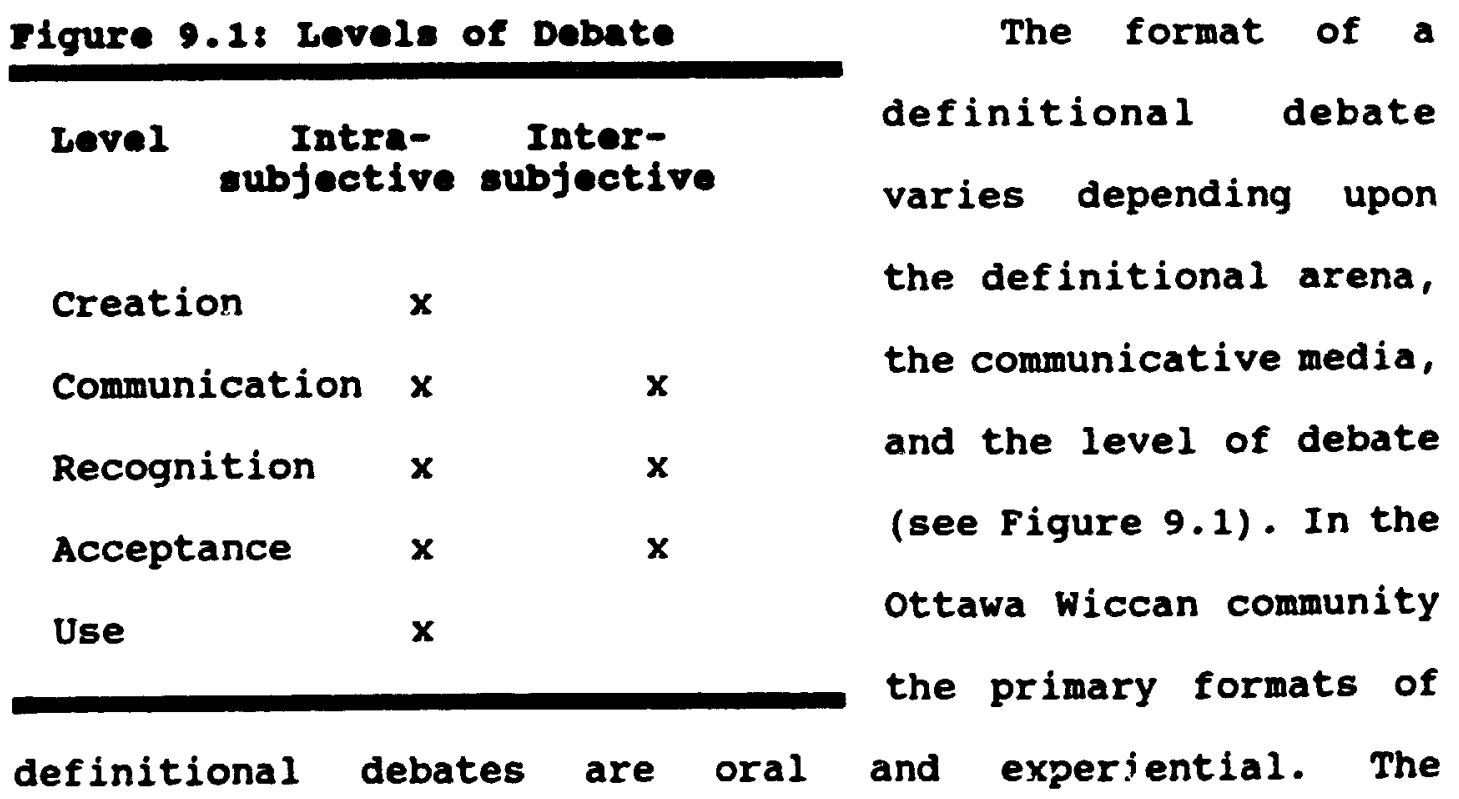


development of early Christianity follows a similar pattern. However, in the broader study of the institutionalization of religion, other formats of definitional debate are readily apparent. These include textual, praxitic, doctrinal (ideological) and pragmatic (social) formats. These formats represent the axiological assumptions of the religious subculture. It should be possible to construct an ideal typology of religious subcultures based around definitional formats and temporal loci.

For example, British Gardnerian derived wicca tends towards the use of experiential and praxitic formats and a transtemporal locus (evolutionary time). American Wicca tends towards the use of doctrinal (ideological) and pragmatic (social) formats and a present time locus.

In the ottawa community, the public wcc presentation tends towards praxitic, pragmatic and oral formats with a present temporal locus. Quicksilver is similar to the British Gardnerian derived Wiccans. The Web of Herodias centers around an experiential format with a transtemporal focus, while the Merydians concentrate on experiential and oral formats with a present temporal locus.

The development of a full typology is well beyond the scope of this work. However, I believe that such a typology would prove useful in any further study of the institutional- 
ization of religion. While there are definite limits to the use of any taxonomic system, I believe that many of these limits can be overcome.

The limit of imposed absolutism (taxonomic imperialism) may be surpassed through the use of "fuzzy logic" in the categorization schema. The limit of imposed evolution (theoretical imperialism) may be overcome through the use of "chaos" dynamics in prediction schema. Finally, the limit of imposed valuation (ideological imperialism) may be surmounted through a reliance on subculture internal valuations.

Examination of the institutionalization of religious subcultures should be based on one main consideration: the subculture examined must be able to speak for itself. The purpose of the researcher is not to tell the community studied what it believes and how it comes to these beliefs. Rather, the role of the researcher is to report on what the subculture believes about itself, to translate these statements into a general "academic" language, and to extrapolate general patterns of socio-cultural action from these statements. ${ }^{393}$

Furtherwore, the reporting of these patterns of sociocultural action must also recognize and explicate the

393 For more on this, see Tyrrell, n.d. 
differert levels of movement operations. ${ }^{394}$ Patterns of action that are considered as "valid" at one level of operations may also be seen as "invalid" at other levels.

The process of institutionalization in religious movements is neither monocausal nor monolocal (i.e. resident in one level of operations). It is ongoing, arising from many causes, and engaged in action on many different levels and in many different forums. The process of institutionalization is the continuing production, maintenance, modification and presentation of the group and individual "self" to the social "other".

394 See, for example, Melucci (1989) 
Bibliography

Abraham, Ralph

1991

Complex Dynamical systems Theory: Historical origins, Contemporary Apllications, in Ervin Laslo (ed), "The New Evolutionary Paradigm", Gordon and Breach, New York

Adler, Margot

1986 "Drawing Down The Moon", Beacon Press, Boston

Albanese, Catherine L.

1990

"Nature Religion in America", University of Chicago Press, Chicago

Appadurai, Arjun

1986

"The Social Life of Things", Cambridge University Press, Cambridge

Arieti, Silvano (ed.)

1959

"American Handbook of Psychiatry, Volume I", Basic Books, New York

Ashcroft-Nowicki, Dolores

1982 "First steps in Ritual", Aquarian Press, "The Sacred Cord Meditations", Aquarian Press,

1990 Wellingborough

Atwood, M.A. 1960

"Hermetic Philosophy and Alchemy", Julian Press, New York

Iveni, Anthony

1989

"Empires of Time", Harpercollins

Baintridge, william sims

1991 "Social Construction from within: Satan's Process" in Richardson, Best and Bromley (1991)

Baker, G.L. and Gollub, J.P. 1990

"Chaotic dynamics, an introduction", Cambridge University Press, Cambridge

Bateson, Gregory 1991

"A Sacred Unity", Donaldson, Rodney E. (ed.), Harper Collins, New York 
Bennet, John $w$, and Kohl, Seena

1981

"Longitudinal research in rural North America", in Messerschmidt (1981)

Ben-Yehuda, Nachman

1981

Problems Inlerent in Socio-Historical Approaches to the European Witch Craze, in Journal for the Scientific study of Religions, 20(4), 326-338

1985 Deviance and Moral Boundaries", University of Chicago Press, Chicago

Berger, Peter

1980 "The Heretical Imperative", Anchor Books, New York

Best, Joel (Ed.)

1989 "Images of Issues", Aldine de Gruyter, New York

Best, Joel

1987

Rhetoric in claims-Making: Constructing the Missing Children Problem in Social Problems V. $34: 2,101-121$

Blum, Ralph

1982

"The Book of Runes", St. Martin's Press, New York

Bonewitz, Isaac

1990 The Vision of Ar nDraiocht Fein in The Druids' progress, $\$ 6,11-13,17$

Bromley, David c.

1991 "Satanism: The New Cult Scare", in Richardson, Best and Bromley (1991)

Butler, W.E. 1957

"The Magician: His Training and Work", Wilshire Book Company, N. Hollywood

1975[1952] "Magic: Its Ritual, Power and Purpose",Aquarian Press, Wellingborough

1978 [1964] "Magic and the Qabalah",Aquarian Press, Wellingborough

1979 [1968] "How to Develope Clairvoyance", Weiser, New York $1981[1962]$ "Apprenticed to Magic", Aquarian Press,

1986 "Practical Magic and the Western Mystery 1990 Tradition", Aquarian Press, Wellingborough "Lords of Light", Destiny Books, Rochester 
Campbell, Colin 1972

"The cult, the cultic Millieu and secularization", in A sociological yearbook of religion in Britain, 119-136

Campbell, Joseph

1970

"The Masks of God: Primitive Mythology", Viking Books, New York

deChant, Dell

1991

Taproots of the New: New Thought and the New Age, in the Quest, vol.4 \#4 (Winter) 68-77

Chidester, David

1987

"Patterns of Action", Wadsworth, Belmont

Cus. sernard $s$.

19p" "Representing Authority in Victorian India", in Hobsbawm and Ranger (1983:165-210)

Connerton, Paul

1989 "How Societies Remember", Cambridge University Press, Cambridge

Crowley, Aleister

1983[1973] "Magick Without Tears", Falcon Press, Phoenix

Crowley, Vivianne

1909 "Wicca: The old Religion in the New Age", Aquarian Press, Wellingborough

Crysdale, stewart and wheatcroft, Les (eds)

1976

"Reiigion in Canadian Society", Maclean-Hunter

Press, Toronto

Cunningham, scott

1983

"Magical Herbalism", Llewellyn Publications, St.

PauI

Demerath (III), N.J. and Hammond, Phillip E.

1969 "Religion in Social Context", Random House, New York

Douglas, Mary

1986 "How Institutions Think", Syracuse University Press, Syracuse 
Duerr, Hans Peter

1985[1978] "Dreamtime", Felicitas Goodman (trans.), Basil
Blackwell, Oxford

Durkheim, Emile

1915 "The Elementary Forms of Religious Life", Joseph Ward Swain (trans.), George Allen and Unwin, London

1938[1895] "The Rules of the Sociological Method", Soloway, Sarah A. and Mueller, John H. (Trans.), Catlin, George E.G. (ed.), The Free Press, New York

Ejerfeldt, Lennart

1974

"Sociology of Religion and the Occult Revival", in New Religions, Haralds Biezais (ed), Almqvist and Wiskell, Stockholm

Eliade, Mircea

1958

1964 [ 1951$]$

1976

1977

"Patterns in Comparative Religion", Rosemary Sheed (trans.), Meridian, New York

"Shamanism: Archaic Techniquesof Ecstasy", Bollingen Series LXXVI, Princeton University Press, Princeton "Occultism, Witchcraft and cultural Fashions", University of Chicago Press, Chicago

"From Primitives to Zen", Harper and Row, New York

Ellwood, Robert S.

1973 "Religious and Spiritual Groups in Modern America", Prentice-Hall, Englewood Cliffs, NJ

Evans, Arthur

1978 "Witchcraft and the Gay Counterculture", FAG RAG Books, Boston

Evans-Pritchard, E.E.

1976 "Witchcraft Oracles and Magic among the Azande", abridged edition, Eva Giles (ed), clarendon Press, Oxford

Evans-Wentz, W.Y.

1966[1911] "The Fairy faith in Celtic Countries", Citadel Press, New York

Eyerman, Ron and Jamison, Andrew 1991

"Social Movements, A Cognitive Approach", Pennsylvania State University Press, University Park 
Farrar, Janet and Farrar, stewart

1981 "Eight Sabbats for Witches", Magical Childe, New York

1984 "The Witches' Way", Magical Childe, New York

1987a "The Life and Times of a Modern Witch", Piatkus, London

1987b "The Witches' Goddess", Phoenix Publishing, Custer

1990 "Spells and How They Work", Phoenix Publishing, Custer

Favret-Saada, Jeanne

1980 "Deadly Words, witchcraft in the Bocage", Catherine Cullen (trans), Cambridge University Press, Cambridge

1989 Unbewitching as therapy, Catherine cullen (trans.), in American Ethnologist, 16(1)

Fortune, Dion (aka Violet Firth)

1957 "Psychic Self-Defence", Aquarian Press, Wellingborough

1976 "The Demon Lover", Star Books, London

1978 [1926] "The Secrets of Dr. Taverner", Llewellyn Pubiications, Saint Paul

1982[1930] "The Training and Work of an Initiate", Aquarian Press, Wellingborough

1985[1922] "The Machinery of the Mind", Samuel Weiser, York Beach, MN

$1987 a$

"Sane Occultism",Aquarian Press, Wellingborough

$1987 \mathrm{~b}$

$1987 \mathrm{C}$

"Applied Magic", Aquarian Press, Wellingborough "Esoteric Orders and Their Work", Aquarian Press, Wellingborough

Friedman, Paul

1959 "The Phobias", in Arieti (1959:293-306)

Galbraith, John Kenneth

1983 "The Anatomy of Power", Houghton Miflin, Boston

Gardner, Gerald

1939

1954

1955

1959
Witchcraft, in Folklore, Vol 50

"Witchcraft Today", Arrow Books, London

The Religion of the wica, commonly called Witchcraft, in "Atti deII'vIII congresso internazionale di storia delle religioni (Roma, 17-23 Aprile)", G.C. Sansoni (ed), Florence, 376378

"The Meaning of Witchcraft", Magickal Childe, New York 


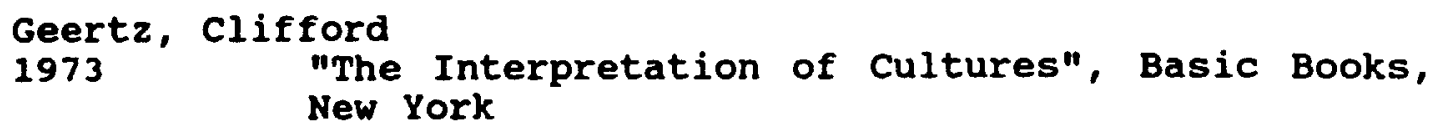

Ginzburg, Carlo 1980
Yorelli. Freud and Sherlock Holmes: Clues and Scientific Method, in History Workshop, Issue 9 (Spring)
1985[1966] "The Night Battles", John and Anne Tedeschi (trans.), Penguin Books, New York
1991 [1989] "Ecstasies", Raymond Rosenthal (trans.), Pantheon Books, New York

Ginzburg, Carlo and Poni, Carlo

1991[1979] "The Name and the Game: Unequal Exchange and the Historiographic Marketplace", in Muir and Ruggiero (1991)

Gleick, James

1987 "Chaos", Viking (Penguin), New York

Goffman, Erving

1959 "The Presentation of self in everyday Society", Anchor Books, New York

Graves, Robert

1964 Witches in 1964, in The Virginia Quarterly, XL, 550-559

Greely, Andrew

1969 There's a New-Time Religion on Campus, New York Times Magazine, June 1, 14-15, 17, 19, 22, 24, 26,28

Gusdorf, Georges

1965[1953] "Speaking (La Parole)", Paul T. Brockelman (trans), Northwestern University Press, Evanston

Gusfield, Joseph R.

1981 "Drinking-Driving and the symbolic order", University of Chicago Press, Chicago

Habermas, Jurgen

1979[1976] "Communication and the Evolution of Society", McCarthy, Thomas (trans.), Beacon Press, Boston 
1984 [1981] "The Theory of Communicative Action, Volume 1", McCarthy, Thomas (trans.), Beacon Press, Boston 1987[1981] "The Theory of Communicative Action, Volume 2". McCarthy, Thomas (trans.), Beacon Press, Boston

Hakim, Catherine

1987 Research Design", Allen \& Unwin, London

Hawkes, Terence

1977 "Structuralism and Semiotics", University of California Press, Berkely

Hennigh, Lawrence

1981 "The Anthropologist as key informant", in Messerschmidt (1981)

Heritage, John

"Garfinkle and Ethnomethodology", Polity Press, Cambridge

Hicks, Robert

1989 "Satanic Cults: A Skeptical View of the Law Enforcement Approach", Cassandra News, North Hollywood

Highfield, A.C. 1984

"The Book of Celestial Images", Aquarian Press, Wellingborough

Hilgartner, Stephen and Bosk, Charles L.

1988

The Rise and Fall of Social Problems: A Public Arenas Model, in The American Journal of Sociology, V. 94:1 (July), 53-78

Hobsbawn, Eric

1983 "Inventing Traditions", in Hobsbawm and Ranger (1983:1-14)

Hobsbawm, Eric and Ranger, Terence (eds.)

1983 "The Invention of Tradition", Cambridge University Press, Cambridge

Holy, Ladislav and Stuchlik, Milan

1980 "The Structure of Flok Models", Academic Press, London

Holzner, Burkart

1968

"Reality Construction in Society", Schenkman Publishing Company, Cambridge 
Howes, David

1987 Qlfaction and Transition: an essay on the ritual uses of smell, in The Canadian Review of Sociology and Anthropology, 24(3), 398-416

Hsia, R. Po-Chia (ed)

1988 "The German People and the Reformation", Cornell University Press, Ithaca

Huson, Paul

1970 "Mastering Witchcraft", Perigee Books, New York

Husser 1, Edmund

1970[1954] "The Crisis of European Sciences", David Carr (trans.), Northwestern University Press, Evanston

Innis, Harold A.

1951 "The Bias of Communications", University of Toronto Press, Toronto

1956 "Essays in Canadian Economic History", University of Toronto Press, Toronto

1972 "Empire and Communications", University of Toronto Press, Toronto

Jackson, Winston

1988 "Research Methods", Prentice-Hall, Scarborough

Jade (aka Samantha Jade River)

1991 "To Know", Delphi Press, Oak Park

Jahn, Robert G. and Dunne, Brenda $J$.

1987 "Margins of Reality", Harcourt Brace Jovanovtich, New York

James, Richard

1987 "The Wic-Can Handbook: a Guide to the wiccan Church of Canada. 1987 edition, Toronto

1991 Letter, wiccan Church of Canada to the "Federal Interfaith Commitee on Chaplaincy", January, Toronto

James, Tamarra

n.d. "An Introduction to the Doctrine of signatures", Botanic Medicine Society, Toronto

James, William

1902 "The Varieties of Religious Experience", Random House, New York 
Johns, June

1969 "King of the Witches", Coward-McCann, New York

Johnson, Joan

1984 "The Cult Movement", Franklin Watts, New York

Johnson, John $M$.

1989 "Horror stories and the Construction of Child Abuse", in Best (1989)

Jorgenson, Danny L. and Jorgenson, Lin

1982

social Meanings of the occult in The sociological Quarterly, 23 (Summer), 373-389

Jung, Carl Gustav

1953 [1944] "Psychology and Alchemy", R.F.C. Hull (trans.), Collected Works, V.12, Bollingen Series $X X$, Routledge and Kegan Paul, London

1964 [1958] "A Psychological View of Consciousness", R.F.C. Hull (trans.), Collected Works, V.10:437-455, Bollingen Series XX, Pantheon Books, New York

1976[1945] "Marginalia on Contemporary Events". R.F.C.Hull (trans.), Collected Works, V.18:591-603, Bollingen Series XX, Princeton University Press, Princeton

Jung, Emma and Von Franz, Marie-Louise

1986[1970] "The Grail Legend", Sigo Press, Boston

Kelly, Aidan A.

1982 The Invention of Witchcraft, in zetetic Scholar $10,17-25$

1991 "Crafting The Art of Magic", Llewellyn Publications, st. Paul

Kieckhefer, Richard

1990

"Magic in the Middle Ages", Cambridge University Fress, Cambridge

King, Francis and skinner, Stephen

1976 "Techniques of High Magic", Destiny Books, New York

Kingsman, Caroline

1990

"High Theory... No Culture: or De-colonizing a Canadian Cultural studies", unpublished MA thesis, Institute of Canadian studies, Carleton University, Ottawa 
Klaits, Joseph 1985

"Servants of Satan", Indiana University Press, Bloomington

Klassen, William

1977 Two Wise Men From the West in "Religion and Culture in Canada, Peter slater (ed), Canadian Corporation for studies in Religion

Knight, Gareth

1978 "The work of a Modern Occult Fraternity", in Fortune, 1978:258-272

1990 "The Magical World of the Inklings", Element Books, Shaftesbury

1991[1978] Magic and the Western Mind", Llewellyn Publications, st. Paul

Kopytoff, Igor

1986 "The cultural biography of things: commoditization as process", in Appadurai (1986), 64-91

Kors, Alan C. and Peters, Edward (eds.)

1972 "Witchcraft in Europe, 1100-1700", University of Pennsylvania Press, Philadelphia

Kraig, Donald Michael

1988 Modern Magic", Llewellyn Publications, St.Paul

Kuhn, Thomas S.

1970[1962] "The structure of Scientific Revolutions", 2nd Edition, Chicago University Press, Chicago

Kurtz, Katherine

1983

"Lammas Night", Ballentine Books, New York

Laslo, Ervin (ed)

1991 "The New Evolutionary Paradigm", Gordon and Breach, New York

Laughlin, Charles D., McManus, John, Rubenstein, Robert A., and Shearer, Jon

1983

"Anthropology and Phenomenology: Ritual and Transformation of Experience", Department of Sociology and Anthropology Working paper 83-6, Carleton University, Ottawa

LaVey, Anton Szandor

1970 "The Satanic Witch", Feral House, Los Angeles 
Leek, Sybil

1971

"The Complete Art of witchcraft", signet Books, New York

Leiter, Kenneth

1980 "A Primer on Ethnomethodology", Oxford University Press, Oxford

Leland, Charles G.

1990 "Aradia: Gospel of the Witches",Phoenix Publishing Inc., Custer

Levi, Giovanni

1988[1985] Inheriting Power", Lydia G.Cochrane (trans.), University of Chicago Press, Chicago

Lewis, Charles

1988 Witchcraft: Ancient Religion that bulievers shroud in secrecy, in the ottawa citizen, August 3, $\mathrm{Cl}$

Lipp, Deborah

1990

Witchcraft and Dxuidism: What They Share and How They Differ, in The Druids' Progress, 6:50-55

Lippert, Randy 1990

The construction of satanism as a social problem in Canada, in The canadian Journal of Sociology, v. 15:4 (Fall), 417-440

Llyod, Susonnah Miller

1978 "The Occult Revival: witchcraft in the Contemporary United States", PhD dissertation, department of Anthropology, Universitty of Missouri-Colombia

Luhrman, T.M.

1985

Persuasive Ritual: The role of the imagination in the occult, in archives de science sociale des Religions, $60(1), 151-170$

1986

"Scions of Prospero:Ritual Magic and witchcraft in Present-day England", Unpublished doctoral dissertation. Department of Social Anthropology,

1989 University of Cambridge "Persuasions of the witch's craft", Harvard University Press, Cambridge 
Luck, George (trans., ed.)

1985 "Arcana Mundi", Johns Hopkins University Press, Baltimore

Magnus

1992

Personal Interview, January 12, 1992

Malinowski, Bronislaw

1954

"Magic, Science and Religion", Anchor Books, Garden City

Margulis, Lynn

1987

"The Microbes have priority", in W. I. Thompson (1987)

Marron, Kevin

1989 "Witches, Pagans, Magic in the New Age", Seal Books, Toronto

Matthews, Caitlin and Matthews, John

1985

1986

1990

"The Western Way", Arkana, London

"The Western Way, Volume 2", Arkana, London

"Hallowquest", Aquarian Press, Wellingborough

McFarland, Janet

1987 The witches of ottawa: store chain discovers pagan rites profitable, ottawa citizen, July 11, F3

McLean, Adam

1989 "The Alchemical Mandala", Phanes Press, Grand Rapids

McLuhan, Marshall

1964 "Understanding Media", Signet Books, Toronto

Melucci, Alberto

1989 "Nomads of the Present", John Keane and Paul Mier

(eds), Temple University Press, Philedelphia

Melton, Gordon

1983 Witchcraft: An Inside view, in christianity Today, $27(16), 22-25$

1986 "Encyclopedic Handbook of Cults in America", Garland Publishing, New York

Messerschmidt, Donald $A$.

1981 "Anthropologists at home in North America", Cambridge University Press, Cambridge 
Moore, Sally F, and Meyerhoff, Barbara G.

1977 "Secular Ritual", Van Gorcum, Amsterdam

Morgan, Prys

1983

"From a Death to a View: The Hunt for the Welsh Past in the Romantic Period", in Hobsbawm and Ranger (1983:43-100)

Morwyn

1988

"Secrets of a Witch's Coven", Whitford Press, West Chester PA

Muir, Edward and Ruggiero, Guido

1991 "Microhistory the Lost Peoples of Europe", Eren Branch (trans.), Johns Hopkins University Press, Baltimore

Murray, Margaret Alice

1955

The Divine King in England, in "Atti dell'vIII congresso internazionale di storia delle religioni (Roma, 17-23 Aprile)", G.C. Sansoni (ed), Florence, 378-380

1960[1933] "The God of the Witches", Anchor Books, Garden City

1963[1921] "The Witch-Cult in Western Europe", Clarendon Press, oxford

Nattiez, Jean-Jacques

1990 "Music and Discourse", Princeton University Press, Princeton

Neitz, Mary Jo

1990 "In Goddess We Trust", in In Gods We Trust, Thomas Robbins and Dick Anthony (eds.), Transaction Publishers, New Brunswick NJ, 353-373

Niccoli, Ottavia

1990 "Prophecy and People in Renaissance Italy", Lydia G. Cochrane (trans.), Princeton University Press, Princeton

Ong, Walter $\mathrm{J}$.

1982 "Orality and Literacy", Methuen, London

Pacey, Arnold

1983

1990

"The Culture of Technology", MIT Press, Cambridge "Technology in World civilization", MIT Press, Cambridge 
Pagels, Elaine

1973 "The Johannine Gospel in Gnostic Exegesis: Heracleon's Commentary on John", Abingdon Press, New York

1988 "Adam, Eve, and the Serpent", Random House, New York

Parrinder, Geoffrey

1958

"Witchcraft", Penguin Books, Harmondsworth

Peneff, Jean

1990

"Myths in Life Storjes", in Samuel and Thompson (1999:36-48)

Rabinovitch, Shelly

1991

"The Institutionalization of wicca within Ontario through the Wiccan Church of Canada", unpublished manuscript.

Rado, Sandor

1959 "Obsessive Behavior", in Arieti (1959:324-344)

Randolph, Vance

1947 "Ozark Superstitions", Columbia University Press, New York

Ranger, Terence

1983 "The Invention of Tradition in Colonial Africa", in Hobsbawm and Ranger (1983:211-262)

Reed, Ellen Cannon

1990 "The Goddess and the Tree", Llewllyn Publications, st. Paul

Rees, Alwyn and Rees, Brinley

1961 "Celtic Heritage", Thames and Hudson, London

Richardson, James T., Best, Joel, and Bromley, David G. (eds) 1991

"The Satanism Scare", Aldine de Gruyter, New York

Ronayne, Edward

1917

"Ronayne's Hand-Book of Freemasonry" (rovised edition), Ezra A.Cook, Chicago

Rose, Elliot

1989 [1962] "A Razor for a Goat", University of Toronto Press (reprint), Toronto 
Rowe, Laurel and Cavender, Gray 1991

"Cauldrons Bubble, Satan's Trouble, But Witches are Okay: Media Constructions of Satanism and Witchcraft", in Richardson, Best and Bromley (1991)

Ruelle, David 1989

"Chaotic evolution and strange attractors". Cambridge University Press, Cambridge

Russell, Jeffrey Burton

1972

"witchcraft in the Middle Ages", Cornell University Press, Ithaca

Ryall, Rhiannon

1989 "West Country Wicca", Phoenix Publishing Inc., custer

Samuel, Raphael and Thompson, Paul (eds.)

1990 "The Myth we Live By", Routledge, London

Sanders, Maxine

1976 "Maxine: The Witch Queen", Star Books, London

Sandilands, Catriona A.H.

1988

"Spirituality and Praxis: Witchcraft and Neopaganism in Canada", MA thesis, Department of Sociology, York University, Toronto

Sapir, Edward

1961

"Culture, Language and Personality", University of California Press, Berkely

Saunders, P.T.

1980

"An Introduction to Catastrophe Theory", Cambridge University Press, Cambridge

Sawyer, Ronald C.

1988

'Strangely Handled in all her Lyms': Witchcraft and Healing in Jacobean England in Journal of Social History, 22, 461-485

Schutz, Alfred

1967

"The Phenomenology of the Social world", George Walsh and Frederic Lehnert (trans.), Northwestern University Press, Evanston 
Schutz, Alfred and Luckmann, Thomas

1973 "The Structures of the Life-world", Richard M. Zaner and H.Tristram Engelhardt, Jr. (Trans.), North-western University Press, Evanston

1989[1983] "The Structures of the Life-World, Volume II", Richard M. Zaner and David J. Parent (Trans.), Northwestern University Press, Evanston

Schwartz, Tom J.

1990

Fuzzy Systems in the Real world, in AI Expert, $5(8)$, August

Shearer, Jon, Laughlin, Charles D., and McManus, Jon 1983

"A Biogenetic Structural model of Phenomenological Phases", Departmental Working Paper 83-1, Dept. of Sociology and Anthropology, Carleton University

Shuttle, Penelope and Redgrove, Peter

1978

"The Wise Wound", Richard Marek Publishers, New York

Simmel, Georg

1950

"The Sociology of Georg Simmel", Kurt H. Wolff (trans.), Macmillan, New York

1955

"Conflict and The Web of Group Affiliations", Kurt H. Wolff and Reinhart Bendix (trans.), Macmillan, New York

Skelton, Robin

1991

"The Magical Practice of Talismans", Beach Holme Publishers, Victoria

Smillie, Ben

1991 "Beyond the Social Gospel", United Church Publishing House, Toronto

Spector, Malcolm and Kitsuse, John I.

1987 "Constructing Social Problems", Aldine de Gruyter, New York

Spiro, Melford E.

1982 [1970] "Buddhism and Society", 2nd Edition, University of California Press, Berkely

Squire, Charles

1975[1905] "Celtic Myth and Legend", Newcastle Publishing Co. 
Stanislavski, Constantin

1961 "Creating a Role", Theatre Arts Books, New York

Starhawk (aka Meriam Seimos)

1979

1982

1987

"Spiral Dance", Harper and Row, San Francisco

"Dreaming the Dark", Beacon Press, Boston

"Truth or Dare", Harper and Row, San Francisco

Stark, Rodney, and Bainbridge, William Sims

1985 "The Future of Religion", University of California Press, Berkely

Stigler, stephen $M$.

1986 "The History of statistics", Belknap Press (Harvard University Press), Cambridge

Tambiah, Stanley, Jeyaraja

1990

"Magic, science, religion, and the scope of rationality", Cambridge University Press, Cambridge

Teller, Joseph

n.d.

"The Mycenean Traditiun", electronically published (data file)

Thompson, C.J.S.

1990

"The Lure and Romance of Alchemy", Bell Publishing, New York

Thompson, Clara

1959

"An Introduction to Minor Maladjustments", in Arieti (1959:237-244)

Thompson, William Irwin (ed)

1981 "The Time Falling Bodies take to Light", st. Martin's Press, New York

1987 "Gaia a Way of Knowing", Lindisfarne Press, Great Barrington, MA

1989 "Imaginary Landscape", st. Martin's Press, New York

Three Initiates

1940 "The Kybalion", Yogi Publication Society, Chicago

Timlett, Peter Valentine

"The Seed Bearers", Futura, London

"The Power of the Serpent", Futura, London

"The Twilight of the Serpent", Futura, London 
Trevor-Roper, Hugh

1.983

"The Invention of tradition: The Highland Tradition of Scotland", in Hobsbawm and Ranger (1983:15-42)

Turner, Terence

1977

"Transformation, Hierarchy and Transcendence", in Moore and Myerhoff (1977)

Turner, Victor

1974 "Dramas, Fields, and Metaphors", Cornel University Press, Ithaca

1977 "Variations on a Theme of Liminality", in Moore and Myerhoff (1977)

1982 "From Ritual to Theatre", Performing Arts Journal Publications, New York

1986 "The Anthropology of Performance", PAJ Publications, New York

Tyrrell, Marc W.D.

nd. "The False Knight on the Road: or what Happens When Theory Meets Praxis", paper presented to the Centre for Research in Culture and society spring Symposium (1992), Carleton University

Tyson, Donald

1988 "The New Magus", Llewellyn Publications, St. Paul

Underhill, Evelyn (ed)

1956

"The Cloud of Unknowing", John M. Watkins, London

Valiente, Doreen

1964 "Where Witchcraft Lives", Aquarian Press, London

1989 "The Rebirth of Witchcraft", Phoenix Publishing Inc., Custer

Van Gennep, Arnold

1960[1908] "The Rites of Passage", Monika B. Vizedom and Gabrielle $L$. Caffee (trans), University of Chicago Press

Victor, Jeffrey $S$.

1991 "The dynamics of Rumour - Panics about Satanic Cults", in Richardson, Best and Bromley (1991)

Von Franz, Marie-Louise 1980

"Redemption Motifs in Fairytales", Inner City Books, Toronto 
Waite, Arthur Edward

1926

"The Secret Tradition in Alchemy", Kegan Paul, Trench, Trubner \& Co., London

Walker, Edward L., and Heyns, Roger $w$.

1962

"An Anatomy for Conformity", Prentice Hall, Englewood cliffs, NJ

Wallis, Roy

1984

"The elementary forms of the new religious life", Routledge and Kegan Paul, London

Ward, Colleen A. and Beaubrun, Michael $\mathrm{H}$.

1980

Correlates of Mystical and Diaboloical

Experiences in a Sanple of Female University

students, in The Journal for the scientific study

of Religion, V. 19:2, 201-207

Warren-Clarke, Ly

1987

"The Way of the Goddess", Prism Press, Dorset

Watt, Montgomery

1953 "The Faith and Practice of al-Ghazali", George

Allen and Unwin, London

Webber, Mark

1980

"Ritual: a Model of Symbolic Penetration", MA Thesis, Dept. of Sociology and Anthropology, Carleton University.

Webber, Mark and Laughlin, Charles D.

1979

"The Mechanism of Symbolic Penetration", Departmental Working Paper 79-8, Dept. of Sociology and Anthropology, Carleton University

Weber, Max 1947

"The Theory of Social and Economic Organization", Talcott Parsons (trans.), CollierMacMillan, Toronto

1963[1922] "The Sociology of Religion", Ephraim Fischoff (trans.), Beacon Press, Boston

Weinstein, Marion 1980

"Positive Magic", revised edition, Phoenix Publishing, Custer

1986

"Earth Magic", revised edition, Phoenix
Publishing, Custer 
Whorf, Benjamin

$$
1956
$$

"Language, thought and reality", John B. Carrol (ed), Technology Papers of M.I.T., Cambridge

White, Geoffrey M. 1990

Moral discourse and the rhetoric of emotions, in "Language and the politics of emotion", Catherine A. Lutz and Lila Abu-Lughod (eds), Cambridge University Press, Cambridge, 46-68

wilber, Ken 1977

1983 "A Sociable God", Shambh

"The Spectrum of Consciousness", Theosophical Publishing House, London

1967

"The I Ching or Book of Changes", Bollingen Series XIX, Princeton University Press, Princeton

Williams, Neil

n.d. "Quest for a Tribe: Neopaganism as a Nativistic Movement in Contemporary North America", unpublished ms.

Wolkstein, Diane and Kramer, Samuel Noah

1983

"Inanna: Queen of Heaven and Earth", Harper and Row, New York

Yates, Frances A.

1964

"Giordano Bruno and the Hermetic Tradition", University of Chicago Press, Chicago

Young, T.R. 1991

Chaos Theory and Symbolic Interaction Theory: poetics for the Postmodern sociologist, in Symbolic Interaction V $14: 3,321-334$

Zatti, Mario 1988

"Anthropic Biology", in F. Bertola and U. Curi (eds), "The Anthropic Frinciple", Cambridge University Press, Cambridge 


\section{Appendix A}

\section{A Wiccan Glossary}

\section{Copyright 1991 by Rowan Moonstone and Durwydd MacTara}

I have updated this glossary for the Ottawa wiccan community. Permission has been granted (E-mail messages) by both authors to print, reproduce and modify this document as long as the copyright remains intact.

Arnsan- the spiritual ether (or Aether); the omnipresent fifth occult element which embraces the other four-earth, air, fire, and water; and from which they stem. This is the realm of "pattern" or causality, from which the realm the normally thought of "five senses manifests. Some define it is the "other" of the "two worids" that the witch or magician walks between.

NRNDIA- Daughter of the Goddess Diana, and a name for the Goddess used by Italian witches or strega, commonly used in many wiccan traditions today.

ATEnYs- black handled, dovble edged dagger. Principally used to cast and dissolve the ficle, for which purposes it is interchangeable with the magic sord. A tool of the "Element" of Fire in the seorgian Tradition and some others.

BuLTARs- May Eve festival, one of the Ancient celtic "Fire Festivals." on this night, the cattle were driven between two bonfires to protect them fror disease. Couples wishing for fertility would " jum che fires" on Beltane night. Also the traditional sabbath where the rule of the "Wheel of the Year" is returned to the Guddess. This Festival also marks the transition point of the threefold Goddess energies from those of Maiden to Mother. (AKA BELTHANE, BELTAINE)

BoOx OF 8BnDOWs- Traditionally hand copied book of rituals, recipes, training techniques, guidelines, and other materials deemed important to a witch or a coven. Each tradition has it's own standard version of the Book and each witch's book will be different as he or she adds to it with time from many different sources. Only another witch can see your book of shadows. Also, traditionally, it may never leave your hands or possession until death, when it should be destroyed, or (in some traditions) returned to the coven to be disposed of. (AKA BOSH)

BUDMIMC TIMEs- a term used by some witches for the period of persecution in the Middle Ages and later. It is in fact a misnomer in some places, as witches were only burned in Scotland, and on the continent of Europe. In England and the U.S., they were hanged. 
Canderus- Festival held on Feb. 1. One of the 4 Celtic "Fire Festivals. Commemorates the changing of the Goddess from the Crone to the Maiden. Celebrates the first signs of Spring. Also called "Imbolc" (the old Celtic name). This is the seasonal change where the first signs of spring and the return of the sun are noted, i.e. the first sprouting of leaves, the sprouting of the Crocus flowers etc. In other words, it is the festival commemorating the successful passing of winter and the beginning of the agricultural year.This Festival also marks the transition point of the threefold Goddess energies from those of crone to Maiden. (AKA BRIGHID, BREID)

CRRDIMnL POINr8- North, South, East, and West, marked in the Georgian Tradition by candles of green, red, yellow, and blue, respectively. The circle is drawn to connect these four points.

Canlicz- one of the tools of the witch. Placed on the altar to represent the element of Water.

CanRes of THE CODDE88- The Traditional words of the Goddess to her followers, or "hidden children". Normally declaimed by the HPS at every coven Circle. (See Appendix B)

CIRCLE- the area in which the magickal worship and spells takes place. Can also be used to designate a particular group of witches or Pagans such as "Silver Acorn Circle".

COAE OF POWER- power raised in the circle by the witches assembled, and sent out into the world to work magick, is usually visualized as being retained and built in the form of a "cone" prior to release.

coven- an organized group of witches, led by a High priestess and/or a High Priest who meet regularly for worship and fellowship. The traditional membership is 13 , but in fact most covens number considerably less. 3 is the minimum in the Georgian Tradition. In Middle English, "Covin" a group of confederates; In old French "Covine" a band or group with a single purpose; Latin "Com"-together, "Venire"-to come or move.

COVBABTBAD- regular meeting place for a coven. Usually the home of the High Priestess or High Priest.

cowny- a non-witch. Formerly used in a very derogatory manner. Still used in Masonic Ritual to indicate the non initiate and/or pretender to "real craft". Not often used today among most Witches.

COYOTE ENERGY - trickster energies. Named for the American Indian Trickster, Coyote, who tricks man into learning what he needs to learn. Applies to one who constantly jokes and clowns. Also applies to the concept of "Holy Fool" in many traditions. (NB, not used in the ottawa community) 
CRO8B QUARTER DAYB- The modern name for the Celtic Fire Festivals of Samhain, Imbolc, Beltane, and Lammas.

DsC8IL- clockwise, or sunwise. Traditional direction for working "building" magick.

DRAIING DOW THE HOON- Ritual invocation of the spirit of the Goddess into the body of the High Priestess by the High Priest.

DIVImATION- magical method or exploration or inquiry into a situation via such methods as Tarot cards, runestones, I-Ching, etc.

ELENBWT8- Earth, air, fire, and water, plus spirit, which includes them all. These are regarded as realms or categories of nature (both material and non-material) and are not to be confused with the physicists table of elements, which the modern witch, of course, accepts.

EBBAT- weekly or biweekly meeting of a coven. Traditionally held either on the full moon or the new moon.

FAMIIIARs- Either a Witch's pet animal which has been trained to be a magickal helper, or an artificially created "elemental" which performs the same functions as the animal friend.

FIVEFOLD II88, FIVEFOLD BALUTE- The Witches' ritual salute, with kisses; (1) on each foot, (2) on each knee, (3) above the pubic hair, (4) on each breast, and (5) on the lips- really 8 kisses in all. It is only used within the circle, but the words that go with it are the origin of "Blessed Be."

GRRDNERIANB- Tradition of witchcraft descended from the teachings of Gerald Gardner.

orous8- an "entity" or "elemental" that dwells in the plane of Earth or is associated with the EARTH Element.

GREAT RITE- The rite which is the main feature of the third degree initiation, and which is also laid down for certain festivals. It is sexual in nature, but may be 'actual' (and private to the couples concerned) or symbolic, as the participants wish.

muLows - name used by some traditions for Sambain, or Halloween

mMDFAstrug- Wiccan equivalent of a wedding. It can be made legal if the Priestess and/or Priest are registered as clergy with the local authorities, or it may only be considered binding within the coven.

HIOA PRIEBT/EB8- Technically speaking, a Witch who has received the 3rd. degree initiation. More usually, the male and female leaders of a coven. 
Imborc- Celtic name for Candlemas.

Invocarios- The ritual "calling-in" of an entity (or energies) higher than human, either for communication with the caller through a medium or by visible manifestation or else to enter into a human body as in the Drawing Down the Moon. In some traditions, a Prayer.

Inuns-August 1st. Witch Festival. The old Celtic name for this festival is Lughnassadh. It is the Festival of the First Fruits, and is the first of the 3 harvests. This festival also marks the change of the Threefold Goddess energies from that of Mother to Crone. (Technically, Lammas (Auqust 1st) and Lughnassadh (Auqust 2nd) are seperate festivals, Lammas as the first harvest, and Lughnassadh as the Feast of the Wedding of Lugh, However, many Wiccans merge the two together, NT)

unIDas- An appointment held by one of the women of the coven. She is virtually the assistant High Priestess. This term is also the descriptive term used to describe the first of the aspects of the Threefold Goddess Energies (Maiden, Mother, and Crone). It is traditionally associated with the Waxing Moon, and the period from Imbolc (Candlemas) to Beltane (May eve) where the energies are those of initiating, beginning, and creation.

OLD RELIGION- another name for the craft.

PAoNarma- Presentation of an infant to the circle and to the Gods. (AKA WICCANING)

PEsmcLs- a disc shaped talisman; in particular, the metal disc which represents the earth element among the witch's working tools.

Parrsorns- The five-pointed star. With a single point uppermost, it represents the human being. Inverted, with two points uppermost, it can have satanist associations; but not necessarily. Some traditions of Wicca use the inverted pentagram to signify an initiate of the second degree.

QONRTwR8- The North, East, South, and West parts of a magickal circle or other ritual area. (See also "Watchtowers")

REDE- rule or law.

8ABBAT- one of the Eight festivals or high holy days of wicca.

BALNONDER- an entity that dwells in the realm of Fire.

Bxwany- The festival of remembrance for the dead, held on the eve of Nov. 1st. It is the last of the three harvests. This festival also warks the transition of rulership of the "Wheel of the Year from that of the Goddess to that of the God. (It is also the Feast of the Dead or the Ancestors in the ottawa community.) 
8CRYIXG- divination, usually using such methods as crystal gazing, or divination via incense smoke, or water as opposed to tarot or other manipulative means.

8RELI8- a prayer; or verbal direction of magickal energiea + nward the accomplishment of some goal.

8OnOABR- The male officer of the coven who corresponds to the Maiden. He is the assistant High Priest.

8YLPR- an "entty" or "elemental" that dwells in the plane of Air or is associated with the AIR Element.

TRNDITION8- any of the various "sects" of Wicca such as Gardnerian, Alexandrian, Georgian, Seax, etc.

OxDIns- an "entity" or "elemental" that dwells in the plane of Water or is associated with the WATER Element.

WND- A rod or staff that is prepared so that it say be used for magickal or psychic purposes, usually to project some form of power.

walock- a term coined in the Burning Times. It was used to denote a traitor to the craft, or one who had betrayed the followers of the old Religion. It $s$ origin is Scottish. Because of the negative connotations, it is not used by most wiccans today. (NB, originally from the scotts gaelic "wearlogan" or "oathbreaker". The original denotation appears to refer to one who broke his christian oaths and practiced magic, MT)

WATCA TOWBRB- Originally from the Enochian branch of Ceremonial Magick, now incorporated into many "Traditions" of Wicca, these are the four elemental "directions" or "quarters" (corresponding to the appropriate points on the compass) called to protect the circle during its establishment. Each of them have a correspondence between the compass point, an element, and (varying amongst different traditions) color associated with them.

wIccx- the name most modern day witches use for the craft. It comes from the Anglo-Saxon word Wicce, meaning to bend or to shape. This is the root word from which we get wicker. (This is the movement internal etymological derivation. There are a number of desenting views on the actual connotations and even on the exct root. MT)

WIDDERBHIM8- counter clock wise. Used for "tearing down" OR BANISHING magick.

WITs ENDDLSD IMIFE- the working knife of a witch. It is used to carve candles, and for fashioning the other tools. Traditionally, it can only be used in a circle. 


\section{Appendix $B$}

\section{The Charge of the Coddess}

HP: Listen to the words of the Great Mother; she who of old was also called among men Artemis, Astarte, Athene, Dione, Melusine, Aphrodite, Cerridwen, Dana, Arianrhod, Isis, Iride and by many other names. At her altars the youth of Lacedaemon in Sparta made due sacrifice.

HPS: Whenever ye have need of anything, once in the month, and better it be when the moon is full, then shall ye asselible in some secret place and adore the spirit of me, who am Queen of all the witcheries. There shall ye assemble, ye who are fain to learn all sorcery, yet have not won its deepest secrets; to these will I teach things that are yet unknown. And ye shall be free from slavery; and as a sign that ye be really free, ye shall be naked in your rites; and ye shall dance, sing, feast, make music and love, all in my praise.

For mine is the ecstasy of the spirit, and mine also is joy on earth; for my law is love unto all beings. Keep pure your highest ideal; strive ever towards it; let naught stop you or turn you aside. For mine is the secret door which opens upon the Land of Youth, and mine is the cup of the wine of life, and the cauldron of Cerridwen, which is the Holy Grail of immortality. I am the Gracious Goddess, who gives the gift of joy unto the heart of man. Upon earth, I give the knowledge of the spirit eternal; and beyond death, I give peace and freedom and reunion with those who have gone before.

Nor do I demand aught in sacrifice; for behold, I am the Mother of all living, and my love is poured out upon the earth.

HP: Hear ye the words of the Star Goddess; she in the dust of whose feet are the hosts of heaven, and whose body encircles the Universe.

HPS: I who am the beauty of the green earth, and the white Moon among the stars, and the mystery of the waters, and the desire of the heart of man, call unto thy soul. Arise, and come unto me. For I am the soul of nature, who gives life to the universe. From me all things proceed, and unto me all things must return; and before my face, beloved of sods and of men, let thine innermost divine self be enfolded in the rapture of the infinite.Let my worship be within the heart that rejoiceth; for behold, all acts of love and pleasure are my rituals. And therefore let there be beauty and strength, power and compassion, honour and humility, mirth and reverence within you. And thou who thinkest to seek for me, know thy seeking and yearning shall avail chee not unless thou knowest the mystery; that if that which thou seekest thou findest not within thee, thou wilt never $f$ ind it without thee. For behold, I have been with thee from the beginning; and I am that which is attained at the end of desire. 


\section{Appondix c \\ The "Old Law"}

1. The Law was made and ordained of old.

2. The Law was made for the wicca, to advise and help in their troubles.

3. The Wicca should give due worship to the gods and obey their will, which they ordain, for it was made for the good of wicca as the worship of the Wicca is good for the gods. For the gods love the brethren of Wicca.

4. As a man loveth a woman by mastering her,

5. So should the wicca love the gods by being mastered by them.

6. And it is necessary that the circle which is the temple of the gods, should be truly cast and purified. And that it may be a fit place for the gods to enter.

7. And the wicca shall be properly prepared and purified to enter into the presence of the gods.

8. With love and worship in their hearts, they shall raise power from their bodies to give power to the gods.

9. As has been taught of old.

10. For in this way only may men have communion with the gods, for the gods cannot help man without the help of man.

HPS \& HP

11. And the High Priestess shall rule her coven as the representative of the Goddess.

12. And the High Priest shall support her as the replesentative of the God.

13. And the High Priestess shall choose whom she will, be he of sufficient rank, to be her High Priest.

14. For, as the God Hinself kissed Her feet in the five-fold salute, laying $H$ is power at the feet of the Goddess because of Her youth and beauty, Her sweetness and kindness, Her wisdom and justice, Her humility and generosity,

15. So He resigned all His power to Her.

16. But the High Priestess should ever mind that the power comes from Him.

17. It is only lent, to be used wisely and justly.

18. And the greatest virtue of a High Priestess be that she recognize that youth is necessary to the representative of the Goddess.

19. So she will gracefully retire in favour of a younger woman shculd the coven so decide in council.

20. For a true High priestess realizes that gracefully surrendering pride of place is one of the greatest virtues.

21. And that thereby she will return to that pride of place in another life, with greater power and beauty.

SECURITY

22. In the old days, when witchdom extended far, we were free and worshipped in all the greater temples.

23. But in these unhappy times we must celebrate our sacred mysteries in secret. 
24. So be it ordained that none but the wicca may see our mysteries, for our enemies are many and torture loosens the tongue of man.

25. So be it ordained that no coven shall know where the next Coven bide.

2u. Or who its members be, save only the Priest and Priestess and messenger.

27. And there shall be no communication between them, save by the messenger of the gods, or the summoner.

28. And only if it be safe may the covens meet in some safe place for the great festivals.

29. And while there, none shall say whence they came nor give their true names.

30. To this end, that if any be tortured, in their agony, they may not tell if they do not know.

31. So be it ordained that no one shall tell anyone not of the craft who be of the Wicca, nor give any names or where they bide, or in any way tell anything which can betray any of us to our foes.

32. Nor may he tell where the Covendom be.

33. Or the Covenstead.

34. Or where the meetings be.

35. And if any break these Laws, even under torture, THE CURSE OF THE GODDESS SHALL BE UPON THEM, so they may never be reborn on earth and may remain where they belong, in the hell of the christians.

DISPUTES

36. Let each High Priestess govern her Coven with justice and love, with the help and advice of the High Priest and the Elders, always heeding the advice of the Messenger of the Gods if he cometh.

37. She will heed all complaints of all Brothers and strive to settle all differences among them.

38. But it must be recognized that there will always be people who will ever strive to force others to do as they will.

39. These are not necessarily evil.

40. And they oft have good ideas and such ideas should be talked over in council.

41. But if they will not agree with their Brothers, or if they say,

42. "I will not work under this High Priestess,"

43. It hath ever been the old Law to be convenient to the Brethren and to avoid disputes.

NEW COVENS

44. Any of the third may claim to found a new coven because they live over a league away from the covenstean or are about to do so.

45. Anyone living within the Covendom and wishing to form a new Coven, shall tell the Elders of their intention, and on the instant avoid their dwelling and remove to the new covendom.

46. Members of the old Coven may join the new one when it is formed. But if they do, they must utterly avoid the old coven. 
47. The Elders of the new and old Covens should meet in peace and brotherly love to decide the new boundaries.

48. Those of the craft who dwell outside both Covendoms may join either but not both.

49. Though all may, if the Elders agree, meet for the great festivals if it be truly in peace and brotherly love,

50. But splitting the Coven oft means strife, so for this reason these Laws were made of old and may the CURSE OF THE GODDESS BE ON ANY WHO DISREGARD THEM. So be it ordained.

\section{GRIMOIRE}

51. If you would keep a book, let it be in your own hand of write. Let brothers and sisters copy what they will, but never let the book out of your hands, and never keep the writings of another.

52. For if it be found in their hand of write, they may be taken and arraigned.

53. Let each guard his own writings and destroy them whenever danger threatens.

54. Learn as much as you may by heart and, when danger is past, rewrite your book, an it be safe.

55. For this reason, if any die, destroy their book an they have not been able to.

56. For, an it be found, 'tis clear proof against them.

57. And our oppressors know well "Ye may not be a witch alone".

58. So all their kin and friends be in danger of torture,

59. So destroy everything not necessary.

60. If your book be found on you, 'tis clear proof against you alone, you may be arraigned.

\section{PERSECUTION}

61. Keep all thoughts of the craft from your mind.

62. If the torture be too great to bear, say "I will confess. I cannot bear this torture. What do you want me to say?"

63. If they try to make you speak of the Brotherhood, do not.

64. But if they try to make you speak of impossibilities such as flying through the air, consorting with a Christian devil or sacrificing children, or eating men's flesh,

65. To obtain relief from torture say "I had an evil dream, I was beside myself, I was crazed."

66. Not all magistraces are bad, if there be an excuse, they may show mercy.

67. If you have confessed aught, deny it afterwards, say you babbled under torture, say you knew not what you said.

68. If you are condemned, fear not.

69. The Brotherhood is powerful and will help you to escape if you stand steadfast, but if you betray aught there is no hope for you in this life or in that to come.

70. Be sure, if steadfast you go to the pyre, drugs will reach you, you will feel naught. You go to death and what lies beyond, the ecstasy of the goddess. 
TOOLS

71. To avoid discovery, let the working tools be as ordinary things that any may have in their houses.

72. Let the pentacles be of wax so that they may be broken at once or melted.

73. Have no sword unless your rank allows it.

74. Have no names or signs on anything.

75. Write the names and signs on them in ink before consecrating them and wash it of immediately afterwards.

76. Let the colours of the hilts tell which is which.

77. Do not engrave them lest they cause discovery.

\section{CONDUCT}

78. Ever remember ye are the hidden children of the Goddess so never do anything to disgrace them or Her.

79. Never boast, never threaten, never say you would wish ill of anyone.

80. If any person not in the circle, speak of the craft, say, "Speak not to me of such, it frightens me, 'tis evil luck to speak of it."

81. For this reason, the Christians have their spies everywhere. These speak as if they were well affected to us, as if they would come to our meetings, saying, "My mother used to worship the oid Ones. I would I could go myself."

82. To such as these, ever deny all knowledge.

83. But to others, ever say, "'Tis foolish men talk of witches flying through the air. To do so they must be as light as thistledown. And men say that witches all be blear-eyed old crones, so what pleasure can there be at a witch meeting such as folks talk on ?"

84. And say, "Many wise men now say there be no such creatures."

85. Ever make it jest) and in some future time perhaps, the persecution may die and we may worship our gods in safety again.

86. Let us all pray for that happy day.

87. May the blessings of the Goddess and God be on all who keep these Laws which are ordained.

VALUABLES

88. If the craft hath any appanage, let all guard it and help to keep it clear and good for the craft.

89. And let all justly guard all monies of the craft.

90. And if any Brother truly wrought it, 'tis right they have their pay, an it be just. An this be not taking money for the art, but for good and honest work.

91. And even the Christians say, "The Jabourer is worthy of his hire," but if any Brother work willingly for the good of the craft without pay, 'tis but to their greater honour. So be it ordained.

\section{QUARRELS}

92. If there be any dispute or quarrel among the Brethren, the High Priestess shall straightly convene the Elders and inquire into the matter, and they shall hear both sides, first alone 
and then together.

93. And they shall decide justly, not favouring one side or the other.

94. Ever recognising there be people who can never agree to work under others.

95. But at the same time, there be some people who cannot rule justly.

96. To those who must ever be chief, there is one answer.

97. "'Void the Coven or seek another one, or make a Coven of your own, taking with you those who will go."

98. To those who cannot rule justly, the answer be, "Those who cannot bear your rule will leave you."

99. For none may come to meetings with those with whom they are at variance.

100. So, an either cannot agree, get hence, for the craft must ever survive. So be it ordained.

\section{CURSES}

101. In the olden days when we had power, we could use the art against any who ill-treated the Brotherhood. But in these evil days we must not do so. For our enemies have devised a burning pit of everlasting fire into which they say their god casteth all the people who worship him, except it be the very few who are released by their priest's spells and masses. And this be chiefly by giving monies and rich gifts to receive his favour for their great god is ever in need of money.

102. But as our gods need our aid to make fertility for man and crops, so is the god of the Christians ever in need of man's help to search out and destroy us. Their priests ever tell them that any who get our help are damned to this hell forever, so men be mad with the terror of it.

103. But they make men believe that they may escape this hell if they give victims to the tormentors. So for this reason all be forever spying, thinking, "An I can catch but one of these Wicca, I will escape from this fiery pit."

104. So for this reason we have our hidels, and men searching long and not finding, say, "There be none, or if there be, they be in a far country."

105. But when one of our oppressors die, or even be sick, ever is the cry, "This be witches' malice", and the hunt is up again. And though they slay ten of their own to one of ours, still they care not. They have countless thousands.

106. While we are few indeed. So be it ordained.

107. That none shall use the art in any way to do ill to any.

108. However much they may injure us, harm none. And nowtimes many believe we exist not.

109. That this Law shall ever continue to help us in our plight, no one, however great an injury or injustice they receive, may use the art in any way to do ill, or harm any. But they may, after great consultations with all, use the art to restrain Christians from harming us Brothers, but only to constrain them and never to punish.

110. To this end men will say, "Such a one is a mighty searcher out, and a persecutor of old women whom they deemeth to be 
witches, and none hath done him harm, so it be proof that they cannot or more truly there be none."

111. For all know full well that so many folk have died because someone had a grudge against them, or were persecuted because they had money or goods to sieze, or because they had none to bribe the searchers. And many have died because they were scolding old women. So much that men now say that only old women are witches.

112. And this be to our advantage and turns suspicion away from us.

113. In England and scotland 'tis now many a year since a witch hath died the death. But any misuse of the power might raise the persecution again.

114. So never break this Law, however much you are tempted, and never consent to its being broken in the least.

115. If you know it is being broken, you must work strongly against it.

116. And any High Priestess or High Priest who consents to its breach must immediately be deposed for ' $t$ is the blood of the Brethren they endanger.

117. Do good, an it be safe, and only if it be safe.

118. And keep strictly to the old Law.

PAYMENT

119. Never accept money for the use of the art, for money ever smeareth the taker. 'Tis sorcerors and conjurers and the priests of the Christians who ever accept money for the use of their arts. And they sell pardons to let men ascape from their sins.

120. Be not as these. If you accept no money, you will be free from temptation to use the art for evil causes.

121. All may use the art for their own advantage or for the advantage of the craft only if you are sure you harm none.

122. But ever let the Coven debate this at length. Only if all are satisfied that none may be harmed, may the art be used.

123. If it is not possible to achieve your ends one way, perchance the aim may be achieved by acting in a different way so as to harm none. MAY THE CURSE OF THE GODDESS BE ON ANY WHO BREAKETH THIS LAW. SO be it ordained.

124. 'Tis judged lawful if ever any of the craft need a house or land and none will sell, to incline the owner's mind so as to be willing to sell, provided it harmeth him not in any way and the full price is paid without haggling.

125. Never bargain or cheapen anything whilst you buy by the art. So be it ordained.

LAW OF THE LAND

126. "Tis the Old Law and the most important of all laws, that no one may do anything which will endanger any of the craft, or bring them into contact with the law of the land or any persecutors.

127. In any dispute between Brethren, no one may invoke any laws but those of the craft.

128. Or any tribunal but that of the Priestess, Priest and Elders. 
DISCUSSION OF WITCHCRAFT

129. It is not forbidden to say as Christians do, "There be witchcraft in the land," because our oppressors of old make it a heresy not to believe in witchcraft and so a crime to deny it which thereny puts you under suspicion.

130. But ever say, "I know not of it here, perchance there may be but afar off. I know not where."

131. But ever speak of them as old crones, consorting with the devil and riding through the air.

132. And ever say, "But how may many ride the air if they be not as light as thistledown."

133. But the curse of the Goddess be on any who cast suspicion on any of the Brotherhood.

134. Or who speak of any real meeting-place or where they bide.

\section{WORTCUNNING}

135. Let the craft keep books with the names of all herbs which are good, and all cures so all may learn.

136. But keep another book with all the Bales and Apies and let only the Elders and other trustworthy people have this knowledge. So be it ordained.

137. And may the blessings of the gods be on all who keep these Laws, and the curses of both the God and the Goddess be on all who break them.

USE OF THE ART

138. Remember the art is the secret of the gods and may only be used in earnest and never for show or vainglory.

139. Magicians and Christians may taunt us saying, "You have no power, show us your power. Do magic before our eyes, then only will we believe," seeking to cause us to betray the art before them.

140. Heed them not, for the art is holy and may only be used in need, and the curse of the gods be on any who break this Law.

\section{RESIGNATIONS}

141. It ever be the way with women and with men also, that they ever seek new love.

142. Nor should we reprove them for this.

143. But it may be found a disadvantage to the craft.

144. And so many a time it has happened that a High Priest or a High Priestess, impelled by love, hath departed with their love. That is, they left the Coven.

145. Now if the High Priestess wishes to resign, she may do so in full Coven.

146. And this resignation is valid.

147. But if they should run off without resigning, who may know if they may not return in a few months?

148. So the Law is, if a High Priestess leaves her Coven, she be taken back and all be as before.

149. Meanwhile, if she has a deputy, that deputy shall act as High Priestess for as long as the High Priestess is away.

150. If she returns not at the end of a year and a day, then shall the Coven elect a new High Priestess, 
151. Unless there is a good reason to the contrary.

152. The person who has done the work should reap the benefit of the reward. If $s$ mebody else is elected, the deputy is made maiden and deputy of the High Priestess.

TRAINING

153. It has been found that practicing the art doth cause a fondness between aspirant and tutor, and it is the cause of better results if this be so.

154. And if for any reason this be undesireable, it can easily be avoided by both persons from the outset firmly resolving in their minds to be as brother and sister or parent and child.

155. And it is for this reason that a man may be taught only by a woman and a woman by a man, and women and women should not attempt these practices together. So be it crdained.

\section{PUNISHMENT}

156. Order and discipline must be kept.

157. A High Priestess or a High Priest may, and should, punish all faults.

158. To this end all the craft must receive correction willingly.

159. All properly prepared, the culprit kneeling should be told his fault and his sentence pronounced.

160. Punishment should be followed by something amusing.

161. The culprit must acknowledge the justice of the punishment by kissing the hand on receiving sentence and again thanking for punishment received. So be it ordained. 
Appendix D

article Index from open circle

\begin{tabular}{|c|c|c|}
\hline ISSUE & DATE & ARTICLE \\
\hline 1 & May, 1988 & 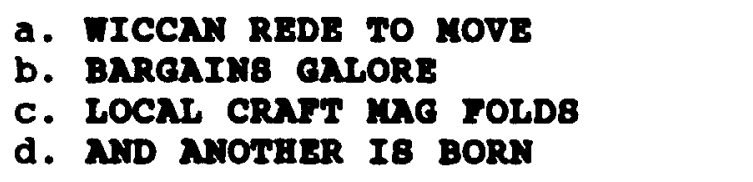 \\
\hline 2 & July, 1988 & $\begin{array}{l}\text { a. COUNCIL MBETING } \\
\text { b. DIBCOBBION OROUP } \\
\text { c. OA COMUITY BERVICEB }\end{array}$ \\
\hline 3 & Sept, 1988 & $\begin{array}{l}\text { a. MEET G GREET } \\
\text { b. CNLL FOR BUBMIBBIONB }\end{array}$ \\
\hline 4 & Nov, 1988 & $\begin{array}{l}\text { a. HEW CROOPB FORMING } \\
\text { b. LABT TEHPTATION } \\
\text { C. REBOORCEB PAMPALET }\end{array}$ \\
\hline 5 & Jan, 1989 & $\begin{array}{l}\text { a. GROURS UPDATE } \\
\text { b. REBOURCEB PAYPHLET } \\
\text { c. WIC-CAN FEBT ' } 89\end{array}$ \\
\hline 6 & Feb, 1989 & $\begin{array}{l}\text { a. INITIATIONB } \\
\text { b. OVER } 30^{\prime} 8 \text { GROOP } \\
\text { c. CIRCLE WATCH } \\
\text { d. WRT' } 8 \text { MET }\end{array}$ \\
\hline 7 & March, 1989 & $\begin{array}{l}\text { a. M8K RHLAED } \\
\text { b. CIRCLE WATCA } \\
\text { c. WHAT' } 8 \text { MET }\end{array}$ \\
\hline 8 & April, 1989 & $\begin{array}{l}\text { a. ABK KHRLED } \\
\text { b. CIRCLE WATCE } \\
\text { c. WRAT'B IEA }\end{array}$ \\
\hline 9 & May, 1989 & $\begin{array}{l}\text { a. GOTTA GET EVEN? DO IT RIGHT! } \\
\text { b. CIRCLE WATCH } \\
\text { c. WHAT'B WEW }\end{array}$ \\
\hline 10 & $\begin{array}{l}\text { June-July, } \\
198^{\circ}\end{array}$ & $\begin{array}{l}\text { a. NBT IHALED } \\
\text { b. CIRCLE WATCH } \\
\text { c. WHT' } 8 \text { IEW }\end{array}$ \\
\hline 11 & August, 1989 & $\begin{array}{l}\text { a. MEET \& GREET MOVES } \\
\text { b. CIRCLE WATCH } \\
\text { c. WHT' } 8 \text { MEW }\end{array}$ \\
\hline
\end{tabular}



12
Sept, 1989
a. BNTEAIX HYBTERY PLAY
b. CIRCLE MATCA
c. NEED A JOB?
13
Oct, 1989
a. YA CAN'T PLEABE EVERYBODY
b. CIRCLE WATCH
c. WHAT' 8 IEW
14
Nov, 1989
a. MYBTERY PLAY
b. CIRCLE WATCH
c. WRAT' 8 MET
15
Dec, 1989
a. GIFTB TO THE WIBE
b. CIRCLE watch
c. what's vew
16
Jan, 1990
a. GOT THE MIDWIWTER BLAH8?
b. CIRCLE WATCH
Feb, 1990
a. KEYB TO BUCCEB8PUL IIVINe
b. CIRCLE WATCA
c. What's NET
18

$\begin{array}{ll}\text { March, } 1990 & \text { a. RELATIONBAIP8 } \\ & \text { b. CIRCLE WATCH } \\ & \text { c. WHAT' } 8 \text { MEW }\end{array}$
April, 1990
a. ENRTH DNY
b. CIRCLE WATCH
c. WHAT' 8 MEW
20 May, 1990
a. BTAREAWK WITCECNKP
b. CIRCLE WATCE
c. EDITOR COOFB
d. WHAT' 8 HEW
21
June, 1990
a. ORC DI8BOLVEB
b. MAGS I8 BORN
c. CIRCLE WATCR
d. WHAT' 8 HEW
22
July, 1990
a. BTUCK IA CHNRGe
b. CIRCLE WATCA 

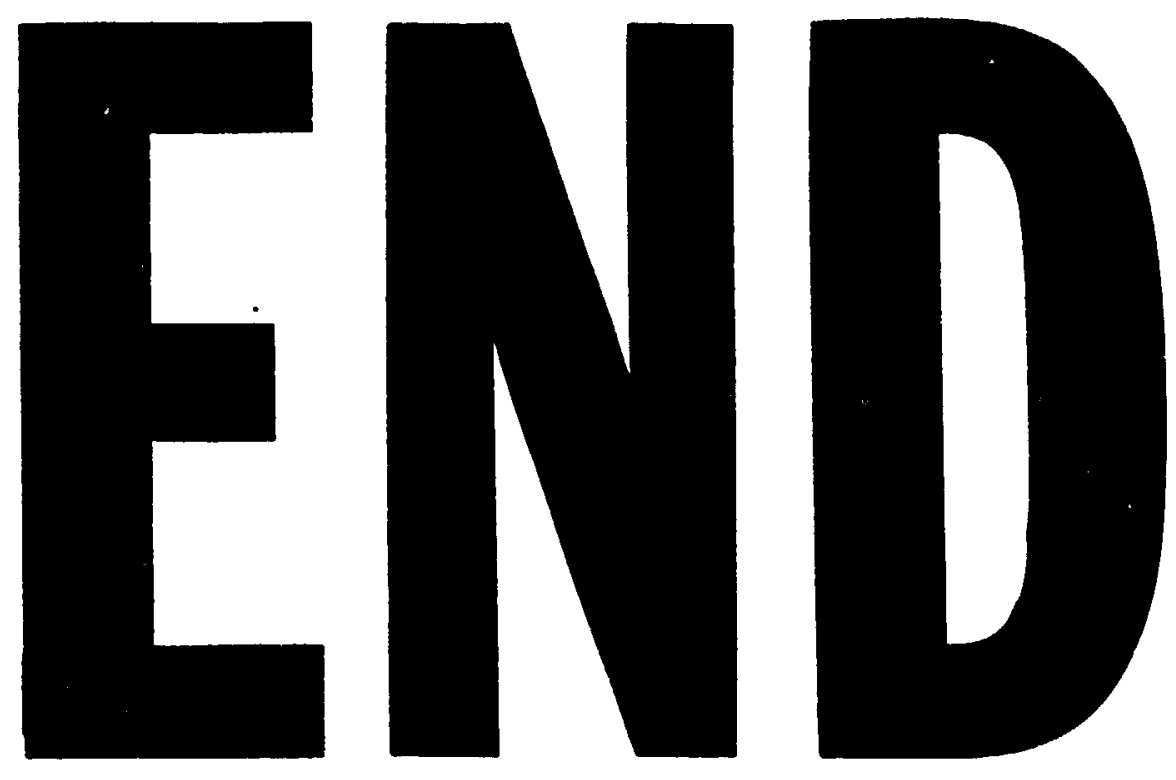

21
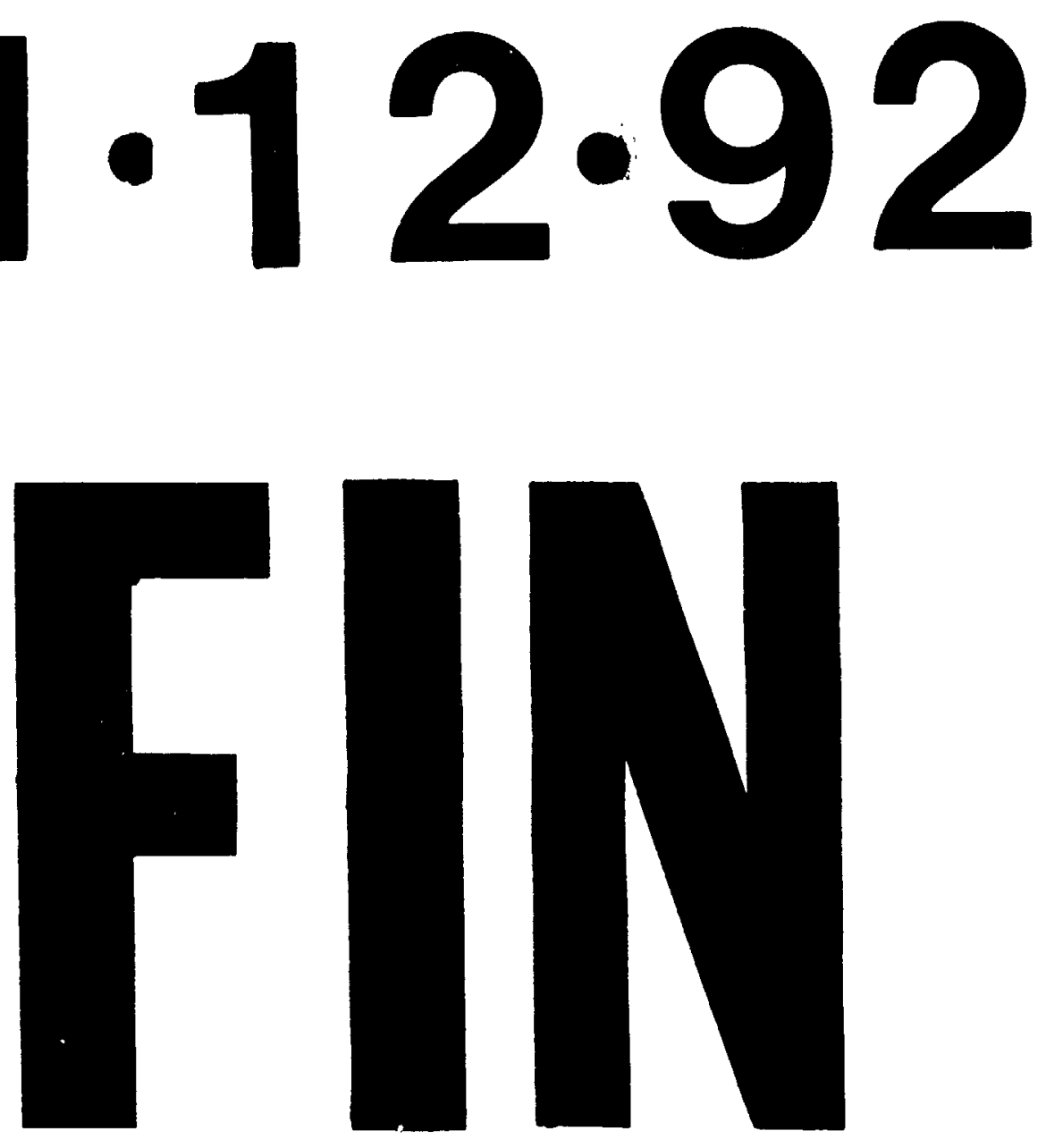